\title{
NOVEL INSOLE MATERIAL FOR WEIGHT-BEARING MONITORING MEDICAL DEVICE TO BE USED IN FRACTURED BONE CLINIC
}

\author{
by \\ SOFYA RUBTSOVA \\ B.Sc. Chemistry \\ Saratov State University, Russia, 2011 \\ A thesis presented \\ to Ryerson University \\ in partial fulfillment of the requirements for the \\ degree of Master of Applied Science \\ in the program of \\ Chemical Engineering
}

Toronto, Ontario, Canada, 2019

(C) Sofya Rubtsova, 2019 


\section{AUTHOR'S DECLARATION}

I hereby declare that I am the sole author of this thesis. This is a true copy of the thesis, including any required final revisions, as accepted by my examiners.

I authorize Ryerson University to lend this thesis to other institutions or individuals for the purpose of scholarly research.

I further authorize Ryerson University to reproduce this thesis by photocopying or by other means, in total or in part, at the request of other institutions or individuals for the purpose of scholarly research.

I understand that my thesis may be made electronically available to the public. 


\title{
NOVEL INSOLE MATERIAL FOR WEIGHT-BEARING MONITORING MEDICAL DEVICE TO BE USED IN FRACTURED BONE CLINIC \\ SOFYA RUBTSOVA \\ Master of Applied Science, Chemical Engineering, Ryerson University, Toronto, Canada 2019
}

\begin{abstract}
Partial Weight-Bearing (PWB) regime is a part of a recreation process for patients with lower limb fractures/strains/sprains. In order to avoid a frequent foot overloading and achieve better patient compliance with requirement of PWB, the application of Weight-Bearing Monitoring System (WBMS) is highly attractive. However, it is challenging to find an affordable material for protective insole cover that is also a good shock-absorber. In this regard, a new formulation for protective covering material that preserves and isolates the sensors of WBMS device is suggested in this thesis. Twenty one samples of renewably sourced Polyurethane Foam (PUF) composed of poly (trimethylene ether) glycol (PO3G) and unmodified castor oil (CO) were synthesized and evaluated according to predetermined criteria.

Response surface methodology of Box - Behnken design was applied to study the effect of the following parameters (polyols ratio, isocyanate index (II), and blowing agent ratio) on the properties (hardness, density) of PUFs. Results showed that CO/PO3G/TDI PUFs with hardness Shore A 17-22 and density of $0.19-0.25 \mathrm{~g} / \mathrm{cm}^{3}$ demonstrate the required characteristics and can potentially be used as a durable and functional insole material. Phase separation studies have found the presence of well-segregated structure in PUFs having polyols ratio CO:PO3G 1:3 and low II, which further explains their extraordinary elastic properties (400\% elongation). Analysis of cushioning performance of PUF signified that 5 samples have Cushioning Energy (CE) higher than $70 \mathrm{~N} \cdot \mathrm{mm}$ and Cushioning Factor (CF) in the range of 4-8, hence are recommended for application in WBMS due to superior weight-bearing and pressure-distributing properties. Moreover, the developed formulation undergoes anaerobic soil bacterial degradation and can be categorized as "green" bio-based material.
\end{abstract}




\section{ACKNOWLEDGEMENTS}

First and foremost, I would like to express my sincere gratitude to my supervisor, Dr. Yaser Dahman, who has supported me throughout my thesis with his patience and knowledge whilst allowing me the room to work in my own way. He has been a great mentor and without him this thesis would not have been completed or written. One simply could not wish for a better or friendlier supervisor. He has been a great source of inspiration and motivation for me.

I also thank both Dr. Hadis Zarrin, Dr. Farhad Ein-Mozaffari and Dr. Chil-Hung Chen for being part of my thesis committee and for providing invaluable feedback to this work. I would like to express my sincere gratitude to Dr. Duever for teaching me experimental design and further helping me with statistical analysis of my results. Also, I would like to thank Dr. Stephania Impelizzeri (Dept. of Chemistry and Biology, Ryerson University) for consulting me regarding spectroscopic techniques that I utilized in my work.

I have really appreciated the help of technical staff: Daniel Bothie and Ali Hemmatti who skillfully produced all required molds and templates for my research. Separately, I would like to thank Shawn McFadden (Technologist, Dept. Chemistry and Biology) for providing me with necessary instrumental trainings. I thank the academic and financial support received from the Department of Chemical Engineering at Ryerson University. Many thanks for the help received from Mr. Qiang Li, from the Department of Mechanical Engineering at Ryerson University, who conducted SEM analyses.

Last, but not the least, I would like to express gratitude to Allessa GmbH and Momentive Performance Materials companies for kindly providing me with necessary reagents. 


\section{DEDICATIONS}

Dedicated to my husband Alexey and kids - Olga and Ilya, my parents and parents-in-law, to all who supported me on the way to completion of master's degree studies, and also to all the researchers who strive to scratch their names in the world of tomorrow. 


\section{TABLE OF CONTENTS}

AUTHOR'S DECLARATION ........................................................................... ii

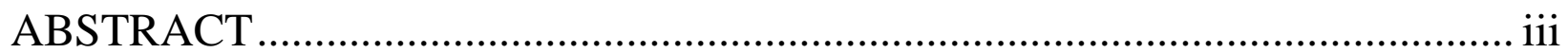

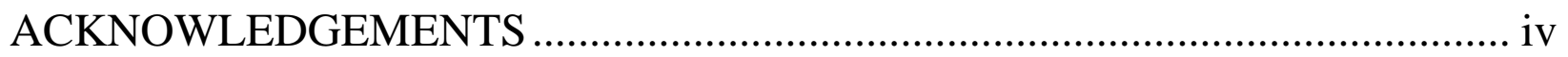

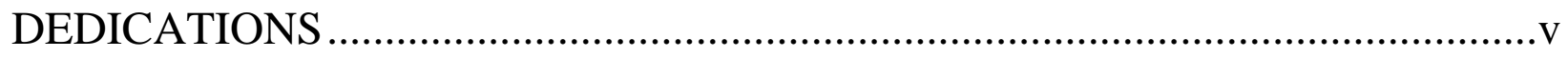

AUTHOR'S DECLARATION ……………….....................................................................

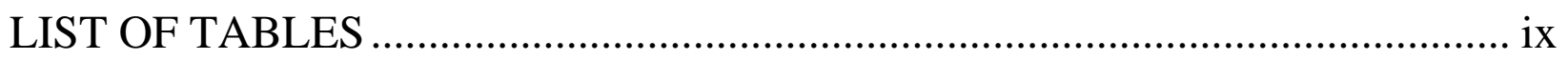

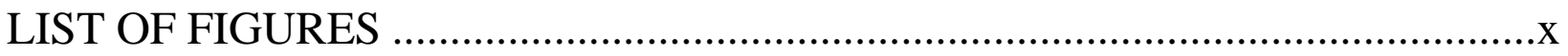

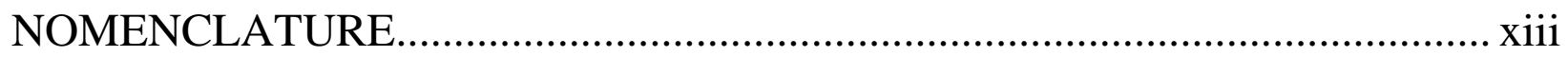

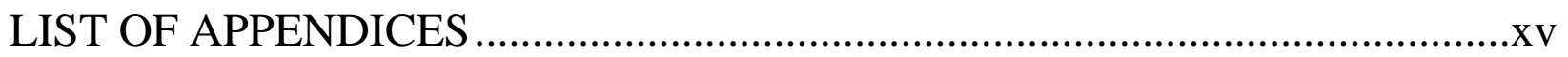

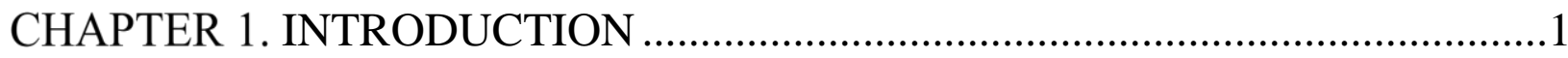

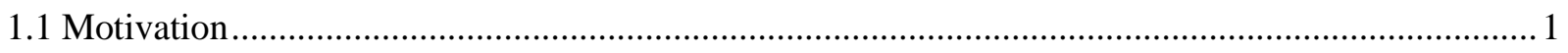

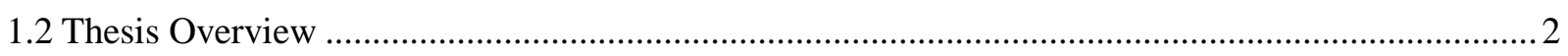

1.3 Weight-Bearing Monitoring System (WBMS) …………………………………………..........

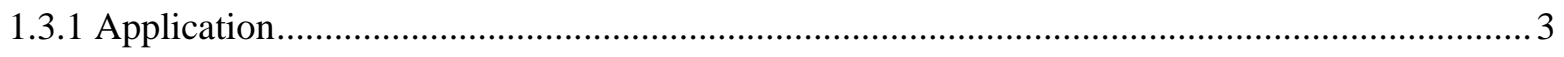

1.3.2 Overview of the device ………………………………...................................................

1.3.3 WBMS Design Limitations............................................................................................

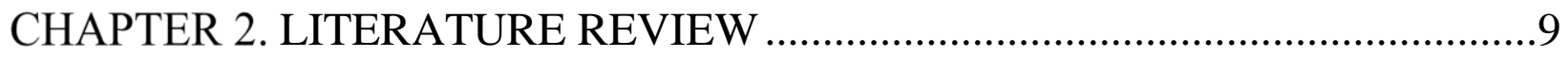

2.1 Shock Absorbing Materials..............................................................................................

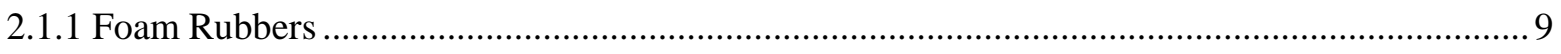

2.1.2 Nature-Originated Materials ……………………………………………………………. 10

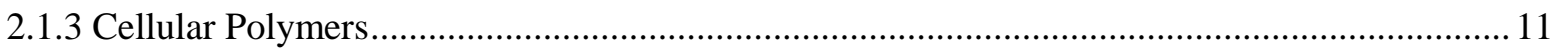

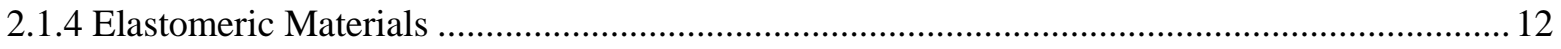




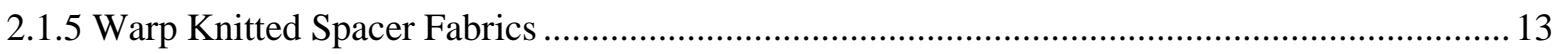

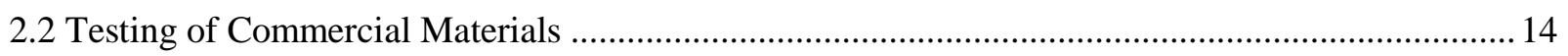

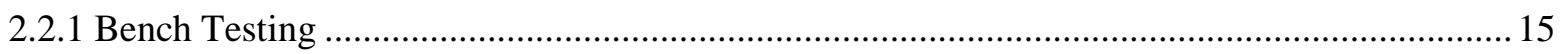

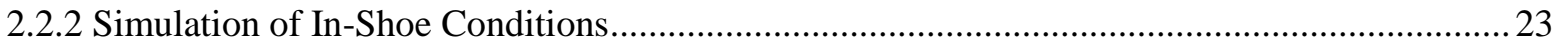

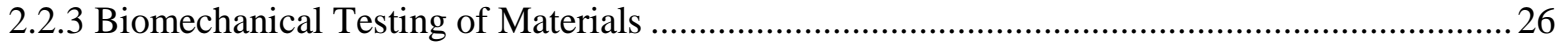

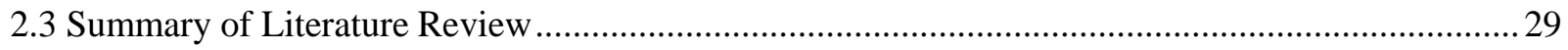

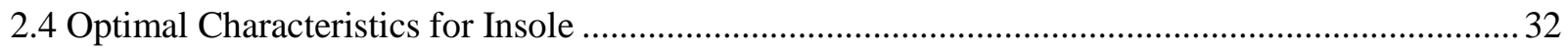

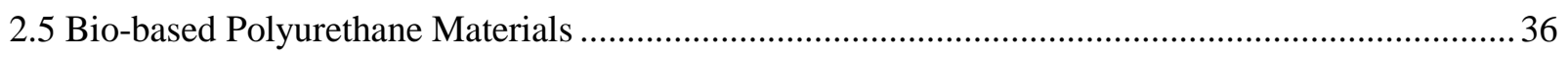

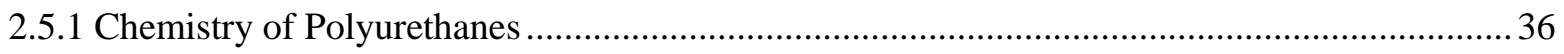

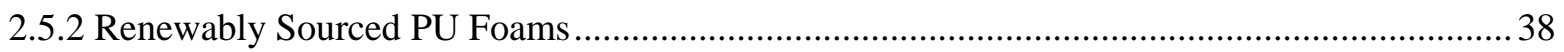

CHAPTER 3. MATERIALS AND METHODS ...............................................41

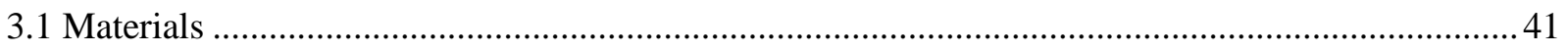

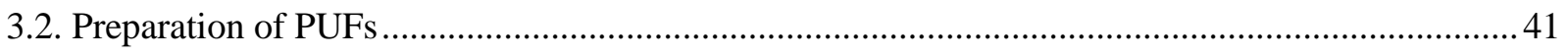

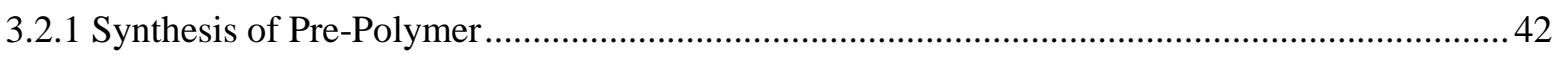

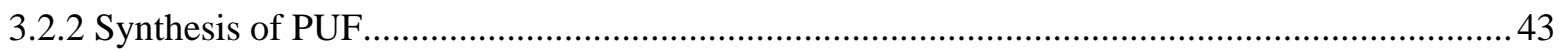

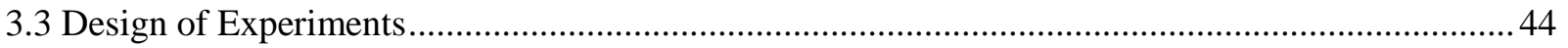

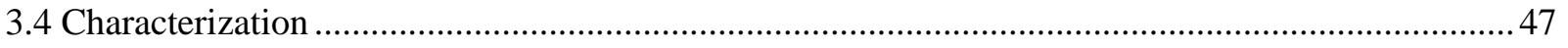

3.4.1 Fourier-Transform Infrared Spectroscopy ….................................................................. 47

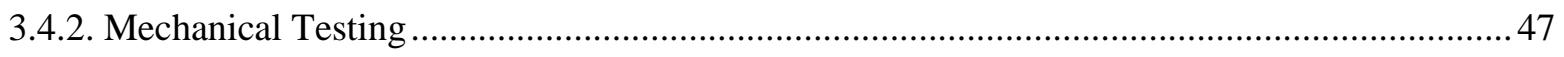

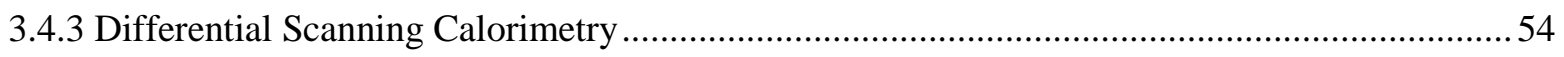

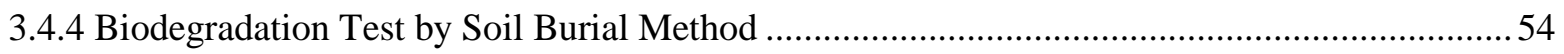

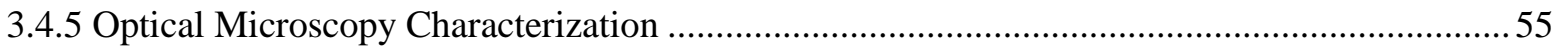

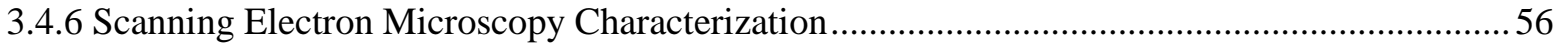

CHAPTER 4. RESULTS AND DISCUSSION .................................................57

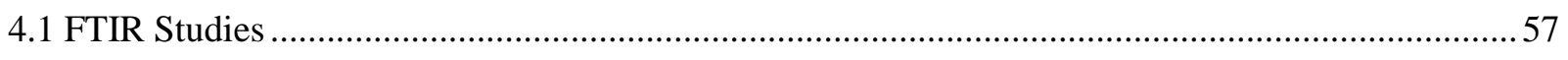

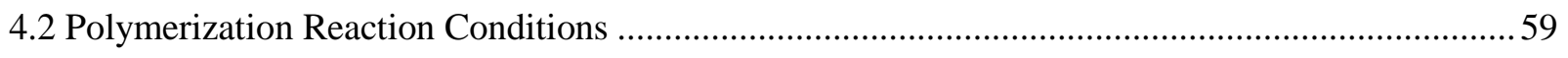

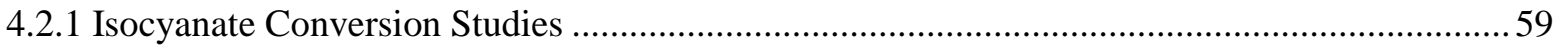




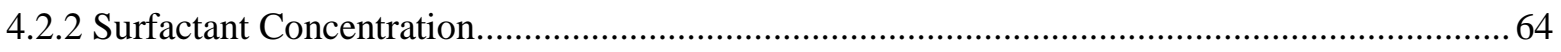

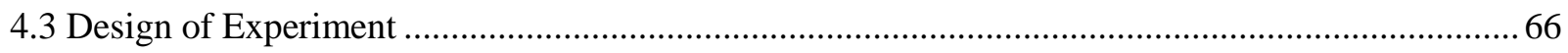

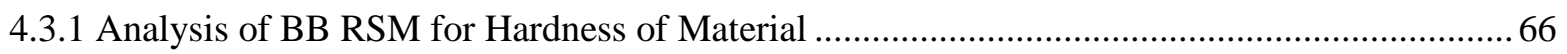

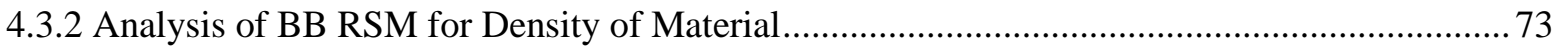

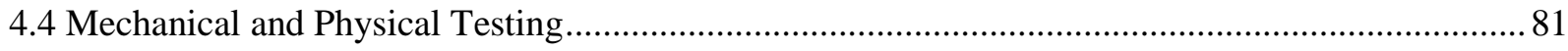

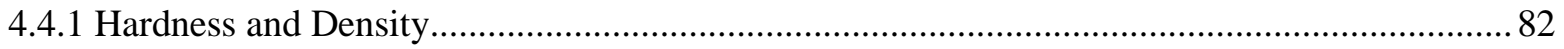

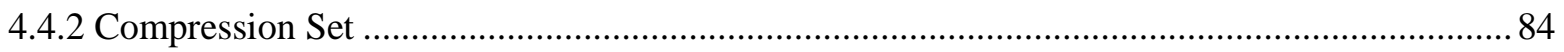

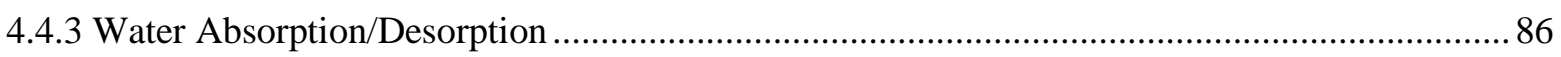

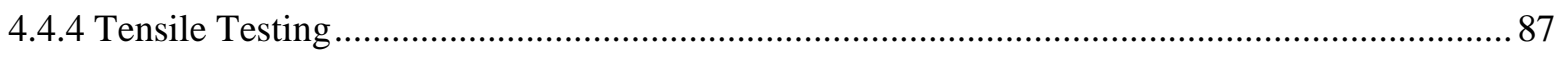

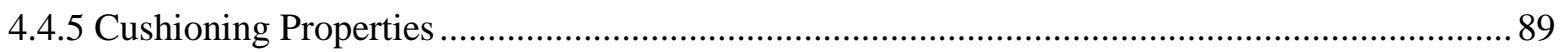

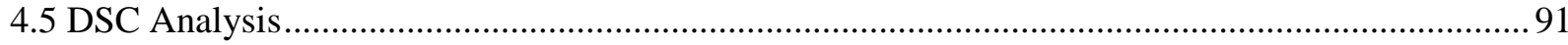

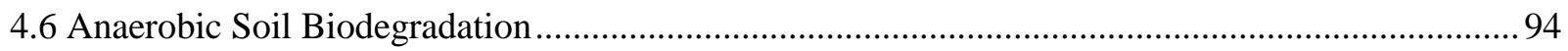

CHAPTER 5. CONCLUSIONS AND FUTURE WORK...................................102

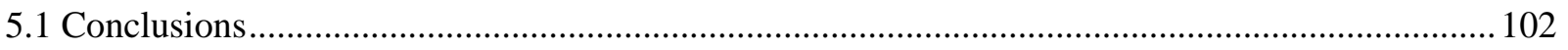

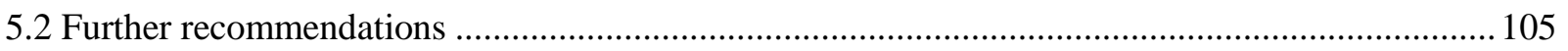

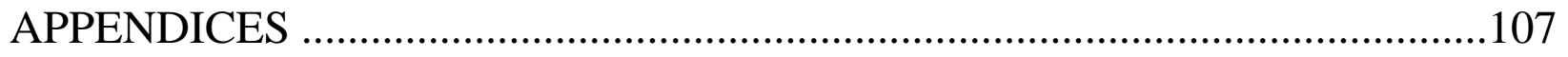

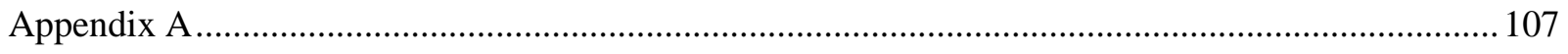

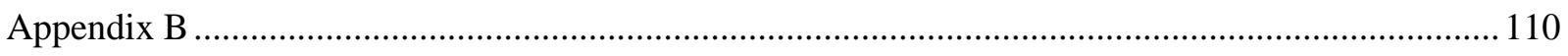

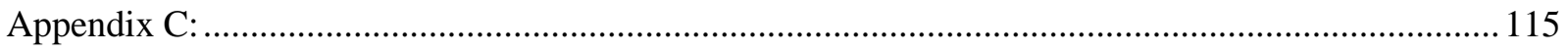

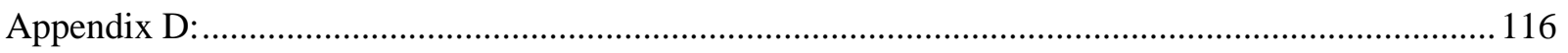

REFERENCES................................................................................ 117 


\section{LIST OF TABLES}

Table 2.1. Shock absorbing materials ranking based on shape of stress-strain curve .15

Table 2.2. Performance index matrix from Paton et al. (2007).................................................................. 18

Table 2.3. Performance index results from Paton et al. (2007) ................................................................ 19

Table 2.4. Recommendation for suitability of material for cushioning, adaptation and filling based on bench

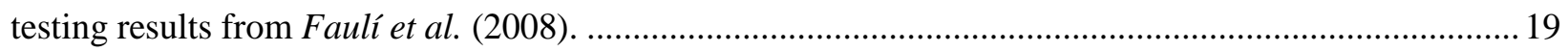

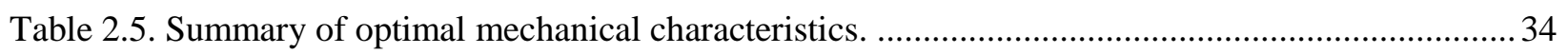

Table 2.6. Application of castor oil for synthesis of PU foams and elastomers. .................................... 39

Table 3.1. Box - Behnken response surface design matrix. …........................................................... 45

Table 4.1. Peak assignment for FTIR spectra of CO/PO3G/TDI formulation........................................58

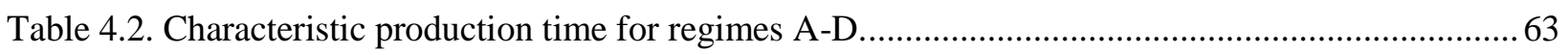

Table 4.3. Summary of the method for BB RSM for hardness as a response variable .............................66

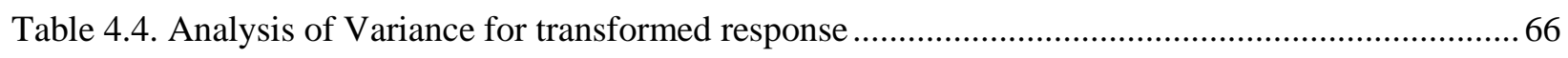

Table 4.5. Model Summary for transformed response ...................................................................... 67

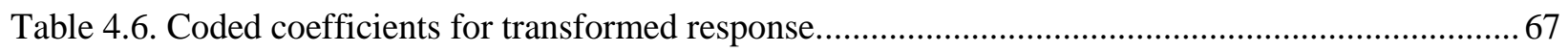

Table 4.7. Summary of method for BB RSM for density as a response variable ....................................73

Table 4.8. Analysis of Variance for Transformed Response for density as a response variable. ...............74

Table 4.9. Model Summary for Transformed Response in case of density of PUF as a response variable 75

Table 4.10. Coded Coefficient for Transformed Response for density of PUF as a response variable......75

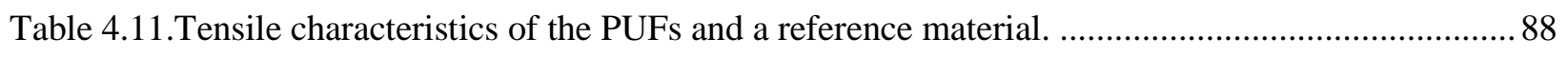

Table 4.12. Cushioning energy and cushioning factor of the developed PUFs and a reference material...90

Table 4.13. Tensile characteristics of PUF samples after 2 and 4 month of anaerobic soil biodegradation and untreated control sample. 100 


\section{LIST OF FIGURES}

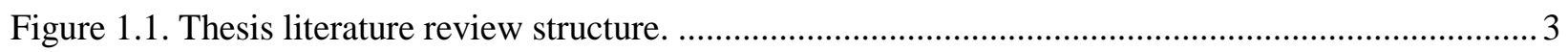

Figure 1.2. Pressure sensitive insole prototype (left) and WBMS operating scheme (right).....................5

Figure 1.3. Effects of type of actuator on sensor output. (right - application of pressure by actuator, left -

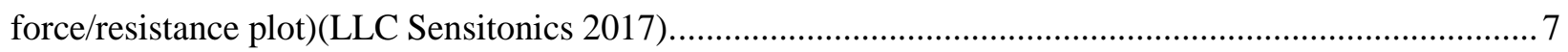

Figure 1.4. Effect of temperature on FSR sensor output from Luo et al. (1998) ...................................... 8

Figure 2.1. Compression curves for very stiff (left), moderately deformable (middle) and highly deformable (right) classes of insole materials (Campbell et al. 1982) ................................................................... 16

Figure 2.2. Typical compression loading/unloading curve (left) and shear stress-strain loading/unloading (right) characteristics of insole materials (Shariatmadari et al. 2012) .................................................2 21

Figure 2.3. Change in compression strength (left) and in shear force (right) behavior of elastomeric foam

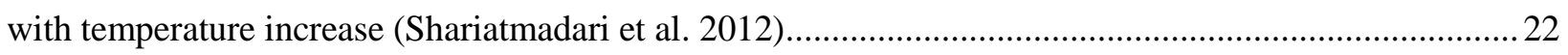

Figure 2.4. Change in compression characteristics (left) and energy absorption (right) at various

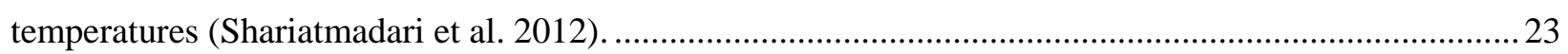

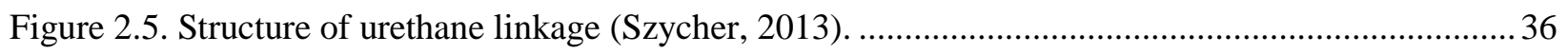

Figure 2.6. 3D structure of polyurethane. HS are linked by hydrogen bonds (Szycher 2013) .................. 37

Figure 2.7. Phase separated (top) and phase mixed (bottom) polyurethane structure(Hong et al. 1992)...37

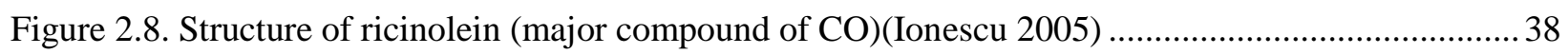

Figure 3.1. Equation of chemical reaction for the synthesis of PUF: Gelling reaction (top) and blowing

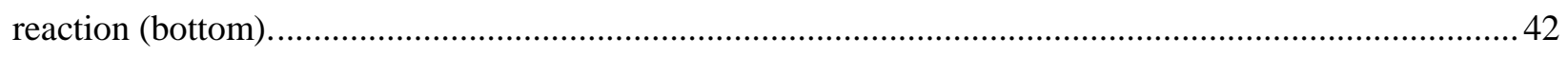

Figure 3.2. Schematic of synthesized CO/PO3G/TDI polymer ...................................................... 42

Figure 3.3. Schematic of experimental set-up for synthesis of PO3G/CO/TDI foam.............................. 43

Figure 3.4. Compression Set (CS) experimental set up according to SATRA TM 64 standard.................49

Figure 3.5. Tensile test specimen die according to SATRA TM 2 standard..........................................51 
Figure 3.6. Cushioning properties of insole. Area 1 corresponds to cushioning energy during walking (CEw); sum of Area 1 and Area 2 is cushioning energy during running (CEr) (Saraswathy et al. 2009).. 52 Figure 4.1. FTIR spectra of a typical CO/PO3G/TDI PUF formulation (sample 200)(top); magnified FTIR spectra of a typical CO/PO3G/TDI PUF formulation for range 1800-1000 cm-1(bottom). .57

Figure 4.2. FTIR spectra change over the course of polymerization reaction in the sample of CO/PO3G/TDI foam (represents the data for $1 \mathrm{pphp}$ DBTDL, $0.1 \mathrm{pphp}$ DABCO followed by post curing) 60

Figure 4.3. Kinetics of CO/PO3G/TDI foam synthesis at different experimental conditions: A - 1 pphp DBTDL, no heat curing; B -1 pphp DBTDL, 0.1 pphp DABCO, no heat curing; C-1 pphp DBTDL followed by post curing at $70^{\circ} \mathrm{C} ; \mathrm{D}-1 \mathrm{pphp}$ DBTDL, $0.1 \mathrm{pphp} \mathrm{DABCO}$ followed by post curing.

Figure 4.4. Effect of surfactant concentration on the cell structure of PUF samples. Top left-1 pphp, top right -2 pphp, bottom left-3 pphp, bottom right-4 pphp. Sample: 000 from experimental design. .65

Figure 4.5. Cell diameter distribution for PUF samples with $2 \mathrm{pphp}$ of surfactant (left) and 3 pphp surfactant (right) .65

Figure 4.6 Pareto chart of the standardized effects 69

Figure 4.7. Main effects plot for hardness of PUF as a response variable............................................. 70

Figure 4.8. Two way interactions plot for hardness as a response variable .......................................... 70

Figure 4.9. Residuals vs fitted values plot for BB RSM for hardness as a response variable. ...................71

Figure 4.10. Normal probability plot for BB RSM for hardness as a response variable. .........................71

Figure 4.11. Contour plots for BB RSM for hardness as a response variable: A- hardness versus factors I,

W; B- hardness versus factors P, I; C-hardness versus factors P, W ................................................ 73

Figure 4.12. Pareto chart BB RSM modes for density as a response variable........................................ 77

Figure 4.13. Main effects plot BB RSM for density as a response variable ......................................... 77

Figure 4.14. 2-way interactions plot BB RSM for density as a response variable.................................. 78

Figure 4.15 Normal Probability plot BB RSM for density of PUF as a response variable....................... 78

Figure 4.16. Residuals plot BB RSM for density of PUF as a response variable.................................. 79 
Figure 4.17.Contour plots for BB RSM for density of PUF as a response variable: A- contour plot for density vs P,W; B-contour plot for density vs W,I; C-contour plot for density vs W,P.

Figure 4.18.Diagram representing hardness of the materials for corresponding samples. PB- commercial reference material (Poron Blue 4080) 82

Figure 4.19. Diagram of density versus corresponding PUF sample as predicted by BB RSM (blue) and experimental values (grey). PB - reference commercial material.

Figure 4.20. Diagram for compression set of the corresponding PUFs and reference material (PB) at standard (dotted) and elevated (bold) temperatures. 85

Figure 4.21. Diagram for CS of the materials (black) and hardness (grey) for corresponding PUFs and PB (reference material). .86

Figure 4.22. Water absorption (black) and water desorption (grey) for corresponding PUFs and reference material. .87

Figure 4.23. Strain/stress characteristics of developed PUFs and reference material. .88

Figure 4.24. Compression curves for the developed PUFs and the reference material.

Figure 4.25. DSC thermogram of $\mathrm{PO} 3 \mathrm{G}$ polymer (left) and enlarged section of the plot for PO3G

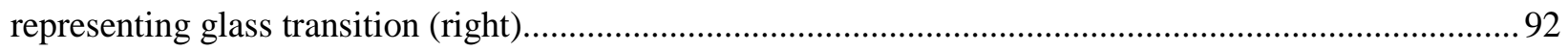

Figure 4.26. DSC thermogram for the developed PUFs. ................................................................. 93

Figure 4.27. Change in transmission in the samples with various degree of phase separation.................. 94

Figure 4.28. SEM images of pristine foam (left) and after 2 months of anaerobic biodegradation (right).

Sample 200... .96

Figure 4.29. Optical microscopy image of initial cell strut (top left), after 2 months (top right) and 4 months of anaerobic soil biodegradation (bottom left). Sample 200.. .96 Figure 4.30. Spectral changes in $\mathrm{N}-\mathrm{H}, \mathrm{C}-\mathrm{H}$ absorption region (A), $\mathrm{C}=\mathrm{O}$ absorption (B) and $\mathrm{C}-\mathrm{O}-\mathrm{C}$ (C) absorption regions of bio-degraded PU foams. .99

Figure 4.31. Change in mechanical properties for treated foam samples and control PUF. Sample 200. 100 Figure 4.32. Weight loss of PUF samples after soil biodegradation versus reference samples. 101 


\section{NOMENCLATURE}

The following list of symbols and abbreviations is used throughout the report including short descriptions.

\begin{tabular}{|c|c|}
\hline Symbol & Description \\
\hline$T_{g}$ & Temperature of Glass-Transition, ${ }^{\circ} \mathrm{C}$ \\
\hline$T_{m}$ & Melting Temperature, ${ }^{\circ} \mathrm{C}$ \\
\hline$T_{c}$ & Crystallization Temperature, ${ }^{\circ} \mathrm{C}$ \\
\hline$A H P$ & Analytical Hierarchal Process \\
\hline$B B R S M$ & Box-Behnken Design for Response Surface Methodology \\
\hline$B D$ & Butane diol \\
\hline$C E$ & Chain Extender \\
\hline$C E$ & Cushioning Energy \\
\hline$C F$ & Cushioning Factor \\
\hline $\mathrm{CO}$ & Castor Oil \\
\hline$D M A$ & Dynamic Mechanical Analysis \\
\hline$D S C$ & Dynamic Scanning Calorimetry \\
\hline$F S R$ & Force Sensing Resistors \\
\hline FTIR & Fourier-Transform Infrared Spectroscopy \\
\hline$H D$ & High Density \\
\hline$H D I$ & Hexane Isocyanate \\
\hline$H S$ & Hard Segment \\
\hline II & Isocyanate Index \\
\hline IPDI & Isophorone Diisoocyanate \\
\hline ISO & The International Organisation for Standardization \\
\hline
\end{tabular}




\begin{tabular}{|c|c|}
\hline$L D$ & Low Density \\
\hline$M D I$ & Methylene-4,4-diphenyl diisocyanate \\
\hline$N C$ & Nanocellulose \\
\hline$N C L$ & Nanoclay \\
\hline$N C O$ & Isocyanate \\
\hline$P C L$ & $\operatorname{Poly}(\varepsilon$-caprolactone)diol \\
\hline$P E$ & Polyethylene \\
\hline$P E G$ & Polyethylene glycol \\
\hline$P M V L$ & $\operatorname{Poly}(\beta$-methyl- $\delta$-valerolactone $)$ \\
\hline$P O 3 G$ & Poly(trimethylene) ether glycol \\
\hline$P P$ & Polypropylene \\
\hline pphp & Parts per hundred parts of polyol \\
\hline$P U$ & Polyurethane \\
\hline$P U F$ & Polyurethane foam \\
\hline$P V C$ & Poly(vinyl) chloride \\
\hline$R A$ & Reinforcement Agent \\
\hline$R I M$ & Reaction Injection Moulding \\
\hline SATRA & Shoe and Allied Trades Research Association \\
\hline$S P E U$ & Segmented Poly(ether) Urethane \\
\hline$S S$ & Soft Segment \\
\hline$T D I$ & Tolyene Diisocyanate \\
\hline UTM & Universal Testing Machine \\
\hline$W B M S$ & Weight-Bearing Monitoring System \\
\hline
\end{tabular}




\section{LIST OF APPENDICES}

APPENDIX A. Properties of commercial materials............................................. 107

APPENDIX B. Summary of literature review on commercial materials testing......................110

APPENDIX C. Properties of raw materials ................................................... 115

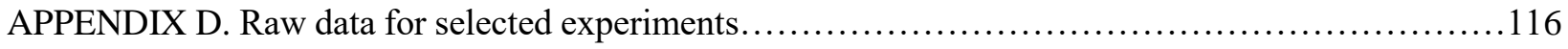




\section{CHAPTER 1. INTRODUCTION}

\subsection{Motivation}

Initial contact between the foot and the ground during walking and running results in high impact forces acting upon the lower limb. Indeed, high loading rates have been associated with cartilage damage (Chen, Burton-Wurster, and Johan 1999), (Ewers et al. 2001), knee pain (Radin et al. 1991) and knee osteoarthritis. Another situation witch can lead to possible complication is transmission of "step shock" to musculoskeletal system during rehabilitation period.

Post-surgery or post-fractures recovery process typically takes several months of a special regiment. It commonly proceeds trough three stages: application of the cast, transition to air boot, and use of conventional shoes and walking with help of mobility devices (crutches, pushcarts). In these stages, "step shock" and loading rated on lower limb should be carefully managed and minimized to a certain level. For instance, clinicians routinely prescribe partial weight bearing during tibial fracture rehabilitation. Partial weight bearing as the primary mechanism to promote fracture healing provides a vague guideline. Maintaining pressure on lower limb at $20 \mathrm{lb}$ without any special equipment and to avoid overloading is a challenging task for patients. As a result, $10 \%$ patients who exceeded the allowable pressure limit end up with prolonged recovery times and repeated surgery procedures. Therefore, clinicians and researchers will greatly benefit from a load-monitoring device that can continually track the weight bearing behavior of a patient between follow up visits, which are typically two weeks apart.

As a medical device, WBMS should demonstrate reliability, safety and low overall life cycle cost products. In order to preserve a high performance of smart pressure monitoring system, main structural elements (sensors, cables) should be protected from external forces that might interfere with their work. One way to provide necessary protection level is to imbed the device inside the protective cushioning material. 
A correct choice of protective cover for WBMS is critical for the device to function properly. Commercial market today presents a vast array of shock absorbing materials with different levels of shock attenuation. However, not all marketed materials are nature friendly and can be recycled. Therefore, consideration should be given not only to functional and economical but also to environmental aspects. In the light of this, the main purpose of the present research study is to develop a functional and inexpensive material with high percent of renewably soured content. It is also desirable that the material not only positively effect the overall devices life span, but also has a potential for recycling or biodegradability in a safe manner.

\subsection{Thesis Overview}

The present research thesis is divided into five chapters. It starts with discussion of WBMS's main features, intended application and design limitations to be addressed in Chapter 1. Later, a comprehensive literature review of shock absorbing materials with emphasise on materials for medical orthotics is conducted. In order to detect optimal properties of a shock absorbing material and establish a link between property and performance, top-down approach is applied (Figure 1.1).

According to the scheme, shock-absorbing materials are categorized by their origin: natural foams, nature originated materials, polymeric foams, solid polymeric materials, knitted polymeric materials. Then all mentioned categories are analyzed in different types of trials: bench analyses, biomechanical or "inshoe" conditions simulation testing. As an inference from a literature review in Sections $2.1-2.3$, the properties of most successful candidates were listed and lacking information about the material properties was supplemented from corresponding technical data sheets. Correctness and rationality of developed methodology is proved by comparing obtained results with general manufacturing guidelines for cushioning insole materials suggested by The International Organisation for Standardisation (ISO) and Shoe and Aliened Trade Research Association (SATRA). Targeted characteristics for insole material are presented in Section 2.4. 


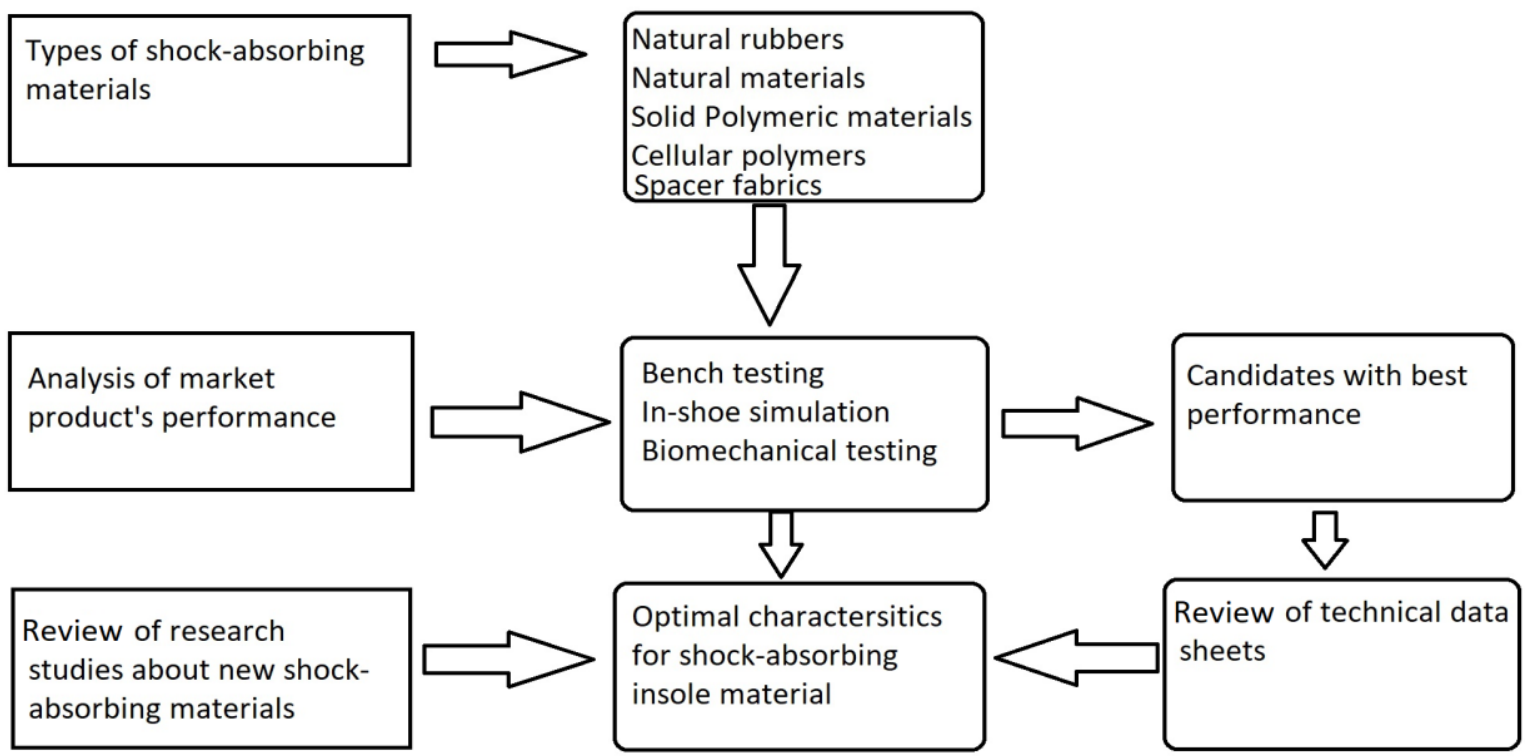

Figure 1.1. Thesis literature review structure.

Considerations about material choice are outlined in Section 2.5. The description of preparation methods, instrumentation and testing techniques are provided in the Chapter 3 of the present thesis. Chapter 4 is addressed to reporting and analysis of obtained results. Finally, the study completes with Chapter 5 where major conclusions and recommendations are gathered.

\subsection{Weight-Bearing Monitoring System (WBMS)}

Sections 1.3.1- 1.3.3 describe possible areas of applications of WBMS device, it's main components and design limitations to overcome.

\subsubsection{Application}

A progressive protocol of weight-bearing as the healing process advances is a common clinical practice. The most common instructions are defined as touch-down weight-bearing (around $10 \mathrm{~kg}$ or $10 \%$ - $20 \%$ of body weight), partial weight-bearing (35 $\mathrm{kg}$ or $20-50 \%$ of bodyweight) and weight-bearing as tolerated, which the patient regulates according to the perceived pain. The health care specialist evaluates 
the progress of patient's injury and progressively reduces weight-bearing restrictions by showing the subjects what the objective load feels like. Several techniques have been employed in the pursuit of this goal, verbal instructions and the use of bathroom scales being the most common. Most of these methods have been shown to have poor outcomes in regards to the ability of the patient to reproduce the weightbearing protocol (Bril et al. 2016). Hence, the device that is able to quantitatively assess the weight- bearing throughout the recovery process is an effective and functional substitute to techniques that are rather based on abstract explanations.

Pressure monitoring devices are useful tools for improvement of athletic performance, for diagnosis of motion abnormalities and scientific research. Nowadays, plethora of smart insoles are presented on the market $\left(\right.$ F-Scan ${ }^{\circledR}$, Pedar ${ }^{\circledR}$, Vicon ${ }^{\circledR}$, Gait Aid ${ }^{\circledR}$, etc.). However, currently there are no commercially available products capable of recording the load placed on an injured limb for more than 1 hour. Insole pressure and gait analysis systems Pedar ${ }^{\circledR}$ and F-Scan $®$ are limited to a maximum recording time of 1 hour and 11 minutes, respectively. None of the product available on the market is addressed specifically to the problem of weigh-bearing monitoring after surgery recovery (Northe et al. 2010). Additionally, these three systems are prohibitively expensive, ranging from $\$ 6,000$ to $\$ 16,000$, making it unpractical to apply these systems for large-scale clinical trials and for general patient monitoring. In order to enable clinicians to study, monitor and guide partial weight bearing during fracture rehabilitation, a low-cost disposable weight bearing system targeted for in-cast recovery stage should be developed.

In fact, the benefit of WBMS becomes apparent when considering the following calculations: Canadian Institute for Health information cites 52,272 hip replacement surgeries, 62,000 knee replacement surgeries, 65,000 tibia fractures (Anon 2017) and 90,370 strains/sprains(Anon 2015) in Canada in 2015. Summing up, over 250,000 casts are applied for proper recovery of the patients and faster healing. It was also reported for USA, that the large number of complications associated with tibia fractures result in an annual direct cost of $\$ 2.8$ billion USD. The long rehabilitation times result in an annual indirect cost of $\$ 95$ billion USD mostly due to lost wages (North et al. 2010). A load sensor that is economic and capable of accurately measuring the normal loads experienced by the limb will enable clinicians to understand how 
partial weight bearing can be used to avoid after fracture complications, thereby reducing fracture-healing time.

\subsubsection{Overview of the device}

The WBMS consist of Force Sensing Resistors located on first metatarsal and fifth metatarsal heads and in the heel area (Figure 1.2, left).
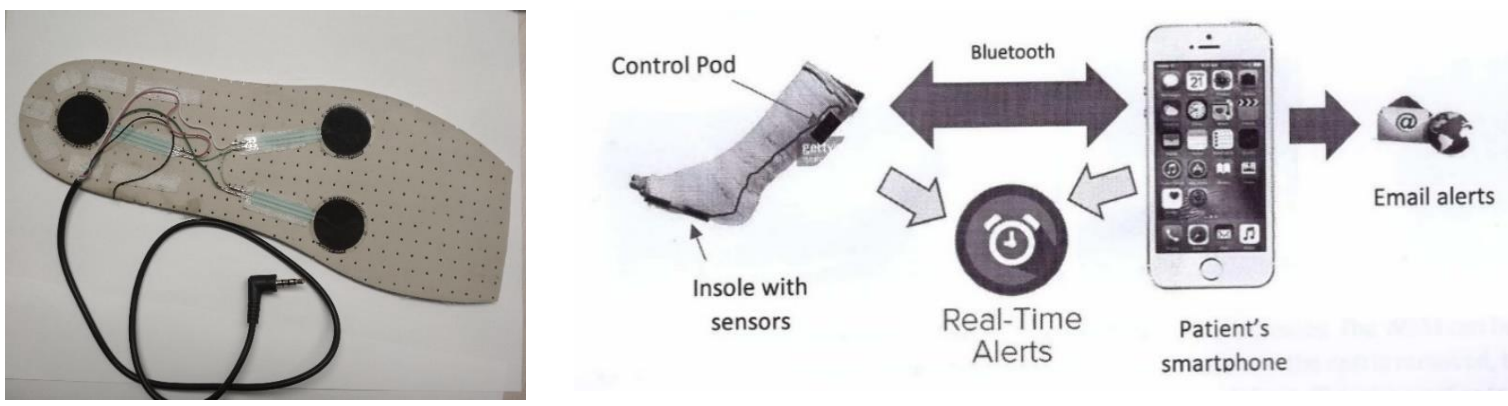

Figure 1.2. Pressure sensitive insole prototype (left) and WBMS operating scheme (right).

Sensors and connecting cables are sandwiched between protective cushioning foot insole. Bothe sides of insoles have an adhesive backing and can be firmly attached to the cotton stockinet, then cast is applied as normal procedure. The signal from Force Sensing Resistors transmits to control pod, attached on the outside of the cast and then to patient's smartphone (Figure 1.2, right).

WBM app enables to get real time alerts (sound, vibration) about exceeding a weight threshold (20 lb) and save the history for doctors and long-term caregivers.

\subsubsection{WBMS Design Limitations}

Force Sensitive Resistors (FSRs) are often first-choice sensors as a base of pressure sensitive device due to low cost, options to create arrays of sensors and their slim shape factor (LLC Sensitonics, 2017). Despite the economical and other benefits of FRSs, these sensors have a limitation of low accuracy of measurements $( \pm 10 \%)$ (LLC Sensitonics 2017$)$ and temperature sensitivity. 
FSRs and wires are delicate equipment that needs to be protected against excessive and uneven compression. Sensor's output largely depends on how the weight is applied. In other words, the FSR is sensitive to pressure (force applied over an area) not to force itself. For instance, the output value is different if weight is concentrated at one point on the sensor or if it covers the whole area of the sensor ( Luo et al 1998). Certainly, the general approach to compensate for variations in sensor output is sensor calibration. However, in case of in-shoe/in-cast application, the sensors can change their position with respect to the foot's bony prominence while walking; hence calibration procedure will be needed for every single step.

The effect of actuation variance is illustrated in the example plots below (Figure 1.3), which show identical force sweeps applied to the same sensor using two different actuators (broad vs narrow tip). The figure 1.3 demonstrates that the slope of resistance curve (output) has a steeper slope when the narrow actuator applies the actuation. Since narrow actuator only covers a part of the sensor, correctness of results highly depends on how equally the pressure is distributed over the sensor surface. The significant difference in responses demonstrates the importance of consistent mechanical actuation in isolating force from pressure response.

As long as the force is applied consistently, cycle-to-cycle repeatability is maintained. A layer of cushioning material placed between the actuator (foot) and the sensor can be used to absorb some error from inconsistent force distribution.

Temperature sensitivity is another disadvantage of FRSs especially in application as insole device. Besides the temperature increase due to heat generation within the electric circuit, the ability of the foot to produce enormous amount of heat has a significant contribution to total temperature profile of the pressure sensitive device. The study by Shariatmatardi et al. (2012) has found that temperature inside the footwear increases for $8-13^{\circ} \mathrm{C}$ already after $15-20$ minutes of activity. 


\section{Broad tip}
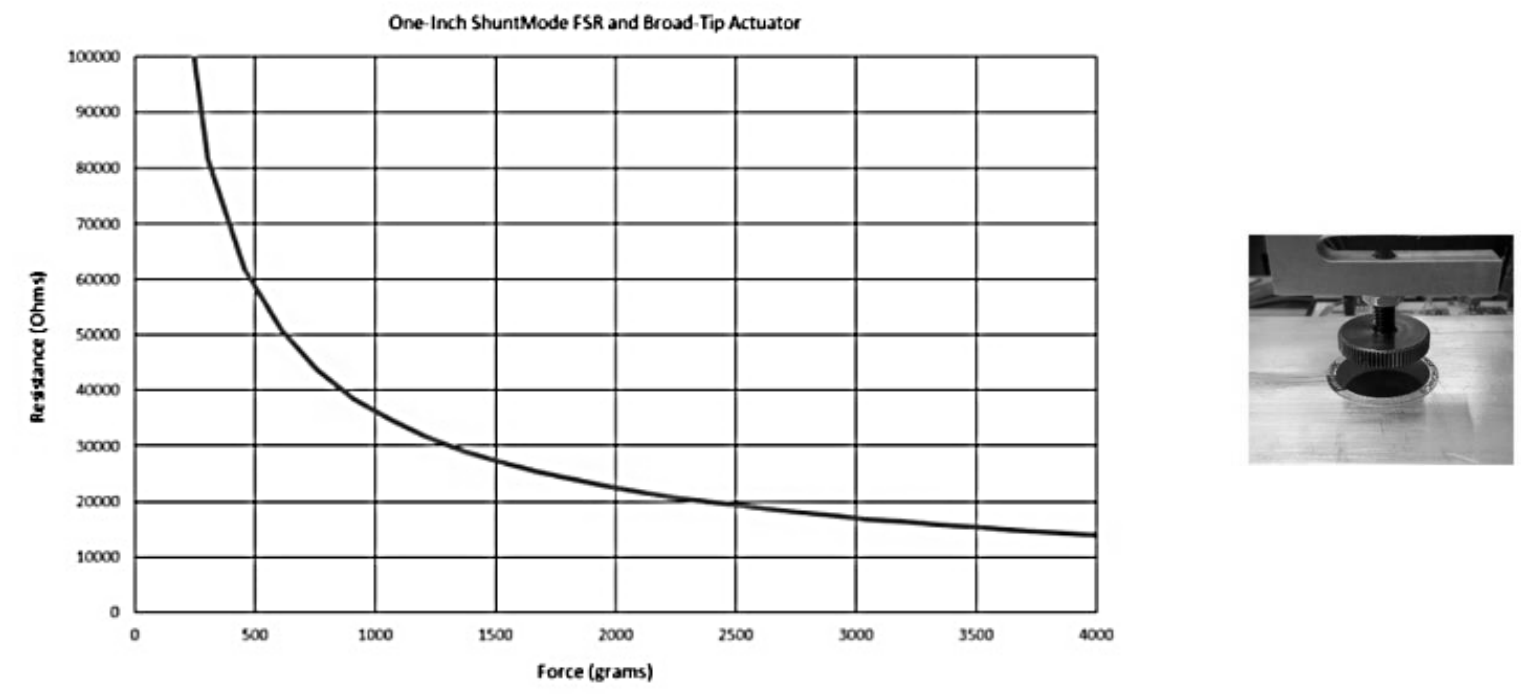

\section{Narrow tip}

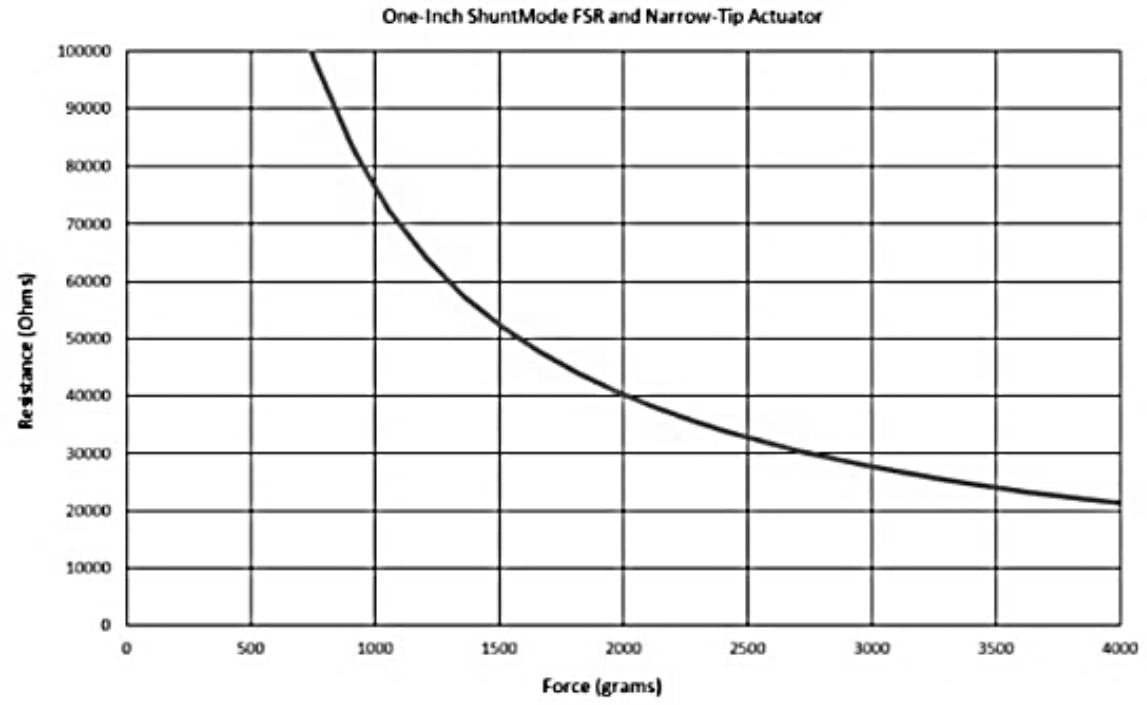

Figure 1.3. Effects of type of actuator on sensor output. (right - application of pressure by actuator, left force/resistance plot)(LLC Sensitonics 2017). 
On the other hand, FRS's based commercially available devices are reported to have sensor output variations depending on ambient temperature (Hurkmans et al. 2006; Luo et al. 1998). Luo and colleagues (1998) report significant error in sensor output after $30^{\circ} \mathrm{C}$ and for this reason, they recommend the use of F-scan ${ }^{\circledR}$ device for only short time in this regime (Figure 1.4). If a high level of force is applied simultaneously with increase in temperature, the process of ink creeping accelerates significantly and variation in output occur.

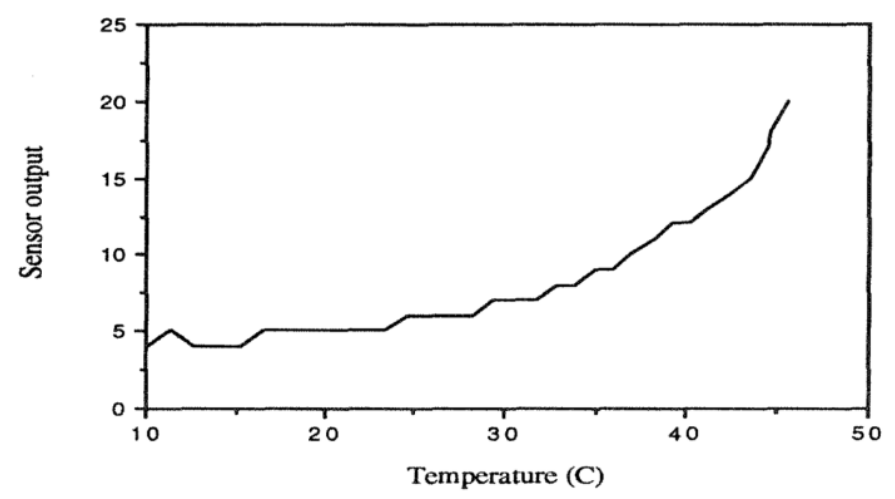

Figure 1.4. Effect of temperature on FSR sensor output from Luo et al. (1998)

In summary, FRSs are highly sensitive sensors that are widely applied in "smart insole" devices. The economical benefit of FRSs outweighs its weaknesses; however, the issue of temperature sensitivity and low accuracy should be addressed, especially when applied in medical devices. Thus, the design of protective pressure distributing insole with low thermal conductivity is necessary to overcome FRSs limitations. 


\section{CHAPTER 2. LITERATURE REVIEW}

\subsection{Shock Absorbing Materials}

Historically, protection of foot tissues from excessive plantar pressure was archived by use of widely available materials such as wood, cork and leather. With advances in material sciences over the last four decades, a wide range of materials have been introduced in the market, including foam rubbers, plastics, warp-knitted fabrics and cellular polymers that possess suitable properties and characteristics for use in offloading insoles. Next, we discuss the main properties characteristic for each type of the material.

For clarity and ease of exposition, all commercial materials mentioned in present report are grouped according to their nature (Table A.1).

\subsubsection{Foam Rubbers}

Rubber can be natural or synthetically manufactured. Synthetic rubber materials are commonly used in numerous orthotic devices. Natural latex (e.g. Superlatex $\left.{ }^{\circledR}\right)$ is lightweight and very soft but prone to rapid and permanent shape deformation. Orthopaedic insoles made of latex foam are mainly used to provide additional cushioning and to temporarily relieve pressure and painful symptoms. However, latex readily stains and deteriorates in practical uses so that the insoles easily 'bottom out' under low loads, which result in little cushioning or shock absorption for the wearer (Campbell et al. 1984; Yick et al. 2013).

Neoprene is a special type of synthetic rubber made of poly(chloroprene) and it is primarily known for its use as an inlay or insole material in the form of either a closed-cell foam (e.g. Spenco®) or an opencell foam (e.g. Lyncoß). Neoprene can reduce friction that is why it is often used as a covering material for sport orthoses when friction and shear forces are expected to be high. However, it has poor ventilation and heat retaining properties. Recently, neoprene cover of insoles was reported as a cause of allergy contact 
dermatitis. Thio-urea compounds contained within neoprene can trigger allergic reactions as severe itching, eczematous eruptions, and in some cases blistering as reported by Hawkey et al. ( 2015).

\subsubsection{Nature-Originated Materials}

Commonly used natural materials are leather (Pauk et al. 2015), cork and felted fabrics (Leber and Evanski 1986). Most of them possess many desirable characteristics for use in orthopaedic insoles, such as wide availability, lightweight, low cost, air and water permeability, and ability to be easily shaped. Leather is extremely durable and conforms to the shape of the foot. It is not only used as an interface material for orthopaedic insoles to protect the skin from irritation, but also for supportive purposes when strength and resiliency are required. It is a frequently used material for many foot orthoses and shoe modifications due to its superior breathability characteristics. The main benefit of the leather is that it is an excellent absorbent. It also takes adhesives, tacks and stitches well and can be relatively light, soft and flexible. Leather insoles, especially vegetable tanned, are not very perspiration resistant and their colour will darken rapidly. Their high cost limits leather insoles application to expensive footwear and orthotics (Brent 2007).

Cork is a lightweight, breathable cushioning material made from the outer bark of a tree. It is usually used in combination with leather due to its rough surface and potential irritation to the skin. Currently, a new composite material that utilizes both hygienic properties of the cork and enhanced durability added by polymer matrix (Corkacell®).

Felted materials such as wool felt (Ortho felt $\left.{ }^{\circ}\right)$ are adopted in orthopaedic insoles because of their softness, smoothness, resilience and excellent shock absorption properties. They also have the advantage of being easily moulded into shapes and give a great deal of warmth (Yick et al. 2013). 


\subsubsection{Cellular Polymers}

Cellular polymers can be made from a vast array of materials, such as polypropylene (PP), polyethylene (PE), ethylene vinyl acetate (EVA), poly(vinyl)chloride (PVC), polyurethane (PU) and segmented poly(ether) urethane (SPEU). They are generally available in a wide range of harnesses, thicknesses and densities, with structural and mechanical properties of diverse usefulness. The choice of materials with suitable structural and cushioning properties is closely associated with the intended use and efficacy of the orthopaedic insoles. PP and PE are both flexible olefin polymers that resist breakage. The materials are soft, tend to be non-brittle and heat-formable in applications, and offer reasonable cushioning and shock absorption performances. Since PE (e.g. Plastazote $® 囚$, Pelite $\AA$, Aliplast $\AA$ ) is a polymer with low density and molecular weight, it has a relatively lower stiffness-to-thickness ratio which suffers high permanent compression set and more rapid shape deformation than PP. Due to the low glass transition temperatures of PP and PE, the materials have poor behaviour (become brittle and break) in cold environment.

EVA is mouldable, resilient and elastic. EVA cellular polymer (e.g. Nora ${ }^{\circledR}$ ) can be made with varying qualities of hardness, density and durability. Low density EVA (e.g. Nora ${ }^{\circledR}$ Lunairmed) is generally soft, which provides good cushioning, shock absorption and high walking comfort. As EVA also deteriorates quite rapidly on wearing, high density EVA is adopted when adequate support for the body is required due to foot deformities. EVA with a closed cell structure is impervious to liquids; it is unlikely to absorb body fluids such as perspiration. Under the effect of sustained loading gas trapped inside the cell struts of EVA foam slowly diffuses out, for this reason several EVA insoles are recommended for use in order to preserve a required level of shock attenuation (Kuncir, Wirta, and Golbranson 1990). Furthermore, orthopaedic insoles made of closed cell foam structures may act as insulators and can be hot when they are worn for extended periods.

Polyurethane (e.g. PORON®, Cleron ${ }^{\circledR}$, Herbiprex ${ }^{\circledR}$ and PPT $®$ ) foam is an open-celled material, which has excellent cushioning properties with regard to vertical loads and shear forces. PU foam is 
available in sheets of various thicknesses that can be laminated together with rigid materials (which are inherently hard and uncomfortable in direct contact) for optimal comfort and functional performance. Due to its good cushioning and pressure distribution properties, as well as high energy absorption behaviour, the use of PU in orthopaedic insoles for spot cushioning not only provides excellent resistance to ground reaction forces when walking, but also high resistance to 'bottoming out' under pressure, shock and shear. Moreover, the open-celled structure of PU adds breathability and reduces heat build-up, and therefore enhances thermal comfort when the insoles are used. In the case of SPEU, its fabrication techniques are flexible. Its physical and mechanical properties can be designed and controlled at various stages during synthesis. Hence, SPEU materials offer superior physical and mechanical properties, flexibility with high strength, wear resistance and a good degree of hardness (Yick et al. 2013).

\subsubsection{Elastomeric Materials}

Viscoelastic PU elastomers (e.g. Epoflex®, Sorbothane ${ }^{\circledR}$, Viscolas $\left.®\right)$ in footwear applications act as shock and vibration absorbers. The insoles can mitigate the ground reaction force of heel strikes while protecting the joints from rebounding spikes of force by gradually and evenly dissipating energy. The material has excellent resilience and can be custom moulded. The use of viscoelastic PU elastomers for insole fabrication provides longer protection without 'bottoming out' and it withstands high compression forces for durability. However, viscoelastic PU are expensive. Mass-produced insoles made of Epoflex ${ }^{\circledR}$ may range from USD $\$ 40$ for a pair of heel pads to USD $\$ 100$ for a pair of full-length insoles.

Silicone elastomers (MaxaCane $\left.{ }^{\circledR}\right)$ is another type of solid non-cellular materials, which are available in a wide variety of formulae, qualities, compression properties and setting times. As silicones can also be readily moulded into custom shapes and designs, they have been extensively used in orthotics in recent years. Silicones are presented as a paste to which a catalyst is added, which transforms the paste into a flexible solid. After the final setting, the material is able to withstand repeated functional loading without dimensional changes or fractures. 


\subsubsection{Warp Knitted Spacer Fabrics}

3-D spacer fabrics are a new generation of materials that combine air permeability, breathability and pressure distributing property superior to foam materials and composites (Liu et al. 2012; Lui et al. 2014). The 3D spacer fabrics consist of two separate knitted substrates that are joined together or kept apart by spacer yarns, and provide support so that the 3D structure will avoid being crushed under body pressure. The 3D structure and a suitable combination of materials used in spacer fabrics can act as a buffer to prevent moisture build-up in the microclimate that surrounds the skin when human subjects intermittently perspire, and can thus guarantee excellent wear comfort.

An interesting study (Basal and Ilgaz 2009) on the development of functional fabrics for pressureulcer prevention indicates that the enhanced wicking ability of channeled polyester makes it ideal for the warp, pile and the top weft in the spacer structure, whilst cotton fibres are used as the bottom weft to improve fabric comfort by trapping the moisture delivered from the top layer. Fabrics can also be moulded for optimal fit and comfort, and engineered to suit the intended purposes. For example, to create a longterm, compression-resistant, climate-controlling zone for ventilating the foot, high resilient fibres can be added to the pile. The rolling action of the foot and the associated pumping effect can also assist the circulation of air in the spacer structure, thus contributing a positive effect on the climate conditions inside the shoe.

Technologically, production of 3D materials requires sophisticated knitting machines. Nowadays, this technology requires a costly equipment and less economical than manufacturing of traditional polymeric materials. Moreover, the literature reviews regarding warp-knitted fabrics for insole fabrications are restricted to assessment of immediate effect of load transmission; long term performance of 3D spacer fabrics remains unestimated (Liu et al. 2012). 


\subsection{Testing of Commercial Materials}

Determination of parameters-to-be-modeled is a crucial part of material design since it is directly related to the properties of end product. Taking into account that myriads of cushioning materials and orthotics has become available on the market in the last two decades, discrimination of right properties becomes an especially challenging task. Majority of these materials have been screened in pursuit to determine the best one for each specific purpose. For this reason, a beneficial strategy would be to sort out the best candidates for cushioning purposes and then analyse, try to mimic and further enhance their mechanical and physical properties.

Medical orthotics are insole devices that intent to provide a reliable cushioning and pressure distribution to its user. Especially their performance is important for the patients with diabetes. One of the complications often triggered by diabetes is foot neuropathy. While having this disorder, zones of innervated tissues of the foot in conditions of elevated plantar pressure and shearing stress are prone to development of foot ulcers. Thus, main requirements to medial orthotics for diabetes patients are high level of pressure attenuation and low friction between skin and contacting surface. Another reasonable requirement is durability of the insole. Thus, it makes sense to conduct the search for potential materials with superior weight-bearing characteristics among the one suggested for use in medical orthotics and diabetes footwear.

As suggested by Healy et al.(2010), the research papers were classified into tree categories. The first category is bench-testing aiming to determine mechanical characteristics of the materials, their damping and cushioning abilities. Secondly, in-shoe conditions simulation is another type of testing when participants compare the samples according to the magnitude of forces produced by stepping or walking on the sheets of different kinds. Finally, the insole materials are analyzed by novel in-shoe technologies while walking or running. 


\subsubsection{Bench Testing}

Bench testing is the basic initial way to study mechanical and physical properties of an insole material. Bench testing was more widespread in last two decades of 19th century, while nowadaystechnological advances enabled to apply more complex methods as sensitized insole devices.

The early work by Campbell et al. (1982), attempted to determine the applicability of a material in orthotics fabrication in respect to its compression behavior. The researchers have analysed 31 sample and categorized them according to stress-strain curve type. Materials were compressed to maximum load of 23 $\mathrm{kg}$, which corresponds the pressure of $3.6 \mathrm{~kg} / \mathrm{cm}^{2}$ exerted by foot during walking. Because of their investigations, all materials were divided into 3 categories: highly deformable, moderately deformable and very stiff (Table 2.1) according to the shape of their characteristic compression curve (Figure 2.1).

Table 2.1. Shock absorbing materials ranking based on shape of stress-strain curve from Campbell et al. (1982)

\begin{tabular}{|c|c|c|c|c|}
\hline \multicolumn{2}{|r|}{ Categories } & \multicolumn{3}{|c|}{ Materials } \\
\hline \multirow{2}{*}{1} & \multirow{2}{*}{ Very Stiff } & High Density Neoprene & Aliplast -10 & Pelite \\
\hline & & Pacer & Kemblo & \\
\hline \multirow{3}{*}{$2 \mathrm{~A}$} & \multirow{3}{*}{ Moderately Deformable } & Poron-20125 & Plastozote Low Density & \\
\hline & & Aliplast-6A & Neoprene R425N & \\
\hline & & Poron Sport & Neoprene 431 & \\
\hline \multirow{6}{*}{$2 \mathrm{~B}$} & \multirow{6}{*}{ Moderately Deformable } & Ensolite & Aliplast-4E & Spenco \\
\hline & & Evazote & Ethafoam & Bonfoam \\
\hline & & Neoprene-R 425N & Celltite & Lynco \\
\hline & & Poron-17125 & & \\
\hline & & \multicolumn{2}{|c|}{ Carpet -Wool(pile weight $1.15 \mathrm{~kg} / \mathrm{m}^{2)}$} & \\
\hline & & \multicolumn{2}{|c|}{ Carpet -Polypropylene(pile weight $0.74 \mathrm{~kg} / \mathrm{m} 2$ ) } & \\
\hline 3 & Highly Deformable & "Dr. Scholls" Cushion Insole & "Odor-Eater" insole & Polyurethane foam \\
\hline
\end{tabular}

Highly deformable materials (Category 3 ) undergo a rapid deformation that commonly referred to as "bottoming-out". Since these materials will not transfer a significant portion of the stress to adjacent regions of the foot, they have been judged to possess poor characteristics for use as an orthotic shoe insole material. The second category named "moderately deformable" demonstrates a reasonable degree of deformation with increased load, almost to the maximum anticipated stress. Category 1 deforms very little, which 
prevents a redistribution of a stress on the bony prominences to the adjacent tissue. Consequently, materials in type 1 are probably less useful as an orthotic shoe insole material.
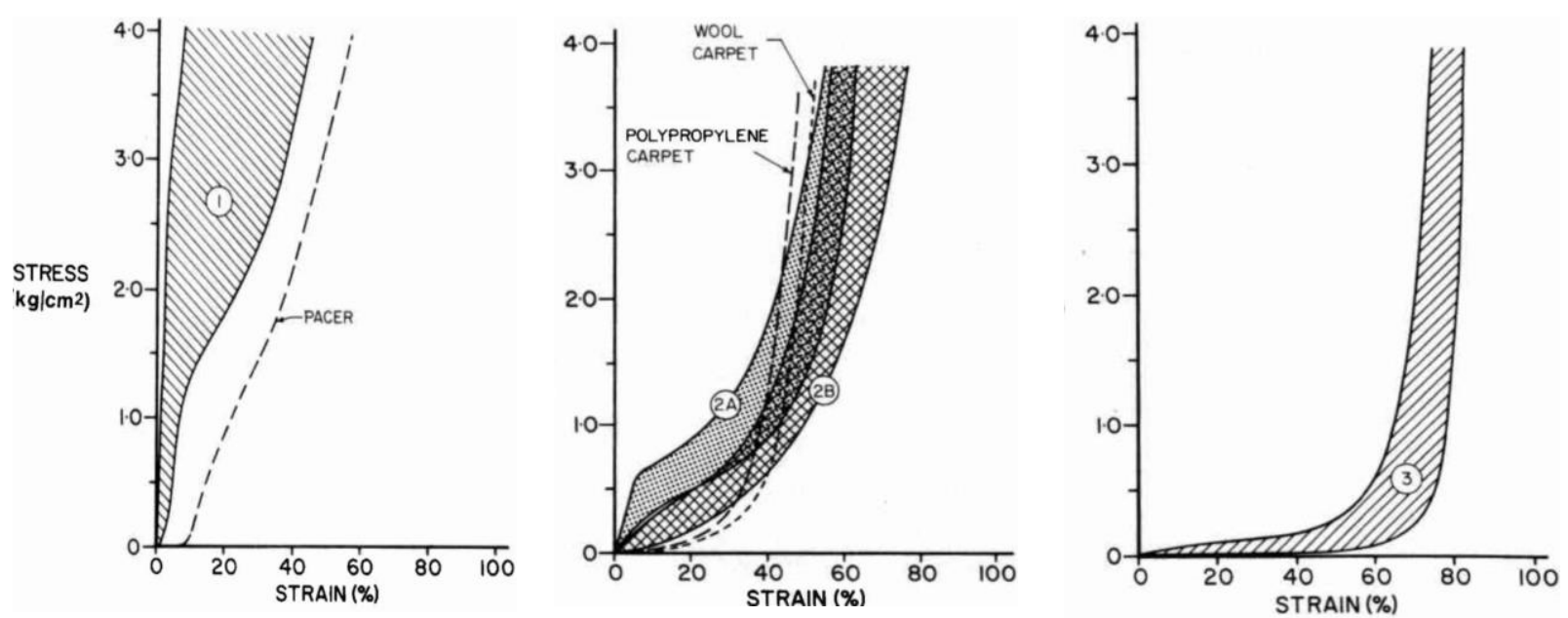

Figure 2.1. Compression curves for very stiff (left), moderately deformable (middle) and highly deformable (right) classes of insole materials (Campbell et al. 1982)

Campbell et al. (1982) concluded that the most appropriate class of materials for shock absorbing insoles fabrication are moderately deformable materials (both Category $2 \mathrm{~A}$ and $2 \mathrm{~B}$ ), but suggest to consider several factors (durability, biocompatibility, compression set) except for stress-strain behavior for more correct assessment of performance.

Other researchers developed multi factor research: by estimating materials damping ability through measuring acceleration (Pratt et al. 1986)), determination and comparison of mechanical properties (Faulí et al. 2008; Paton et al. 2007; Rome 1991) and studying the effect of temperature on materials performance (Shariatmadari et al. 2012). The samples analyzed by Rome et al. (1991) were compared according to their density, hardness, compression set, resilience. The study suggests that a mean value of density $0.333 \mathrm{~g} / \mathrm{cm}^{3}$ is sufficient for material in order not to quickly deform and on the other hand not to be to stiff. According to Rome et al. (1991), materials that are capable of storing high strain energy are the ones with best damping ability. Polyurethane foam and high-density polyethylene foams with hardness Shore A 32-35 are among those with best shock absorption characteristics. 
Pratt et al. (1986) assessed cushioning properties of materials by measuring acceleration and rebound height. The authors conclude that material that demonstrates the lowest acceleration and rebound height is superior in shock absorption. As determined in the study, Poron ${ }^{\circledR}$ and Visolas ${ }^{\circledR}$ have the lowest values of both factors, hence are anticipated to have the best off-loading characteristics. Plastazote ${ }^{\circledR}$ has demonstrated very good initial behavior, but after prolonged use, its properties are destructed and material cannot regain initial performance.

In an attempt to simplify the process of identifying suitable materials for orthoses some authors developed models such as performance indexes (Faulí et al. 2008; Lewis et al. 1991; Lo et al. 2014; Paton et al. 2007), and analytical hierarchy model (Almomani et al. 2016)). So far, none of these is without substantial limitations. The identification of the most crucial material's properties to be considered in the index and the methods used to quantify these properties are important considerations. Lewis et al. (1991) based their index of performance on the materials shock absorption and energy return performance. The testing procedure involved a plunger falling onto the material that was positioned at the base of a resiliometer with the rebound height of the plunger on striking the material and the maximum deceleration and deceleration rate of the material used to calculate the performance index. The authors proposed that the lower the value the better the performance of the material. Testing was completed on different thicknesses of the same materials with the performance index found to decrease as the thickness of the tested material increased. The differences in the values of the performance index accounted for the rebound height and the deceleration rate of the material with no significant differences evident in maximum deceleration between materials.

Based on regression analysis for the dependence of the performance index on the thickness of each material the authors calculated the performance index for all materials at a thickness of $4.8 \mathrm{~mm}$ and rated the tested materials based on this. Poron $®$ was found to perform best followed by Hygard $®$, Isoloss LS®, TL-61 Standard®, Viscolas $®$ and Sorbothane $®$.

Paton et al. (2007) focused on common materials types used for diabetes foot ulcers prevention and compared samples according to their density, resilience, force attenuation, compression set and 
durability. Later the performance indicators matrix was developed. All materials were divided into three categories according their ability to control (the position of the foot), dampen (foot strike shock) and mold (to the shape of the foot). The materials scored from 0 (lowest) to 6 (highest) points depending on their characteristics. The index matrix (Table 2.2) contains tree categories that authors believe to match a general functional purpose of orthotic materials. The mechanical characteristics are roughly divided into high and low categories (except for density).

Table 2.2. Performance index matrix from Paton et al. (2007).

\begin{tabular}{|c|c|c|c|c|c|c|}
\hline \multirow[b]{2}{*}{ Density } & \multicolumn{2}{|c|}{ Control } & \multicolumn{2}{|c|}{ Dampening } & \multicolumn{2}{|c|}{ Moldable } \\
\hline & High & 1 & Medium & 1 & Low & 1 \\
\hline Resilience & High & 1 & Low & 1 & Low & 1 \\
\hline Force Attenuation & Low & 1 & High & 1 & Low & 1 \\
\hline Coefficient of Friction & High & 1 & Low & 1 & Low & 1 \\
\hline Compression Set & High & 1 & High & 1 & Low & 1 \\
\hline Durability & High & 1 & High & 1 & Low & 1 \\
\hline
\end{tabular}

Assigning materials to a specific category highly depends on the compared samples and it makes the result of the performance indicator valid only within the presented study. From Table 2.3, the samples collecting the highest score in all three sections are considered the most appropriate for foot orthotics fabrication (i.e. Poron ${ }^{\circledR}$ 94, Poron ${ }^{\circledR}$ 96, Poron ${ }^{\circledR} 4000$ ).

Similar to the methodology used by Paton et al. (2007), research by Fauli et al.(2008) performed a number of bench tests on orthosis materials testing a total of 30 materials. Based on their results the authors grouped the materials based on their suitability for use as an adaptation, cushioning or filling material (Table 2.4). With their aim to help practitioners in their material selection, the ability to group materials in this manner would be beneficial. 
Table 2.3. Performance index results from Paton et al. (2007).

\begin{tabular}{|l|c|c|c|}
\hline Material & Control & Dampening & Moldable \\
\hline Plastazote $12 \mathrm{~mm}$ & 2 & 2 & 2 \\
\hline Poron $926 \mathrm{~mm}$ & 1 & 3 & 3 \\
\hline Poron $966 \mathrm{~mm}$ & 2 & 6 & 2 \\
\hline Poron $40006 \mathrm{~mm}$ & 2 & 6 & 2 \\
\hline Poron $946 \mathrm{~mm}$ & 3 & 5 & 3 \\
\hline PPT $6 \mathrm{~mm}$ & 3 & 3 & 3 \\
\hline Cleron $6 \mathrm{~mm}$ & 4 & 4 & 1 \\
\hline MaxaCane $3 \mathrm{~mm}$ & 3 & 1 & 2 \\
\hline Poron $40003 \mathrm{~mm}$ & 1 & 5 & 3 \\
\hline PPT 3 mm & 3 & 3 & 3 \\
\hline MaxaCane $3 \mathrm{~mm}$ & 4 & 4 & 1 \\
\hline HD EVA $12 \mathrm{~mm}$ & 3 & 1 & 2 \\
\hline MD EVA $12 \mathrm{~mm}$ & 6 & 2 & 1 \\
\hline MD EVA $12 \mathrm{~mm}$ & 5 & 3 & 1 \\
\hline Lunacell $12 \mathrm{~mm}$ & 6 & 2 & 1 \\
\hline
\end{tabular}

Table 2.4. Recommendation for suitability of material for cushioning, adaptation and filling based on bench testing results from Fauli et al. (2008).

\begin{tabular}{|l|c|c|c|}
\hline \multirow{2}{*}{ Property } & \multicolumn{3}{|c|}{ Function of material } \\
\cline { 2 - 4 } & Adaptation & Cushioning & Filling \\
\hline Hardness & Low-Medium & Low-Medium & High \\
\hline Stress-strain & Low-Medium & Low-Medium & High \\
\hline Compression stress; & High & Low & Low \\
\hline compression fatigue & & & Not Applicable \\
\hline Pesilience & Not Applicable & Low & Not Applicable \\
\hline Permeability & High & High & Not Applicable \\
\hline Most suitable material & High & High & EVA or PU \\
\hline
\end{tabular}

However, as indicated in Table 2.4 the authors recommended polyurethane materials for both cushioning and filling without defining which variation of the material within these categories they would 
classify as being suitable for use as adaptation or filling. With the endless combinations of each material available (material thickness, density and hardness) the actual practicality of the reported method is questionable.

Lo et al. (2014) also applied performance matrix for determination of the best candidate for accommodation, cushioning and control categories. The parameters taken into account for calculation of indexes are density, hardness, shearing, force attenuation, compression stress, moisture regain and water vapor permeability. In contrast to Fauli et al.(2008), the present study recommends the use of Nora® Lunalastik (EVA foam) for cushioning purposes. Hence, by applying different criteria for judgement and varying the set of materials, opposite results and conclusions can be made, which raises a question about validity of applied methodology.

Another attempt to propose a pathway to selection of appropriate orthotic materials was done by Almomani et al.(2016) through development of analytical hierarchal process. The model intends to select the best alternative among available alternatives and constructed by five stages: pair-wise comparison, alternative pair-wise comparison, inconsistency testing, computing the total weight of alternatives and picking alternatives with the highest rank. The importance of criteria was determined by Saaty scale, in descending order: stiffness, energy absorption, density, durability and ease of fabrication.

Besides other criteria the model accounts for choice of the most economical material for production, which for example is not considered as important in performance matrixes suggested by (Faulí et al. 2008; Lewis et al. 1991; Lo et al. 2014; Paton et al. 2007). However, since the input factors differ from previous studies with the use of performance indicator, it makes it challenging to compare with other studies. In addition, the authors propose further improvement of AHP by including resilience and materials hardness.

In contrast to other studies, Shariamatardi et al. (2012) has researched the effect of temperature on the shock absorption capacity of the insole material. Consideration of this factor is reasonable when trying to estimate materials performance in conditions closer to in-shoe environment. The authors report the increase of inside shoe temperature for up to $8-13^{\circ} \mathrm{C}$ that has negative effect on insole performance. This study conducts quasi-static compressive and shear tests at various temperatures $\left(-10\right.$ to $\left.45^{\circ} \mathrm{C}\right)$. 
The materials used for footwear insole design are primarily of viscoelastic nature (i.e. combined response to stress characteristic for viscous and elastic materials). Hence, the loading and unloading cycle do not follow the same curve due to loss of energy dissipated as a heat (absorbed energy). The measure of energy absorption capacity of the materials is represented by the size of hysteresis loop (Figures 2.2). There are three common phases of deformation observed during compression of footwear foams as seen in Figure 2.2 (left). The first phase is a linear elastic response, where stress increases linearly with deformation and the strain is recoverable. The second phase is characterised by continued deformation at relatively constant stress, known as the stress or collapse plateau and provides the bulk of the energy absorption capabilities for the material. The final phase of deformation is densification where the foam begins to respond as a compacted solid. At this point, the cellular structure within the material has collapsed and further deformation requires compression of the solid foam material.
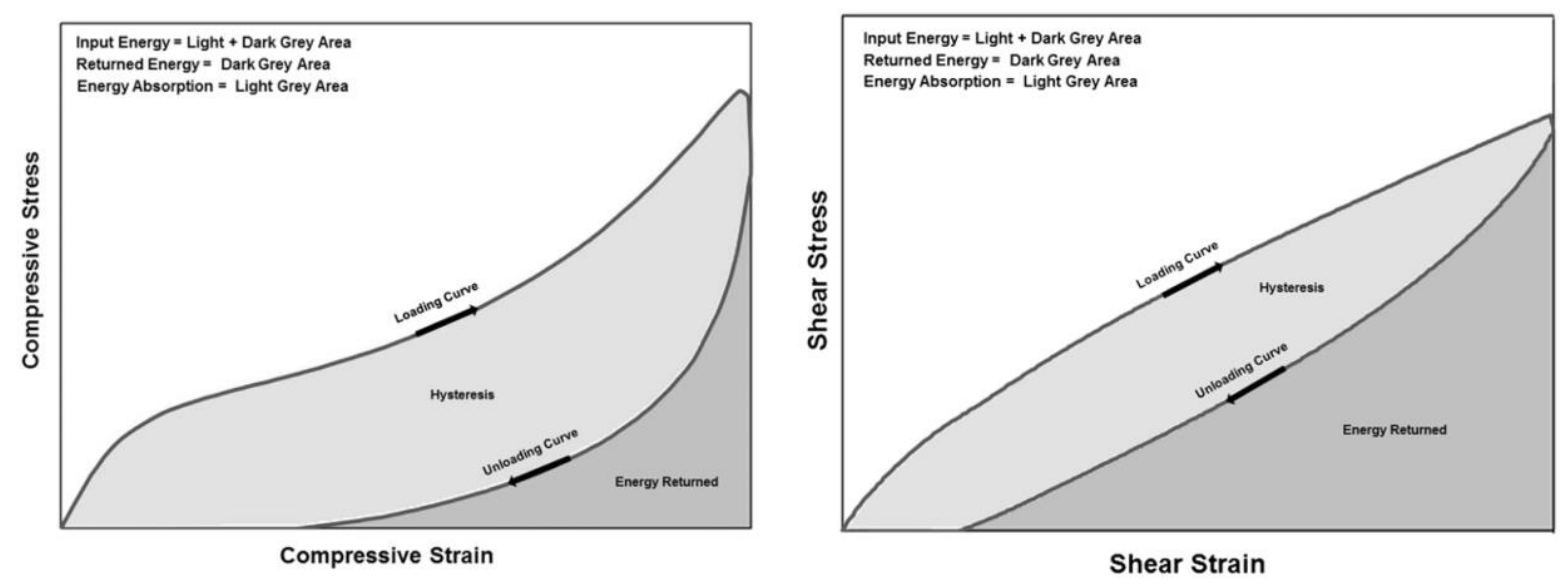

Figure 2.2. Typical compression loading/unloading curve (left) and shear stress-strain loading/unloading (right) characteristics of insole materials (Shariatmadari et al. 2012)

Shears curve follows the same principles as compression curve and produces hysteress due to partial energy dissipation within the material. Both shear and compression curve become less steep, the elastic modulus decreases and densification strain increases with the temperature rise. 
Shariatmadari and collegues (2012) explain that deterioration of cushioning characteristics of the foams at elevated temperatures occur due to material softening and, on the other hand, temperature decrease that entails increase in energy absorption capacity of the foam (Figures 2.3).
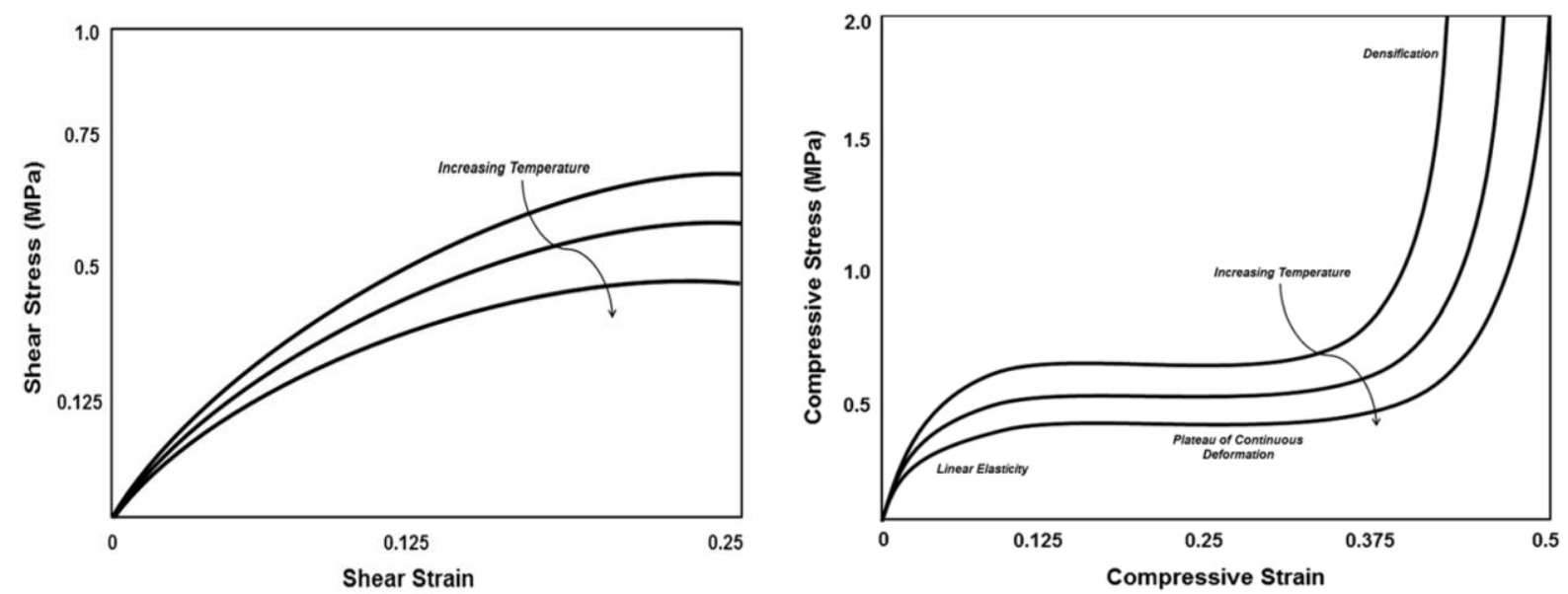

Figure 2.3. Change in compression strength (left) and in shear force (right) behavior of elastomeric foam with temperature increase (Shariatmadari et al. 2012)

The study (Shariatmadari et al. 2012) reveals that density has a little correlation with ability of material to perform at elevated temperatures. As it can be inferred from the Figure 2.4, Poron® (blue) and Poron ${ }^{\circledR}$ (green) have different reduction in cushioning performance despite close values of density. Research done by Shariatmadari et al. (2012) does not aim to find the correlation between loss of performance with other parameters (hardness, stiffness, resilience, polymeric nature). One of the possible reasons for variation in properties even within the same brand type (e.g. Poron ${ }^{\circledR}$ ) can be specific composition of the samples. 

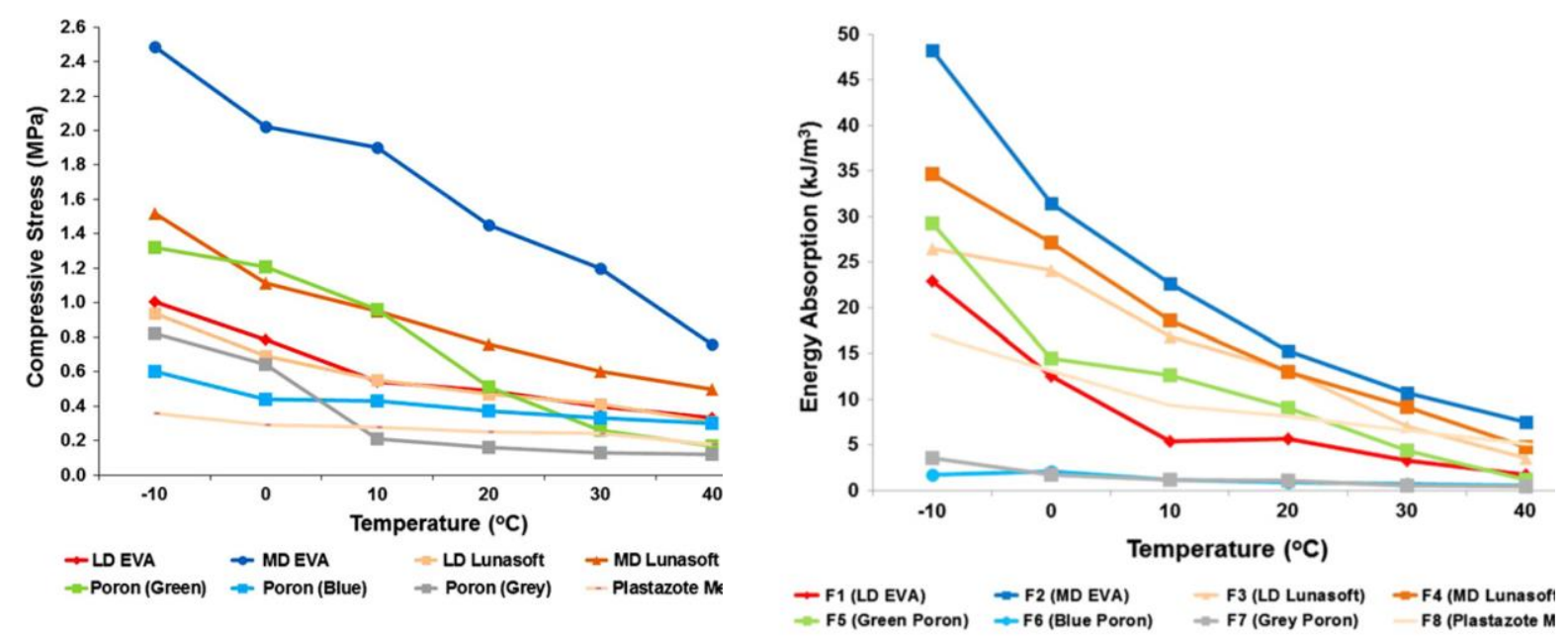

Figure 2.2.4. Change in compression characteristics (left) and energy absorption (right) at various temperatures

(Shariatmadari et al. 2012).

\subsubsection{Simulation of In-Shoe Conditions}

Research to date used a combination of machine and/or participant testing to examine the effects of simulated in-shoe conditions on orthosis materials. Machine testing examined the effect of such simulated in-shoe conditions as heat, sustained and repetitive loading, shear force and force distribution. On the other hand, testing involving participants compared differences in force and pressure measured while walking on sheets of different materials versus walking barefoot. As many foot orthoses are designed with the aim of redistributing and reducing plantar pressures these variables are commonly assessed in orthosis material research.

Brodsky et al. (2007) researched compression characteristics of the materials in closer to in-vivo conditions. The researchers applied a custom designed testing cell with imitation of bony prominence of the foot. As explained, the material under the foot is not compressed by even surface, but rather has more pressure under certain areas. The peak pressures achieved for samples was $283 \mathrm{KPa}$ and compression characteristics are measured after 10,000 cycles. The study found that combination of Poron® and Nickelplast ${ }^{\circledR}$ materials and MD Plastazote ${ }^{\circledR}$ and Nickelplast ${ }^{\circledR}$ did not change the amount of peak force 
transmitted after 10,000 cycles. The results of this testing cannot be compared with findings of other researchers, because the thickness of the material ranges from $8-12 \mathrm{~mm}$, which is almost twice more than samples thickness used in study by Fauli at al.(2008), Campbell at al.(1984).

In further work Brodsky et al.(2012) applied the same equipment to investigate the effect of heating of materials during molding on shock transmission. The researchers replicated clinical practices of creating custom insoles through preheating and immediate application of load imitating patient standing in the sample, when creating the mold. The mouldable materials as Plastazote ${ }^{\circ}$, Nickelplast ${ }^{\circledR}$, Puff $®$ undergo heating, while Poron ${ }^{\circledR}$ was not heated and attached to cooled samples. The study reports significant decrease in a percent compression to reach the maximal load after heating when compared with native sample. Due to adverse effect of temperature on the samples, the authors suggest to develop alternatives to heat molding and further improve shock attenuation capacity of the materials.

Campbell and colleagues (1984) followed their initial bench testing study (Campbell et al. 1982) with one that examined the same 31 materials under simulated in-shoe conditions. The simulated conditions were heat, sustained loading (compression set) and repetitive loading. To test the effects of heat samples of each material were placed in an oven for 7 days at a temperature of $41^{\circ} \mathrm{C}$ (the temperature was selected from thermistor readings for participants barefoot after 1 hour). Following the 7 days the materials were allowed to cool for $24 \mathrm{~h}$ before they were placed on an UTM for compression testing. The sustained loading test involved compressing samples of each material to $50 \%$ of their original thickness and maintaining this compression for 7 days. After the 7 days the materials were removed, the thicknesses were measured (immediately following removal and after $30 \mathrm{~min}$ ) and then compression testing on the UTM was completed. The results from all simulated conditions indicated that the materials identified in their initial study as most appropriate for use as an orthosis material, the moderately deformable group (Table A.2), were also shown to be least affected by the simulated in-shoe conditions with repetitive loading found to have the greatest effect on the tested materials. It is important to note that the effect of the three simulated conditions were examined independently, which does not allow for true simulation of the in-shoe environment where all conditions act together. 
Similar to (Campbell et al. 1982) other studies have customised bench testing equipment to examine the effect of simulated in-shoe conditions (Kuncir et al. 1990). Kuncir et al. (1990) have investigated a compression behavior and recovery of closed cell polyethylene foams. The insoles intended for use in obese patients were studied at conditions of increased loading. In condition of sustained pressure, the gas diffuses out from closed cells, for this reason the foam should rest for some time to regain its shape and recover shock attenuating properties. To implement this strategy patient should be given several pairs of orthotics for daily rotation due to slow recovery of closed celled foams. This practice may not be effective due to economical reasons or patient inconvenience.

A number of studies have examined different footwear orthosis materials by having participants walk barefoot across sheets of the materials, in an effort to simulate the in-shoe condition (Leber et al. 1986; McPoil and Cornwall 1992; Pauk et al. 2015; Sanfilippo, Stess, and Moss 1992). Leber et al. (1986) placed the materials underneath a pressure mat while the others taped the materials to a force plate. The researchers used 26 participants who all complained about forefoot pain from weight bearing and all showed areas of increased pressure under one or more metatarsal heads when tested. While they found that all the materials tested reduced overall plantar pressure when compared to the barefoot condition, they ranked the materials as follows: PPT®, Plastazote ${ }^{\circledR}$ and Spenco® (most effective); Dynafoam ${ }^{\circledR}$, Molo® (somewhat effective); and Ortho® felt and latex foam (least effective). When compared to the barefoot condition all materials examined by Sanfilippo et al.(1992) resulted in a significant reduction in peak pressure, pressure time integral and an increase in contact area. Plastazote ${ }^{\circledR}$, Spenco® and PPT ${ }^{\circledR}$ were found to be superior to Nickelplast ${ }^{\circledR}$ and Pelite ${ }^{\circledR}$. None of the materials tested were found to significantly reduce vertical force or force time integral when compared to the barefoot condition. Furthermore, the contact area results from (McPoil and Cornwall 1992) agree with those of Sanfilippo et al. (1992), who used the same testing equipment, as they also found the greatest increase in contact area between Poron ${ }^{\circledR}$ and Spenco®. Additionally, McPoil et al. (1992) divided the foot into three regions (forefoot: $40 \%$ of total foot length, mid-foot: $30 \%$ of total foot length and rear-foot: $30 \%$ of total foot length) for analysis with results showing all three materials significantly reduced pressure in the forefoot area when compared to the barefoot 
condition with no differences evident between the materials. For the rear-foot a significant reduction (when compared to barefoot) was only evident in PPT® and Spenco® with no difference found between these materials and no significant differences were seen in the mid-foot between any of the four test conditions. This analysis, using division of the foot into three regions, showed interesting results for Viscolas ${ }^{\circledR}$. The rapid movement of the foot at heel strike resulted in a pressure value for Viscolas ${ }^{\circledR}$ similar to that of the barefoot condition in the rear-foot area, whereas in the forefoot area Viscolas ${ }^{\circledR}$ was found to decrease pressure. The authors concluded that Viscolas ${ }^{\circledR}$ is only capable of reducing plantar pressures when the rate of loading is relatively slow and recommended its use for patients with conditions that cause increased plantar pressure in the forefoot.

Pauk et al. (2015) analyzed the change in ground reaction force and also values of friction coefficients for six different density EVA foams and leather materials. The authors conclude that coefficient of friction and vertical ground reaction fore is the lowest for orthotics made of combination of different EVA materials. Leather materials were found to be inferior in performance than EVAs. However, the variation in thicknesses of samples that authors use impedes the proper assessment of each category of materials individually.

\subsubsection{Biomechanical Testing of Materials}

While some earlier studies used force plates and accelerometers to compare orthosis materials (Johnson 1988; Pratt 1990; Pratt et al. 1986); nowadays, the smart devices such as F-scan® or Pedar® are frequently applied for assessment of insoles in a real in-shoe environment. These devices enable to measure parameters such as plantar pressure, transmitted force and force time integral.

Previously, supplementary to their bench testing of materials, Pratt et al.(1986) measured the effect of each material on skeletal shock during walking using an accelerometer mounted between the teeth of the participant. Whilst the results from the bench testing with the old Plastazote ${ }^{\circledR}$ were found worst, new Plastazote ${ }^{\circledR}$, Spenco® and Sorbothane ${ }^{\circledR}$ had similar values and Poron $®$ and Viscolas ${ }^{\circledR}$ performed the best. 
In subsequent long term study, Pratt (1990) has tested the same set of the materials on subject of shock attenuation via Fast Fourier Transform techniques. The shock meter produces a single number between 1 and 10 to indicate the proportion of the accelerometer signal due to impact; the higher the number the greater the shock. Results showed that Viscolas ${ }^{\circledR}$ (prefabricated insole) and PPT® (flat insole) had more long lasting weigh bearing properties than Plastazote ${ }^{\circledR}$ (flat insole) and Gait Aid $®$ (prefabricated insole). Deterioration of cushioning qualities occurred after 6-9 months use for Viscolas ${ }^{\circledR}$ and PPT ${ }^{\circ}$ and after only 2 days for Plastazote®. An analogous technique was utilized by (Johnson 1988) for analysis of skeletal shock; however, the researchers employed a skin mounting arrangement to place the accelerometer on the leg of the participant. The greatest reductions in Shock Factor were seen with the Sorbothane ${ }^{\circledR}$ insoles Lightweight and Soft Blue (30\%), followed by Sorbolite ${ }^{\circledR}$, Nonshock®, and Sorbothane ${ }^{\circledR}$ walking insole $(20 \%)$.

A number of other studies examined the immediate effect of different orthosis materials during walking (Birke and Foto 1999; Healy et al. 2010; Tong et al. 2010), while Rogers et al.(2006) accessed both immediate effect and performance after wear. Birke and Foto (1999) examined the planter pressures of 19 people with diabetes and a history of foot ulceration while wearing extra depth shoes with flat Poron® insoles of different levels of hardness. Mean peak pressure without insoles were compared to those of the seven flat insoles that resulted in supporting the use of medium hardness Poron® material (Shore A 17-25 and densities $270-330 \mathrm{~kg} / \mathrm{m}^{3}$ ) to reduce plantar pressures. The lowest value of walking peak pressure corresponded to $1 / 4$ inch Poron insole (Shore A 25 , density $330 \mathrm{~kg} / \mathrm{m}^{3}$ ). Tong et al.(2010) compared plantar pressures while wearing four different flat insole constructions in five participants without any known history of disease or foot abnormalities. The parameters the researchers assessed were mean, maximum and minimum peak plantar pressures. However, inconsistency in age categories and weight indexes of participants and also thicknesses of used insoles impede comparison of resulted values. While all insoles in the study were found to reduce minimum, maximum and mean peak pressures, the authors concluded that the insole that combines Poron ${ }^{\circledR}$ and firm Plastazote ${ }^{\circledR}$ was superior to the other materials tested as it resulted in a $27 \%$ reduction in mean peak pressure. 
Healy et al.(2012) are aimed to elucidate the effect of materials and insole design on the gait kinematics and pressure distribution. Plantar pressures and kinematics were evaluated for 10 participants while walking on a treadmill under various conditions that included shoes only and shoes with four different flat insoles (LD EVA, MD EVA, LD PU, MD PU) and custom devices created in each of two densities of two materials. The authors recommend medium density PUF (hardness Shore A 55 \pm 3 ) as the best for plantar pressure reduction. Against authors' hypothesis, it was found that insole materials do not effect lower limb kinematics. In addition, the customized orthotic devices were found equally effective in plantar pressure reduction as flat insoles. Rogers et al.(2006) assessed the effect of walking 50,000 steps in two different flat insole constructions with results showing both insoles were effective in reducing peak pressure at the forefoot initially. After 50,000 steps, however the Poron ${ }^{\circledR} /$ Plastazote ${ }^{\circledR}$ flat insole was found to be more effective as reducing peak pressure and the force-time integral under the forefoot. Yet their results must be interpreted with caution, as the authors provide no details on how the participants accumulated the 50,000 steps with each insole. As it was earlier reported by (Kuncir et al. 1990), closed cell foams need a rest time to recover their structure. For this reason, the results of studies when participants tested the material continuously may vary from the case when the test was done in several trials. Either way one or both of the insoles could have had considerable recovery time prior to the post 50,000 steps testing which could affect the plantar measurement.

Several articles describe the research studies involving participants who has a history of diabetes and foot deformities (Burns et al. 2008; Tang et al. 2014; Mohamed et al. 2004). Burns eta l. (2008) provided a case report on a diabetic participant divided into three parts. First, eight insoles (seven flat insoles and one prefabricated insole) were evaluated for patient comfort and plantar pressure distribution with the patient wearing each insole for 1 week each. Secondly, long term effects of the most effective pressure reducing (Step2Evolution ${ }^{\circledR}-$ prefabricated insole) and most comfortable foot orthoses (Poron® Performance/Poron ${ }^{\circledR}$ - flat insole), as determined from part one, were evaluated. Third, the patient nominated his preferred orthosis, from those worn in part two, and a custom fabricated insole in that material was manufactured and assessed. Results showed that all materials tested in part one reduced peak 
pressure and improved comfort scores with a strong correlations found between both peak pressure and comfort and pressure time integral and comfort $\left(r^{2}=0.838\right.$ and 0.756 , respectively). Interestingly, this study was among a few that take into account end users feed, which is very important as it will affect a patient's compliance in wearing the insole. Tang et al.(2014) conducted a long-term randomised trial involving participants with type 1 and type 2 diabetes. For their study the authors produced custom made insoles each made of single hardness EVA material (either EVA Shore A 35 or EVA shore A 55) or used prefabricated insoles Globothech ${ }^{\circledR}$ for control group. The most important finding of the present study is a significantly lower pressure at the heel observed for custom-made insoles in comparison to prefabricated insoles that was confirmed by plantar pressure and pressure time integral analysis. Mohamed et al.(2004) provided two groups of diabetics matched by body mass index and history of current foot ulceration. The groups were provided with either custom Plastazote ${ }^{\circledR}$ or Aliplast ${ }^{\circledR} /$ Plastazote $®$ flat insoles and plantar pressures during walking initially and after one and three months of wear were measured. Prior to the one-month measurements, the orthoptist assessed the insoles making any adjustments required due to wear of the orthoses. This resulted in modifications to three of the Plastazote ${ }^{\circledR}$ and six of the Aliplast $₫ /$ Plastazote ${ }^{\circledR}$

orthoses. When compared to the no-insole condition both insoles resulted in significant decreases in plantar pressure and increases in contact area. The observation that some of the insoles needed modification following only one month's wear could possibly be attributed to the bottoming out effect of Plastazote ${ }^{\circledR}$ that was reported by (Pratt 1990; Pratt et al. 1986).

\subsection{Summary of Literature Review}

The above review discussed all relevant literature on subject of insole testing for the period of 40 years (see Tables B.1-B.3) . Nowadays, endless combinations of materials thickness/hardness/density is available on the market and clinicians need a valid guide to categorization of these materials. From the analysed research studies, it is evident that conclusions and recommendations on the most suitable foot 
orthosis materials proposed by researchers are completely dependent on the methodology (the type of tests they performed; for example: compression, compression set, shear force, etc.) and the material formulation (the same material but of different density/thickness/hardness).

Additionally, conclusions made by some researchers on material characteristics appear to be dependent on the relative relationships between the materials tested within their own research. An example of this is the contradicting views of Pratt (1990; 1986) and Rome et al. (1991) with regard to the suitability of Plastazote $\circledR^{\circ}$ and Kuncir et al.(1990) and Campbell et al. (1984) regarding Aliplast ${ }^{\circledR} 4 \mathrm{E}$ performance as shock absorbing material. It is worth noting that drawing conclusions based on relative relationships can be misleading as no reference values for material characteristics are available. However, conducting "comparison" type research studies is the only available option due to lack of aforementioned information.

In addition to material characteristics, the benefits and limitations of the various test methods need to be explored. Some of the reported tests might not provide a true reflection of results for the material properties that were discussed. Data obtained from drop tests, can depend on the dropping height, the dropping mass and the area of contact with the surface. If the variables are not controlled or if it does not relate to actual environmental conditions in which the material is being tested, the reported results will not provide any useful information. Similarly, when employing UTMs to perform stress-strain tests, the loading rate used is sometimes slower than what would occur in the shoe. Because of the viscoelastic nature of material, their rigidity increases with frequency. This needs to be considered and the appropriate methodology and equipment should be used to increase the reliability and validity of results.

When using accelerometers and other inertial sensors, there should be careful consideration of placement of these sensors on the subject. For example, the most accurate way of placing an accelerometer is to attach it directly to tibia as opposed to a skin-mounted arrangement. In practical terms, this might not be achievable; however, a reasonable compromise could be made. Pratt et al.(1986) employed an accelerometer attached to mouthpiece which according to another study (Lewis et al. 1991) will contribute to a 10 -ms delay to obtain the signal. Furthermore, the recorded values will be higher when compared to skin mounted accelerometers. 
While bench and simulated in-shoe testing provide an understanding of a material's characteristics, they cannot determine the actual performance of the material when placed in the shoe. Although testing of the orthosis materials over time is necessary to understand the performance limits of the materials, it raises issues within study design. Participants are generally given orthoses to wear for a specified time and it is difficult for researchers to accurately assess the amount of time the orthoses were worn and to standardise wear between subjects to allow for accurate statistical analysis. Many of the studies provided limited details on the formulations and thicknesses of the materials they tested. More detailed information on the materials they used should have been provided by researchers in order to allow clinicians to practically apply the recommendations made in footwear orthosis material research.

Many authors have tried to compare bench testing results with in-shoe performance, but this is very difficult to verify as there are many variables that are challenging to simulate in-vitro. There are the cases, when the same brand of a material is tested in both types of trials (for example, Poron testing in (Birke et al. 1999; Lewis et al. 1991)), but the results of studies cannot be used for drawing conclusions, because there is a lack of further details that confirm that the same sample is being tested. This fact emphasizes the need to make a clear and consistent presentation of materials used in manufacture of footwear and foot orthoses.

Several authors have shown durometer readings of density as an indication of material performance whereas others have used kinetic information from force platforms or pressure measuring devices. Due to the range of methodologies and outcome measures used in research works that has tested a large range materials of various compositions (e.g., different densities and thicknesses) and forms (e.g. samples cut to a standard size for bench testing, sheet form and etc.) a summary on the relative qualities of different materials is not possible. However, it is clear from this study, that there is a need to clarify the categories of materials for example the use of generic or trade names and simplify the labelling of the characteristics in an attempt to remove the confused nature of the presentation of these materials, to help inform the clinician. 
In summary, the presented works primarily call attention of clinicians and aim to facilitate easier and better compliance with patients needs. The targeted category of the insole materials reviews is service providers and end users. Unfortunately, only a limited information can be retrieved from the abovementioned works as a benefit for product manufacturers. None of the works individually and no works together can give a conclusive answer about which mechanical properties are responsible for improved cushioning and durability of the materials. Hence, tracking the behavior of the material through all three stages (bench, simulation and in-shoe tests) and linking performance with physical, mechanical and chemical properties can be potentially beneficial for materials design and suggested as a future work.

\subsection{Optimal Characteristics for Insole}

There are several trends observed in the literature reviewed in Chapter 2:

1. Moderately deformable materials have the best durability and shock attenuation properties. This fact is proven by bench study of (Campbell et al. 1984), in-shoe simulations of (Leber and Evanski 1986) and (Campbell et al. 1982). Also, Poron ${ }^{\circledR}$ and Plastazote ${ }^{\circledR}$ (both moderately deformable materials according to Campbell's methodology) were found to significantly reduce peak pressure in biomechanical studies of (Tong et al. 2010) and (Birke et al. 1999).

2. In the majority of research studies (Rome et al. 1992; Faulí et al. 2008; Healy et al. 2012; Paton et al. 2007; Pratt et al. 1986; Shariatmadari et al. 2012), PU open cell foams and PU elastomers are claimed as superior in pressure attenuation in comparison to closed cell foams, latex, felt, leather (Tables B.1-B.3). Closed cell foams are reported to be less durable due to easy cell walls bursting and require significant time to recover its properties (Kuncir et al. 1990).

3. Low-density materials tend to be less durable and have worse weight-bearing properties. Rome et al. (1992) determined that mean value of density $0.333 \mathrm{~g} / \mathrm{cm}^{3}$ and hardness Shore A $32-35$ is sufficient for material in order not to quickly deform and on the other hand not to be to stiff. Birke 
et al. (1999) suggested Poron ${ }^{\circledR}$ materials of hardness Shore A 15-25 for fabrication of orthotics for patient with diabetes. Healy et al.(2012) reported PU foam Shore A 35 and 55 with latter to be best in performance to significantly decrease plantar pressure. In contrast to Rome et al. (1992) and Birke et al. (1999), Healy et al.(2012) used $3 \mathrm{~mm}$ thick insoles, which could be the reason for better properties of harder material.

It is clear from the above review that authors do not to come to an agreement about the methodology for proper assessment of medical orthotics and hence the set of parameters to be tested is not defined. The reviewed papers can be generally categorized as evaluating and presenting the facts about material's behavior, but lacking analysis of factors to contribute to shock absorbing performance. Again, this problem stems from scant information available about mechanical properties of commercial insoles. Certainly, it is challenging to find the link between mechanical characteristics and in-shoe performance, because some parameters (such as shear deformation in combination with compression deformation and humidity) are impossible to simulate. As it was concluded by Healy et al.(2012), the most realistic results reflecting true materials performance can be obtained only through in-shoe testing. However, testing materials with such methods require a very expensive testing equipment and volunteer's participation that makes the procedure unmanageable and costly. Additionally, in-vivo investigations face no less challenge, because it is still unclear how the experiment should be correctly set up.

Certainly, specific standards for footwear industry currently exist, though not mentioned in peerreviewed literature. For instance, manufacturers utilize ISO standards for footwear insoles (ISO /TR 20881:2007) and in-socks (ISO /TR 20882:2007) describing minimal requirements to these footwear components in order to produce a quality product for entering the market. However, presented standards are regulating only such characteristics as durability (abrasion resistance, dimensional stability, resistance to stitch tear) and hygienic properties (water absorption/desorption, perspiration resistance) of the materials but not shock absorption performance. In contrast to ISO test procedures Shoe and Allied Trades Research Association (SATRA), UK has established list of value ranges that correspond to a quality shock absorber. These parameters intend to distinguish an appropriate material for medical orthotics fabrication. The 
recommended values are summarized in Table 2.6 along with mechanical characteristics of recommended materials for orthotics fabrication: Poron ${ }^{\circledR}$ (Medical, Dual Performance; Sport), Sorbothane ${ }^{\circledR}$ (grades 30, 50, 70) and Plastazote ${ }^{(M D, ~ L D) . ~}$

As it follows from data presented, parameters values for Poron ${ }^{\circledR}$ and Sorbothane ${ }^{\circledR}$ materials are close to the optimal values developed by SATRA Technology Center (Wilson 1991). Also, the values of density match the values previously recommended by Birke et al.(1999) and Rome et al.(1991). In contrast to this, Plastazote ${ }^{\circledR}$ materials, which were found by some authors (Campbell et al. 1984; Paton et al. 2007; Rogers et al. 2006; Tong et al. 2010) to be less durable and prone to quick loss of performance, are characterized by values outlying the optimal interval. Optimality of Poron ${ }^{\circledR}$ and Sorbothane ${ }^{\circledR}$ materials finds its proof in clinical studies conducted by (Birke and Foto 1999; Faulí et al. 2008; Johnson 1988; Pratt 1990). Interestingly, Poron ${ }^{\circledR}$ materials demonstrate its superior performance in both bench tests, in-vitro and in-vivo studies.

Table 2.5. Summary of optimal mechanical characteristics.

\begin{tabular}{|l|c|c|c|c|}
\hline \multicolumn{1}{|c|}{ Quality } & SATRA & Poron ${ }^{\circledR}$ & Sorbothane ${ }^{\circledR}$ & Plastazote $^{\circledR}$ \\
& standards & materials & materials $^{\mathrm{b}}$ & materials $^{\mathrm{c}}$ \\
\hline Hardness (shore A) & $15-22$ & $14-26$ & $9-20$ & $14-35$ \\
\hline Density (g/cc) & $0.2-0.3$ & $0.24-0.45$ & $1.3-1.31$ & $2.5-7$ \\
\hline Compression set (\%) & Max. 5 & $5-10$ & $3-6$ & $10-15$ \\
\hline Water absorption (\%) & Max. 30 & $10-15$ & $5-10$ & 100 \\
\hline Water desorption (\%) & 100 & 100 & 100 & - \\
\hline Cushioning Factor & $0.8-1$ & - & - & - \\
\hline CE (N*m) & Min 70 & - & & \\
\hline
\end{tabular}

a-according to technical data sheets for Poron Medical Blue, Poron Cushioning Blue; b-according to technical data sheets for Sorbothane 40, Sorbothane 50, Sorbothane 60; c-according to technical data sheets for Plastazote MD. Data sheets are available at matweb.com 
Besides conventional parameters, there are two categories that are pertinent to SATRA methodology, namely $\mathrm{CF}$ and $\mathrm{CE}$. $\mathrm{CE}$ is described as the energy required to gradually compress a specimen of the material up to a standard pressure. This parameter is measured with a tensile testing machine.

Another important property for insole is cushion ability that is analyzed from values of $\mathrm{CE}$ and $\mathrm{CF}$. The higher the cushion energy, the greater the cushioning effect of the insole is likely to be in wear. Rigid materials and very weak soft foams give low results since the former are incompressible and the latter 'bottom out'. Insoles giving values greater than $70 \mathrm{~N} \cdot \mathrm{mm}$ would be expected to reduce underfoot peak pressures in walking considerably. In addition, a low cushion factor indicates an effective material with typical values ranging from 8 to 4 . Cushion factor is a bulk material property and is assessed using a test specimen greater than sixteen millimeters thick. The volume of the test specimen under no load multiplies the pressure on the surface of the test specimen at a predefined loading. This is then divided by the cushion energy of the specimen at the predefined load.

Tensile and tear strength are typically analysed for insole materials. For the insole materials demonstrating $\mathrm{CE}$ greater that $70 \mathrm{~N} \cdot \mathrm{mm}$ and $\mathrm{CF} 4-8$, the typical value of tensile strength is $0.7-1.05 \mathrm{MPa}$ (Saraswathy et al. 2009), again overlaps with the values for Poron® (0.53-1.38 MPa) and Sorbothane ${ }^{\circledR}$ (0.75-1.2 MPa).

Taking into account a potential application of required insole material as a part of electronic device, the property of low thermal conductivity should be considered. FSRs-based devices such as F-scan® require additional calibration and compensation for elevated temperatures; thereby it is advantageous if the insole material could provide a sufficient level of protection against variations in temperature levels. Typical values of conductivity for PU foams ranges from 0.03-0.35 W-m/K (Wu et al. 1999)(expected to be similar for Poron ${ }^{\circledR}$ materials); Sorbothane ${ }^{\circledR}$ has higher values $0.37-0.39 \mathrm{~W}-\mathrm{m} / \mathrm{K}$. Thus, the functioning of PU foams is expected to be better in respect to thermal insulation than PU elastomers. For comparison, the thermal conductivity of thermal insulation foam is $0.02-0.04 \mathrm{~W}-\mathrm{m} / \mathrm{K}(\mathrm{Wu}$ et al. 1999).

In summary, targeted characteristics that should be tailored for quality performance of insole device are approaching the properties of commercially available Poron ${ }^{\circledR}$ and Sorbothane ${ }^{\circledR}$ materials. 


\subsection{Bio-based Polyurethane Materials}

\subsubsection{Chemistry of Polyurethanes}

A paucity of peer review studies addresses the problem of synthesis of new material for shock absorbing insoles. This section describes the research outcomes that may represent the valuable material for insole purposes despite the initial application is different.

As it was concluded in the Section 2.4, PU foams and PU elastomer are the type of materials that function most effectively in conditions of sustained loading and elevated temperature. This unique features stem from chemical structure of polyurethane polymers. Polyurethanes polymers contain urethane link between the chains. Isocyanates (aliphatic or aromatic) react with $\mathrm{OH}$ group of polyols creating the NHCO-(see Figure 2.5).

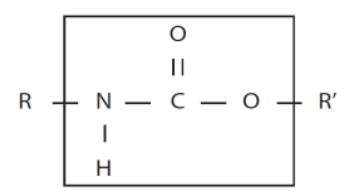

Figure 2.5. Structure of urethane linkage (Szycher, 2013).

Long nonpolar aliphatic chains are of polymer create so called soft segments (SS), whereas isocyanates and short aliphatic or aromatic oligomers (chain extenders (CE)) form hard segments (HS). HS are linked between each other by means of hydrogen bonding (Figure 2.6) and form tightly packed polar domains dispersed in non-polar matrix of long hydrophobic SSs.

The tendency to pack themselves into tight, stereoregular molecular chains (phenomenon referred to as crystallinity) explains the excellent physical properties displayed by polyurethane polymers. In contrast to well-arranged structure, polyurethanes can be mixed phased, in which case pronounced elastic properties 
are absent in the material. When polyurethane consists of a mixture of crystalline and amorphous domains, an arrangement is termed segmentation. The rigid segments act as bridges, and as filler particles, reinforcing the soft segment matrix (Figures 2.7).

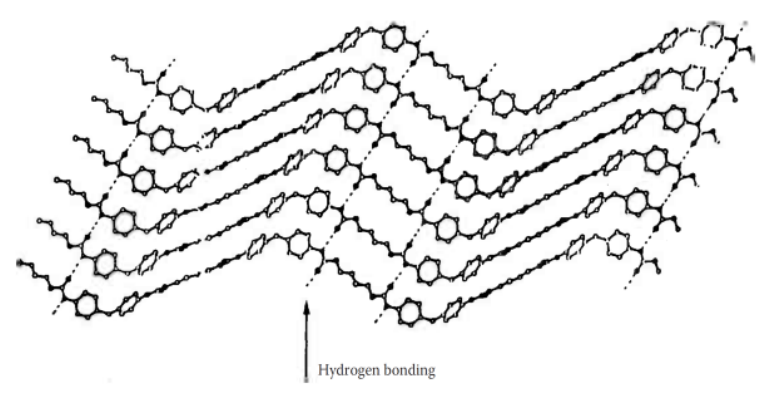

Figure 2.6. 3D structure of polyurethane. HS are linked by hydrogen bonds (Szycher 2013)

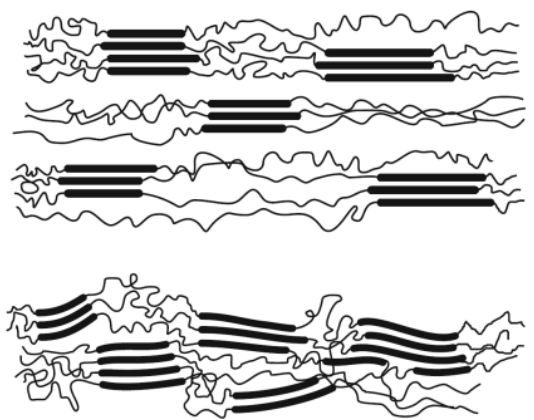

Figure 2.7. Phase separated (top) and phase mixed (bottom) polyurethane structure(Hong et al. 1992).

Polyurethanes are very versatile materials, with properties that can be tuned from viscous liquids to tough and brittle solids. Change in properties can be achieved by altering the length of SS and ratio of HS/SS. Most flexible PU elastomers and foams are produced using polyether-based polyols with molecular weight ranging from 1000-3000 DA (Ionescu 2007). Functionality of polyols (number of OH- groups per molecule) has effect on mechanical properties of final product. Polyols with functionality $>2$ produce threedimensional structures within the polymer and prevent SS chains from sliding along each other. This structural hindrance affects tensile properties of PU. Under the effect of pulling forces, SS of PU are stretching out and then hard segments align in the direction of the force. With the presence of interconnections within the polymer, material tensile properties become diminished, but hardness and compression strength significantly increases.

Increase in ratio of HS/SS leads to formation of growing number of well organised crystalline domains and the mechanical strength of a polymer increases with the loss of elastic properties. An important microstructural feature of a polymer is its architecture, which relates to the way branch points lead to a deviation from a simple linear chain. 
Thermal stability of polyurethanes also finds its explanation in micro phase separated structure of these materials (Hong et al. 1992). At low temperatures, the soft matrix having a low $T_{g}$ influences the properties. HS domains act as cross-link points as well as reinforcing filler entities, and these govern the mechanical performance of the material at elevated temperatures.

\subsubsection{Renewably Sourced PU Foams}

The need for renewable and eco-friendly materials called upon a new class of bio-based polyurethanes. Plant oils can be used as ecofriendly polyols for the synthesis of bio-PU foam because of their advantages such as easy availability, sustainability, and relatively low and stable cost.

The utilization of plant oils such as castor, sunflower, palm, canola, and soybean oils has been extensively studied (Ionescu 2005; Prociak et al. 2018) for making ecofriendly polyols in PU foam. Among these oils, castor oil (CO), which is composed of triglycerides that contain $90 \%$ ricinoleic acid triglyceride and $10 \%$ non-functional acid residues, could be used as a suitable polyol because of its inherent hydroxyl group in the main oil chain (Figure 2.7). The hydroxyl group in $\mathrm{CO}$ allows a direct reaction with an isocyanate group without any further modification (Macalino et al. 2017) .

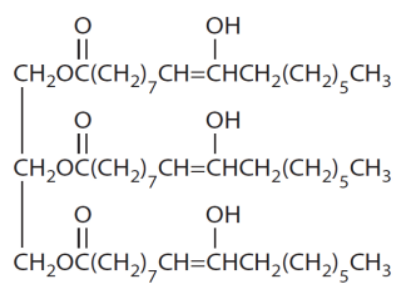

Figure 2.8. Structure of ricinolein (major compound of CO)(Ionescu 2005)

CO based PUF and elastomers are intensively researched in the literature (Table 2.7). The studies report that castor oil can be used as a chain extender of as a major $\mathrm{OH}$ - group source of polyurethane depending on desired characteristics. Depending on HS/SS ratio and castor oil content, the materials can be produced with varying densities and mechanical properties. 
As it follows from the Table 2.6, the PUF with targeted density of $0.2-0.3 \mathrm{~g} / \mathrm{cm}^{3}$ can be produced by using a combination of $\mathrm{CO}$ with higher molecular weight aliphatic polyol. The nature of polyol has a great influence on the properties of resultant PUF. Bulky side groups or carboxyl groups impede sliding of SS chains along each other and cause reduction of elongation ability of the material. Among nature-originated linear polyols the most attractive are poly(trimethylene) ether glycol (PO3G) and poly $(\beta$-methyl- $\delta$ valerolactone)(PMVL) which are products of corn fermentation. The product PO3G is now sold under commercial brand name Velvetol ${ }^{\circledR}$ by Alessa GmbH, while PMVL is relatively new material and is still on its track to the global market. PUF composed of PO3G and CO possesses necessary hydrophobicity and mechanical properties suitable for applications as an insole material (Ugarte et al. 2015).

Table 2.6. Application of castor oil for synthesis of PU foams and elastomers.

\begin{tabular}{|c|c|c|c|c|c|}
\hline Material Type & Reference & Polyol & Isocyanate & $\begin{array}{c}\text { Castor oil } \\
\text { (wt } \%)\end{array}$ & Density \\
\hline $\begin{array}{c}\text { Foam, } \\
\text { open-celled }\end{array}$ & (Wang et al. 2015) & PEG & MDI & $40-60$ & $\begin{array}{l}102-230 \\
\mathrm{~kg} / \mathrm{m} 3\end{array}$ \\
\hline $\begin{array}{c}\text { Foam, } \\
\text { open-celled }\end{array}$ & (Ugarte et al. 2015) & PO3G & TDI & $80-100$ & $39-42 \mathrm{~kg} / \mathrm{m} 3$ \\
\hline $\begin{array}{c}\text { Foam, } \\
\text { open-celled }\end{array}$ & (Lee, Park, and Kim 2018) & PCL & MDI & $20-80$ & $35-48 \mathrm{~kg} / \mathrm{m} 3$ \\
\hline $\begin{array}{c}\text { Foam, } \\
\text { open-celled }\end{array}$ & (Ogunfeyitimini et al. 2012) & $\begin{array}{c}\text { Voranol } \\
3322\end{array}$ & TDI & $5-30$ & $21-22 \mathrm{~kg} / \mathrm{m} 3$ \\
\hline PU elastomer & (Nguyen Dang et al. 2016) & PTMEG & MDI & $12-15$ & - \\
\hline PU elastomer & $\begin{array}{c}\text { (Yeganeh and Mehdizadeh } \\
\text { 2004) }\end{array}$ & PPG & HDI & $3-30$ & $\begin{array}{c}1000-1150 \\
\mathrm{~kg} / \mathrm{m} 3\end{array}$ \\
\hline PU elastomer & (Gao et al. 2012) & PEG & IPDI & 30 & $\begin{array}{c}1000-1080 \\
\mathrm{~kg} / \mathrm{m} 3\end{array}$ \\
\hline
\end{tabular}


Moreover, polyurethane foams of vegetable origin (castor oil, palm oil, rapeseed oil) undergoes biodegradation in the presence of microorganisms (Cangemi et al. 2008). It is important to note that the chemical structure of foam derived from castor oil becomes susceptible to microorganism attack and can be considered a polymer with biodegradable characteristics, which is not the case for petroleum PU foam.

Besides the fact that application of vegetable oils such as CO is a "green" and a potential solution for polyurethane disposal challenges, the use of castor oils is a budget-friendly approach. According to calculations made by Ogunfeyitimi et al. (2012) the price of CO-based foam is $25 \%$ lower in comparison to $100 \%$ petroleum based counterpart with similar characteristics. Hence, application of castor oil is justified from economical and ecological prospective.

Taking above stated considerations into account, a renewably sourced PUF material was selected for synthesis and investigation of its potential for shock absorbing insole fabrication. 


\section{CHAPTER 3. MATERIALS AND METHODS}

\subsection{Materials}

All reagents used in the present research were used as received. Castor oil (chemically pure) was purchased from Sigma Aldrich with hydroxyl and acid values being 162 and 2 mg KOH/g, respectively. Poly (trimethylene) ether glycol (PO3G, Velvetol 1000, Mn = $1046 \mathrm{~g} / \mathrm{mol}$ ) was kindly supplied by Allessa GmbH, Germany. Gelling catalysts (DBTDL) and blowing catalyst (DABCO 33LV) were purchased from Sigma Aldrich company, USA. TDI was used as HRs in PU synthesis and was also supplied by Sigma Aldrich company. Niax L-580 silicon oil surfactant was kindly provided by Momentive Performance Materials, USA. Distilled water was used as environmentally friendly blowing agent. Details of raw materials used in the study are summarized in Table C.1.

\subsection{Preparation of PUFs}

Preparation of polyurethane foam is a complicated chemical process that includes two types of chemical reactions: gelling (formation of a polymer) and blowing (formation of voids). Gelling reaction leads to formation of polyurethane linkages (blue rectangles), at the same time, the reaction between water and isocyanate group produces carbon dioxide gas, which expands the polymer matrix. Schematic equations of chemical reactions are presented on the Figure 3.1. 


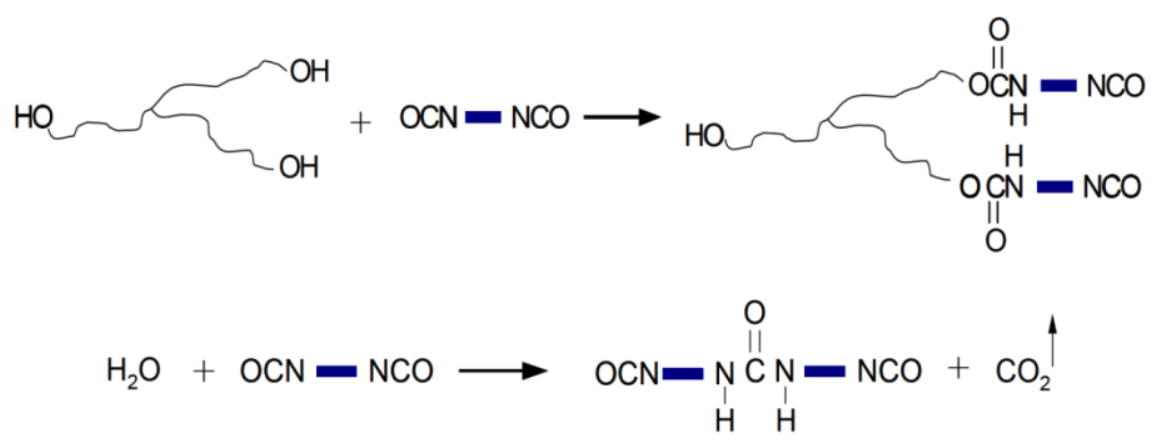

The presence of ricinolein as a hydroxyl bearing component creates an intricate 3D polymeric network which can be visualized as presented on the Figure 3.2. CO (green) as a triglyceride, introduces branching into the PU structure. TDI (red) serves as a cross-linker for joining long polyether chains of PO3G (blue) and CO.

Figure 3.1. Equation of chemical reaction for the synthesis of PUF: Gelling reaction (top) and blowing reaction (bottom).

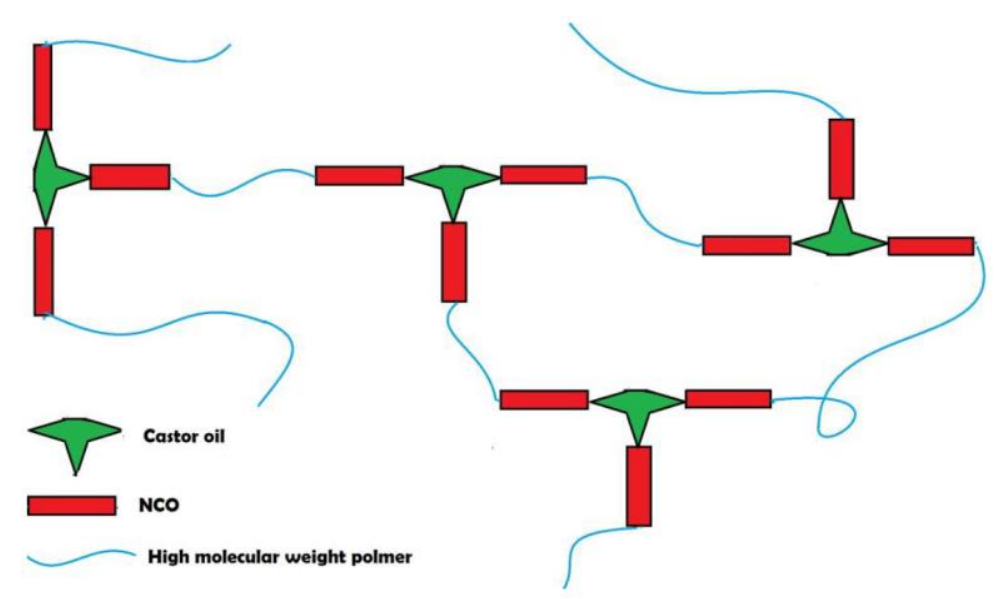

Figure 3.2. Schematic of synthesized CO/PO3G/TDI polymer

\subsubsection{Synthesis of Pre-Polymer}

The pre-polymer method was used to prepare polyurethane because this method is currently used by footwear insole/sole manufacturing industries and shoe manufacturing industries to develop insoles by 
reaction injection molding (RIM) technique (Gnanasundaram et al. 2015). The synthesis was carried out in a $250 \mathrm{ml}$ glass reactor at normal pressure and agitation rate $500 \mathrm{rpm}$ (by standard tri-blade impeller) to ensure homogeneous mixing. Predetermined amount of PO3G, $\mathrm{CO}$ and surfactant was placed in the reactor and heated up to $70{ }^{\circ} \mathrm{C}$ on the oil bath under continuous agitation. Once the required temperature is achieved, predetermined amount of TDI was added to the reaction mixture while continuously agitated. Depending on foam's composition, pre-polymer formation was finished after $15 \pm 5$ min and reactor was removed from the oil bath. Mixing was terminated for $5 \mathrm{~min}$ to let excessive air leave the reaction. The experimental set up used to produce pre-polymer is presented on the Figure 3.3

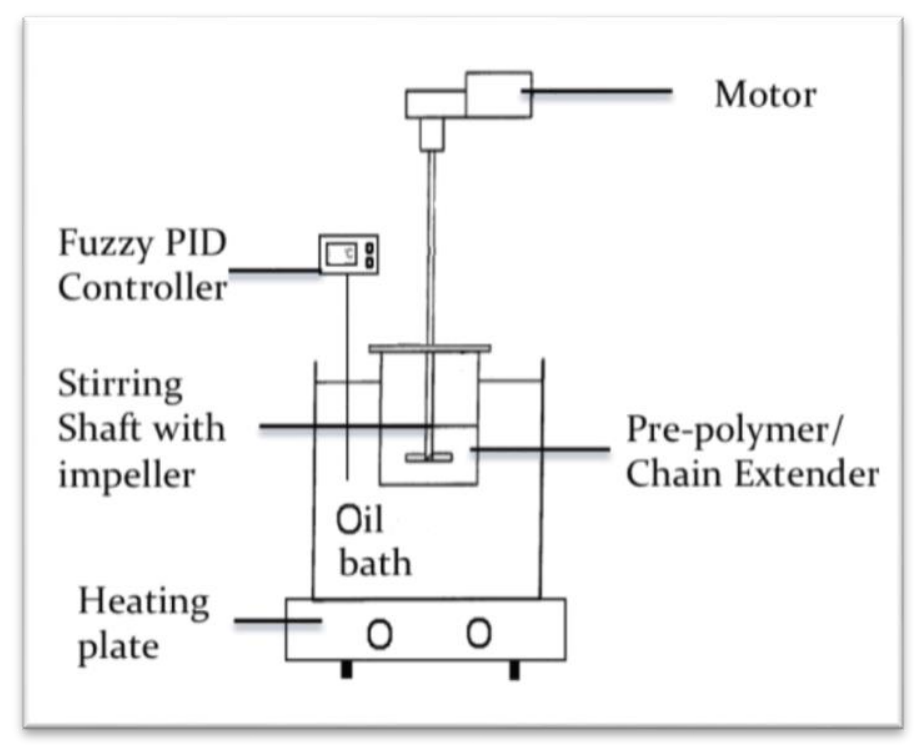

Figure 3.3. Schematic of experimental set-up for synthesis of PO3G/CO/TDI foam.

\subsubsection{Synthesis of PUF}

After mixing was terminated and the mixture was left to rest for 5 minutes, a small amount of DABCO, DBTDL and water were mixed separately in a bicker and injected into reactor with syringe. The mixture was stirred for 10 seconds at $500 \mathrm{rmp}$ and then poured into a pre-heated Teflon-coated mold. All foams were cured in the laboratory furnace at $60 \pm 1^{\circ} \mathrm{C}$ for $15 \pm 5 \mathrm{~min}$. Foam sheets had the dimensions of Length/Width/Height of $22.5 \mathrm{~cm} / 16.5 \mathrm{~cm} / 0.6 \pm 0.1 \mathrm{~cm}$, respectively. The samples were stored in a closed 
container at $25 \pm 2^{\circ} \mathrm{C}, 65 \%$ relative humidity (rh) without light exposure. Characterization of the samples was performed at least after 48 hours after synthesis.

\subsection{Design of Experiments}

BBRSM was chosen in present work to analyse the relationship between foam's composition and its physical properties. A significant advantage of Box - Behnken design is that it requires fewer design points than a Full Factorial or Central Composite Design (CCD) or Fractional Factorial CCD. Moreover, foam reaction balance is very delicate and can be easily ruined in case of extreme concentrations of any of its components. For this reason, Box - Behnken design is more advantageous than Central Factorial Design since the latter requires to include the point of extreme parameters values.

The main objective of experimental design is to develop a model to link hardness and density with composition of the foam (similarly to (Li et al. 2017)). This work will address the effect of isocyanate level, crosslinking and blowing agent ratio on foam density and hardness.

Factor $P$ is the ratio of $\mathrm{PO} 3 \mathrm{G}$ to castor oil taken by equivalents. It is well known in the literature that polyurethane foam that utilizes $\mathrm{CO}$ as the only $\mathrm{OH}$-source is very rigid due to high level of crosslinking. On the other hand, high molecular weight linear polyols will result in very soft and flexible foams. For this reason, the mixture of both polyols (PO3G and $\mathrm{CO}$ ) was utilized in the foam in order to find an optimal combination of these components. The ratio PO3G:CO of 3:1;1:1 and 1:3 were studied in the present work, these levels were chosen based on research by Wang et al. (2015) and structural similarity of PO3G and ethylene glycol polymer utilised in the study by Wang et. al. (2015)

Factor I is isocyanate index. This parameter was chosen for investigation because -NCO moieties are taking part in the reaction with water and production of $\mathrm{CO}_{2}$ that expands polyurethane polymer creating voids. Isocyanate index was studied at three levels 80, 100, and 120, which correspond to scarce, equilibrium, and excess amount of isocyanate, respectively. These levels were chosen intuitively according 
to general understanding of PU chemistry outlined in Szycher at al. (2013). Hardness of the foam is also linked to isocyanate level, i.e., the higher the isocyanate index, the more HS are formed in the polymer (hence harder the foam).

Factor $W$ is a blowing agent (water) ratio. Water is another component in reaction mixture and is responsible for formation of carbon dioxide gas. Since density of the foam is in reverse proportion to the amount of $\mathrm{CO}_{2}$ emitted, ratio of the blowing agent is also expected to be inversely related to foam density.

Ratio of the blowing agent was chosen according to the previous research (Wang et al. 2015) to be 0.5, 1.0, and $1.5 \mathrm{pphp}$. Moreover, urea linkages produced as a result of the reaction between isocyanate group and the blowing agent affect hardness of the polymer on micro-level which is due to the fact that urea linkage is less flexible than urethane linkage and make SS chains movement more restricted.

Table 3.1. Box - Behnken response surface design matrix.

\begin{tabular}{|c|c|c|c|c|c|c|c|}
\hline \multirow{2}{*}{ Run Order } & \multirow{2}{*}{ Point Type } & \multirow{2}{*}{ Blocks } & \multicolumn{3}{|c|}{ Factors } & \multirow{2}{*}{$\begin{array}{c}\text { Response } \\
\text { variable \#1 } \\
\text { Density }\end{array}$} & \multirow{2}{*}{$\begin{array}{c}\text { Response } \\
\text { variable \#2 } \\
\text { Hardness }\end{array}$} \\
\hline & & & $\mathrm{P}$ & I & $\mathrm{W}$ & & \\
\hline 1 & 2 & 1 & -1 & -1 & 0 & 0.2522 & 1.5 \\
\hline 2 & 2 & 1 & -1 & 0 & 1 & 0.1834 & 2.5 \\
\hline 3 & 2 & 1 & -1 & 0 & -1 & 0.6148 & 3.5 \\
\hline 4 & 2 & 1 & 0 & -1 & 1 & 0.1890 & 4.0 \\
\hline 5 & 2 & 1 & 1 & -1 & 0 & 0.2339 & 6.0 \\
\hline 6 & 2 & 1 & -1 & 1 & 0 & 0.1585 & 19.5 \\
\hline 7 & 2 & 1 & 0 & -1 & -1 & 0.7665 & 3.0 \\
\hline 8 & 2 & 1 & 0 & 1 & -1 & 0.2319 & 9.0 \\
\hline 9 & 2 & 1 & 1 & 0 & -1 & 0.2542 & 18.5 \\
\hline 10 & 0 & 1 & 0 & 0 & 0 & 0.2579 & 2.5 \\
\hline 11 & 2 & 1 & 1 & 1 & 0 & 0.2303 & 19.0 \\
\hline
\end{tabular}




\begin{tabular}{|c|c|c|c|c|c|c|c|}
\hline 12 & 2 & 1 & 0 & 1 & 1 & 0.1629 & 16.5 \\
\hline 13 & 0 & 1 & 0 & 0 & 0 & 0.2751 & 2.0 \\
\hline 14 & 0 & 1 & 0 & 0 & 0 & 0.2574 & 2.9 \\
\hline 15 & 2 & 1 & 1 & 0 & 1 & 0.394494 & 8.5 \\
\hline
\end{tabular}

The levels of the factors were coded as -1 (low), 0 (middle) and +1 (high) and organized in the design matrix (see Table 3.1). Response variables were density of the foam $\left[\mathrm{g} / \mathrm{cm}^{3}\right]$ and hardness [Shore A units]. Box - Behnken design included single block of experiments where replicates were done for the middle point (000); the rest of the design had no replication. A total of 15 experiment were required for this type of design. ANOVA analysis and plotting was performed by means of Minitab software. Constitutive equation was considered to forecast the area of optimal parameter values and used for planning of further experiments 


\subsection{Characterization}

\subsubsection{Fourier-Transform Infrared Spectroscopy}

A Fourier-Transform Infrared Spectroscopy (FTIR) (Cary 630 FTIR, Agilent Technologies, Waltham, MA), equipped with a single-bounce Attenuated Total Reflectance (ATR) attachment and a ZnSe detector, was used to collect spectra at foam surfaces. Samples were cut to $2 \times 2 \times 1 \mathrm{~cm}$ cubes from the center of the foam buns; three samples were tested for each formulation. The foam was pressed against the ATR crystal to ensure complete contact. All data were recorded at $25^{\circ} \mathrm{C}$ in the $4000-600 \mathrm{~cm}^{-1}$ range with a resolution of $4 \mathrm{~cm}^{-1}$. The collected spectra were normalized with respect to the absorbance of the aromatic $\mathrm{C}=\mathrm{C}$ stretching in TDI at $1600 \mathrm{~cm}^{-1}$.

\subsubsection{Mechanical Testing}

\subsubsection{Hardness}

Hardness of the sheets was tested with Shore A Digital hardness tester (HTTK-37, TekcoPlus, China) according to SATRA TM 205 standard. Hardness is a major characteristic of any outsole, midsole or foam foot bed as it relates to the ease of flexing and cushioning effect. The method relies on an indenter being pressed into the test material and measuring depth of penetration to indicate hardness. Each $0.025 \mathrm{~mm}$ penetration into the test material equals one hardness point. The test sample was prepared so that it is flat and both surfaces are smooth. Sheets were plied up so that the thickness was $11 \pm 1 \mathrm{~mm}$. A pre-set load is then applied and the amount by which the indenter penetrates the material is indicated on a digital gauge which is calibrated in Shore A hardness units. 


\subsubsection{Density of Insoles}

Density of the insole materials was measured by SATRA TM 12 test method. Polyurethane foam was cut into cylindrical shape samples with height in the direction of foam rise. Thickness and diameter of the samples were measured using calipers. Thickness of samples was $0.55 \pm 1 \mathrm{~mm}$ and diameter of all samples was $20 \pm 0.1 \mathrm{~mm}$. Three specimens were prepared for each material type. Samples were conditioned in the vacuum furnace at $60^{\circ} \mathrm{C}$ for 24 hours until constant mass is reached. The mass of the test specimen was then measured using analytical balances and recorded as $[\mathrm{M}]$ to the nearest $10 \mathrm{mg}$. The density of each test specimen was calculated by Equation $1\left(\right.$ in $\left.\mathrm{g} / \mathrm{cm}^{3}\right)$ and the value of density was averaged.

$$
\operatorname{Density}\left(\mathrm{g} / \mathrm{cm}^{3}\right)=\frac{[\mathrm{M}] * 1000}{[\mathrm{~V}]}
$$

\subsubsection{Compression Set}

Compression Set (CS) of polyurethane foam was determined by constant stress method SATRA TM 64 at the room $\left(23^{\circ} \mathrm{C}\right)$ and at elevated $\left(40^{\circ} \mathrm{C}\right)$ temperatures. CS has a direct relation to elastic properties and ability to recover after deformation. The percentage change in thickness of a test specimen is calculated after it has been compressed by a predefined pressure for a certain time and allowed to recover for a further pre-set time. For each material type, three polyurethane foam specimens (sheets of $60 \mathrm{~mm}$ diameter and $6 \pm 1 \mathrm{~mm}$ height) were cut out. These sheets were placed on the lower platen of the press so that the centers of the test specimen form an equilateral triangle with the edges of adjacent test specimen approximately 5 $\mathrm{mm}$ apart and the centre of the triangle aligned with the centre of the platen as shown in Figure 3.4. The initial height of the specimens was recorded as $\mathrm{T}_{0}$. 


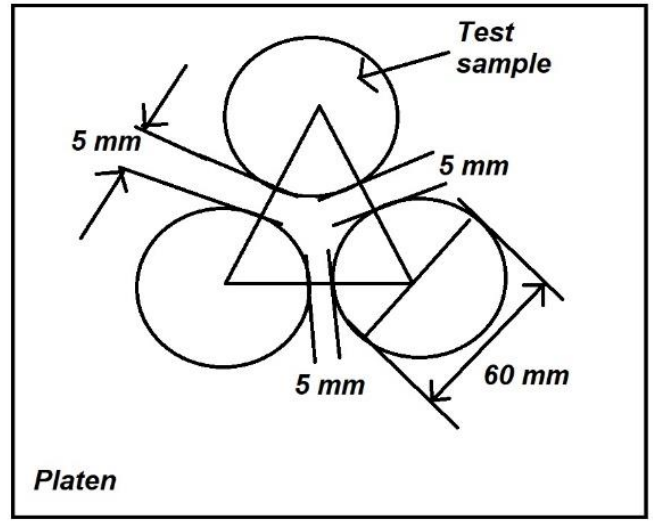

Figure 3.4. Compression Set (CS) experimental set up according to SATRA TM 64 standard.

The spacer plate was placed on top of the test specimens. A compressive force of $453 \mathrm{~kg}$-force equivalent to a pressure of $7 \mathrm{~kg}$-force $/ \mathrm{cm}^{2}$ is applied to the test specimens by means of laboratory press. The apparatus was left for 24 hours without any further adjustments. The specimens were released from the equipment and left for 1 hour at the room temperature. Thickness of the specimens was measured again and recorded at $\mathrm{T}_{1}$. CS at the room temperature (denoted as $\mathrm{CS}_{23}$ ) was calculated according to Equation 2:

$$
C S(\%)=\frac{T_{0}-H_{1}}{H_{0}} * 100 \%
$$

Analogous measurements were performed at the elevated temperature. The specimens were prepared and placed on the platen as described above; laboratory press was placed in a furnace at $40^{\circ} \mathrm{C}$ for 24 hours. $\mathrm{CS}$ at the elevated temperature (denoted as $\mathrm{CS}_{40}$ ) was also measured after all specimens have recovered for 1 hour.

\subsubsection{Water Absorption and Desorption Properties of Insole Materials}

Water absorption and desorption properties of insole materials were studied according to SATRA

TM 6. This method is indented to determine the ability of material to hold water as a measure of its hydrophilicity. Three cylindrical shape specimens (diameter $20 \mathrm{~mm}$ and height $6 \pm 1 \mathrm{~mm}$ ) for each sample 
were cut in the direction perpendicular to foam rise; top and bottom skins were preserved. All specimens were stored at the standard atmosphere $\left(55 \% \mathrm{rh}\right.$ and $\left.22 \pm 2^{\circ} \mathrm{C}\right)$ and mass $\left[\mathrm{M}_{0}\right]$ was measured using analytical balances. Three specimens were placed in a beaker and sufficient amount of water (with $\mathrm{T}=25 \pm 2^{\circ} \mathrm{C}$ ) was poured into the vessel in order to cover the test specimens by approximately $20 \mathrm{~mm}$ in depth.

All samples were removed from the water after $8.0 \pm 0.1$ hours and the excess water was mopped off from the surface of the test specimens using the filter paper. The mass of the test specimen was measured in mg using analytical balances and recorded this value as $\left[\mathrm{M}_{\mathrm{w}}\right]$ to the nearest $10 \mathrm{mg}$. In order to measure water desorption, wet test specimens were left to dry in air at standard atmosphere for $16.0 \pm 0.2$ hours after which the final mass of the specimens $\left[\mathrm{M}_{\mathrm{f}}\right]$ was determined. The water absorption (WA\%) and water desorption (WD\%) as a percentage of the original mass of the test specimens were calculated using the Equations 3 and 4:

$$
\begin{gathered}
W A(\%)=\frac{M_{w}-M_{0}}{M_{0}} * 100 \% \\
W D(\%)=\frac{\left(M_{w}-M_{f}\right)-M_{0}}{\left(M_{w}-M_{f}\right)} * 100 \%
\end{gathered}
$$

\subsubsection{Tensile Properties of Insole Materials}

Tensile properties of insole materials were studied in compliance with SATRA TM 2 test method. A rectangular test specimen was gradually stretched by a tensile testing machine (ELW(EX) Auto-tensile tester, Labthink Instruments Co., China). Three test specimens with the dimensions shown in Figure 3.5 were cut from the foam sheet of the thickness $6 \pm 1 \mathrm{~mm}$ in the direction perpendicular to foam rise. The tensile testing machine was adjusted so that the jaws are $100 \pm 1 \mathrm{~mm}$ apart. Both ends of a test specimen were inserted in corresponding jaws of the tensile testing machine and clamped.

The tensile testing machine was operated at the elongation rate of $100 \pm 10 \mathrm{~mm} / \mathrm{min}$. 


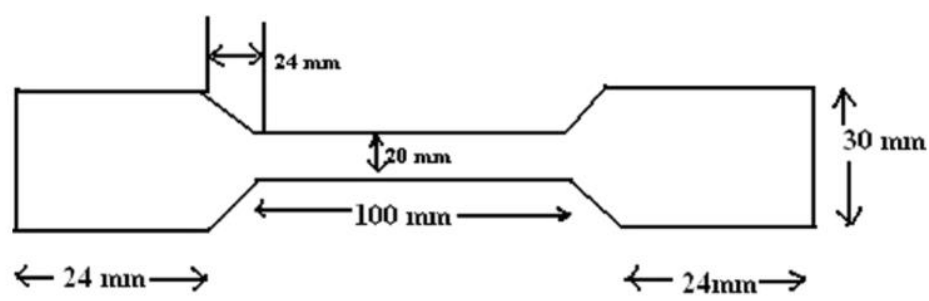

Figure 3.5. Tensile test specimen die according to SATRA TM 2 standard.

All test specimens were tested until failure. The following test parameters were recorded for each test specimen: extension at maximum load (\%), tensile strength at maximum load (MPa), Modulus of elasticity (MPa).

\subsubsection{Cushioning Properties of Insole Materials}

Cushioning properties of insole materials were studied using SATRA 159 test method. According to this test a sample is compressed under a pressure equivalent to those in walking and running. The method assesses two different cushioning properties: Cushioning Energy (CE) and Cushion Factor (CF).

$\mathrm{CE}$ is the energy required to gradually compress a specimen of the material of a given thickness up to a standard pressure. Testing is performed by means of a tensile testing machine. CE is sub-divided into CE during walking (CEw) and $\mathrm{CE}$ during running (CEr) and is calculated as an area under the compression curve restricted by the $\mathrm{x}$-axis and the vertical lines that correspond to the values of loading $113 \mathrm{~N}$ and 216 $\mathrm{N}$ for walking and running, respectively (see Figure 3.6). 


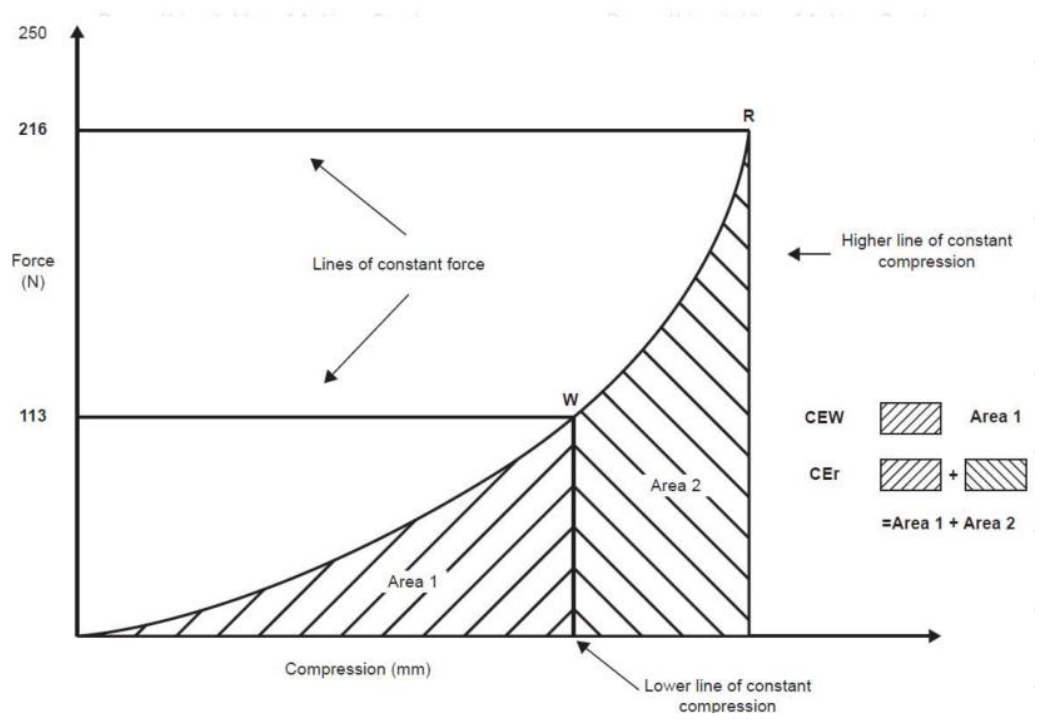

Figure 3.6. Cushioning properties of insole. Area 1 corresponds to cushioning energy during walking (CEw); sum of Area 1 and Area 2 is cushioning energy during running (CEr) (Saraswathy et al. 2009).

In order to calculate CEw and CEr of PUF, circular specimens with diameter of $2 \mathrm{~cm}$ were cut out of $6 \pm 1 \mathrm{~mm}$ thick sheets of material in the direction perpendicular to foam rise. Bottom and top skin layers were kept on. The samples' final thickness was recorded as [t]. Testing was performed using XLW(EX) Auto-tensile tester (Labthink Instruments Co., China) operating at the compression rate of $20 \mathrm{~mm} / \mathrm{min}$. The test specimen was placed between two horizontal compression surfaces so that the line of action of the force during the test passes through the centre of the test specimen. The distance between the horizontal compression surfaces was adjusted until there is a gap of approximately $1 \mathrm{~mm}$ between the top horizontal compression surface and the upper surface of the test specimen. The tensile testing machine was operated so that the horizontal compression surfaces move together until a force of $245 \mathrm{~N}$ on the test specimen was recorded. The direction of travel of the horizontal compression surfaces was reversed so that they move apart until the force on the test specimen is reduced to $0 \mathrm{~N}$. The procedure was repeated for seven times and the force versus compression trace produced by the tensile testing machine was taken for the eighth time. The area under the compression curve was calculated using Origin Pro software.

$\mathrm{CF}$ is a bulk material property and is assessed using a test specimen thickness greater than $16 \mathrm{~mm}$. The volume of the test specimen under no load multiplies the pressure on the surface of the test specimen 
at a predefined loading. The obtained quantity is then divided by CE of the specimen at the predefined load. The result is termed CF. In order to determine CF, circle-shaped test specimens with the diameter of 2.85 $\mathrm{cm}$ were cut with a knife cutter. The thickness of foam specimens was recorded as $[\mathrm{T}]$ and ranged between $6 \pm 1.5 \mathrm{~mm}$. The cut test specimens were stored in a standard controlled environment of $25 \pm 2{ }^{\circ} \mathrm{C}$ and $65 \pm 2 \%$ rh for at least 48 hours prior to measurements. The procedure analogous to determination of CE was performed on the individual specimens.

CFs for the materials were calculated using the Equation 5 and 6:

$$
\begin{gathered}
C F w=\frac{[\mathrm{T}] * 113}{[\mathrm{CEw}]} \\
C F r=\frac{[\mathrm{T}] * 216}{[\mathrm{CEr}]}
\end{gathered}
$$

\subsubsection{Reproducibility of Results and Error Analysis}

All mechanical testing procedures and cell size measurements were done in triplicates. Each data point in table or graph is expressed as mean for $n=3$. The mean is presented in table as an average and standard error (SE), expressed mathematically as $\pm(\mathrm{SE})$. While in graph, the SE is represented by error bar on every data point. Differences between the groups with $\mathrm{p}<0.05$ were considered to be statistically significant, where the average error in every set of data presented was less than 5\%. Tables D.1-D.5 list raw data that obtained from selected replicated experiments for hardness, density, compression set, water adsorption, tensile properties. The error percentage calculated for all results based on replicated tests were: for hardness testing 3-11\%, for density testing ranged from 8-13\%, for compression set testing was from 1-6.5 \%, for water adsorption was between 6-15\% and for tensile properties was between 0.1-6\%. The variability in the data possibly originate from instrumental error, fluctuations of temperature and inhomogeneity of mixing during synthesis.

Equations 7 and 8 were used to calculate standard deviation (SD) and SE respectively: 


$$
\begin{gathered}
S D=\sqrt{\frac{\sum(x-\bar{x})^{2}}{n-1}} \\
S E=\frac{S D}{\sqrt{n}}
\end{gathered}
$$

Where $\bar{x}$ is sample mean value, $\mathrm{x}=$ data point, $\mathrm{n}=$ number of samples.

\subsubsection{Differential Scanning Calorimetry}

Differential scanning calorimetry (DSC) (Q1000, TA Instruments, New Castle, DE) was used to determine thermal transitions within the materials. The amount of 2-3 $\mathrm{mg}$ of foam was loaded into an aluminum pan and sealed hermetically. The sample was first heated at $10^{\circ} \mathrm{C} / \mathrm{min}$ to $110^{\circ} \mathrm{C}$ and equilibrated for 2 minutes before cooling down to $-80^{\circ} \mathrm{C}$. The second temperature ramp heated the samples up to $250^{\circ} \mathrm{C}$ at $10^{\circ} \mathrm{C} / \mathrm{min}$ and was used to determine the characteristic transitions of SSs.

$\mathrm{T}_{\mathrm{g}}$ of polyol $(\mathrm{PO} 3 \mathrm{G})$ was measured in the same instrument by loading approximately $5 \mathrm{mg}$ of the polyol into an aluminum pan and sealed hermetically. The sample was first cooled down to $-100^{\circ} \mathrm{C}$ and equilibrated for 5 minutes followed by heating up to $240^{\circ} \mathrm{C}$ at $10^{\circ} \mathrm{C} / \mathrm{min} . \mathrm{T}_{\mathrm{g}}, \mathrm{T}_{\mathrm{c}}$, and $\mathrm{T}_{\mathrm{m}}$ were determined by means of TA Analysis software.

\subsubsection{Biodegradation Test by Soil Burial Method}

Soil burial test methods have been established and standardized for testing resistance of polyurethanes to micro organisms. The methods were originally used on polyurethanes coming in contact with the ground. The aim was to assess their resistance in soil, rather than their degradability (UrgunDemitras et al. 2007) . But the same procedure can be followed to study the susceptibility of PUF to biodegradation and the samples can be assessed for weight loss, tensile strength, and molecular break down (Gnanasundaram et al. 2015). 
The degree and rate of aerobic biodegradation of the castor oil-based foams were determined in terms of soil burial under laboratory conditions. The foams were cut into dumbbell-shaped specimens (Figure 3.2) of the thickness $5 \pm 0.5 \mathrm{~mm}$ conditioned at standard environment for 24 hours and the mass of test specimens was recorded. Soil composition and compost was prepared in compliance with ASTM D 5988. Four soil beds were developed and 4 sets of 3 samples were buried. PUF samples were buried horizontally in the wooden boxes with soil at $18 \mathrm{~cm}$ depth to ensure anaerobic biodegradation. Water was added daily to maintain moisture environment inside the chambers. Four sets of 3 samples were set aside as negative control of biodegradation. The samples were stored in a dark box in standard environment to avoid exposure to light. The samples were taken out of the container after 2 months, 3 months, and 4 months, washed thoroughly, and dried at $40^{\circ} \mathrm{C}$ in a furnace until constant mass is reached. Mass loss, spectral changes, and tensile properties of specimens were evaluated.

\subsubsection{Optical Microscopy Characterization}

Optical microscopy images were recoded with optical binocular microscope with digital camera attachment (Motic X/X2, Moticam, USA). For this purpose, samples were cut with razor knife to a sheet of $1 \mathrm{~mm}$ in thickness and placed on a glass slide with no further preparation. Calibration of the Motic camera was performed using calibration slides. Determination of cells diameter of PUF was performed using Image Plus software. The Image plus software calculated areas of the cell approximating the cells to circular shape and automatically provided statistical distributions of cell diameters for selected region of the foam. Diameter of the cell was then calculated from the area of the cell (assuming circular cell shape). The experiment was repeated tree times for 3 randomly chosen cross sections of a PUF sample sheet. 


\subsubsection{Scanning Electron Microscopy Characterization}

Morphological study of the final polyurethane-based scaffold was conducted using a scanning electron microscope (SEM). SEM is a type of microscope that produces an electronically magnified image of a specimen for detailed observation. The electron microscope uses a beam of electrons to illuminate the specimen and electromagnetic "lenses" are used to control this electron beam and focus it to form a magnified image. The JEOL/OE equipment model JSM-6380 LV (Oxford Instrument, U.K. - software version SEI England) with a monochromator (Al Xray source) was operated between 5-20 kV generating high-resolution images. Samples of the dimensions $1 \times 1 \times 1 \mathrm{~cm}$ were cut perpendicular to the growth direction from the center of tested foams and fixed in the sample holder of the microscope with no further preparation. Individual cell size was calculated by using scale bar given by SEM image. 


\section{CHAPTER 4. RESULTS AND DISCUSSION}

\subsection{FTIR Studies}

Twenty-one sample of PUF with various composition according to BB RSM were synthesized and characterised by FTIR method. Typical FTIR spectra for CO/PO3G/TDI foam formulation is presented in Figure 4.1.
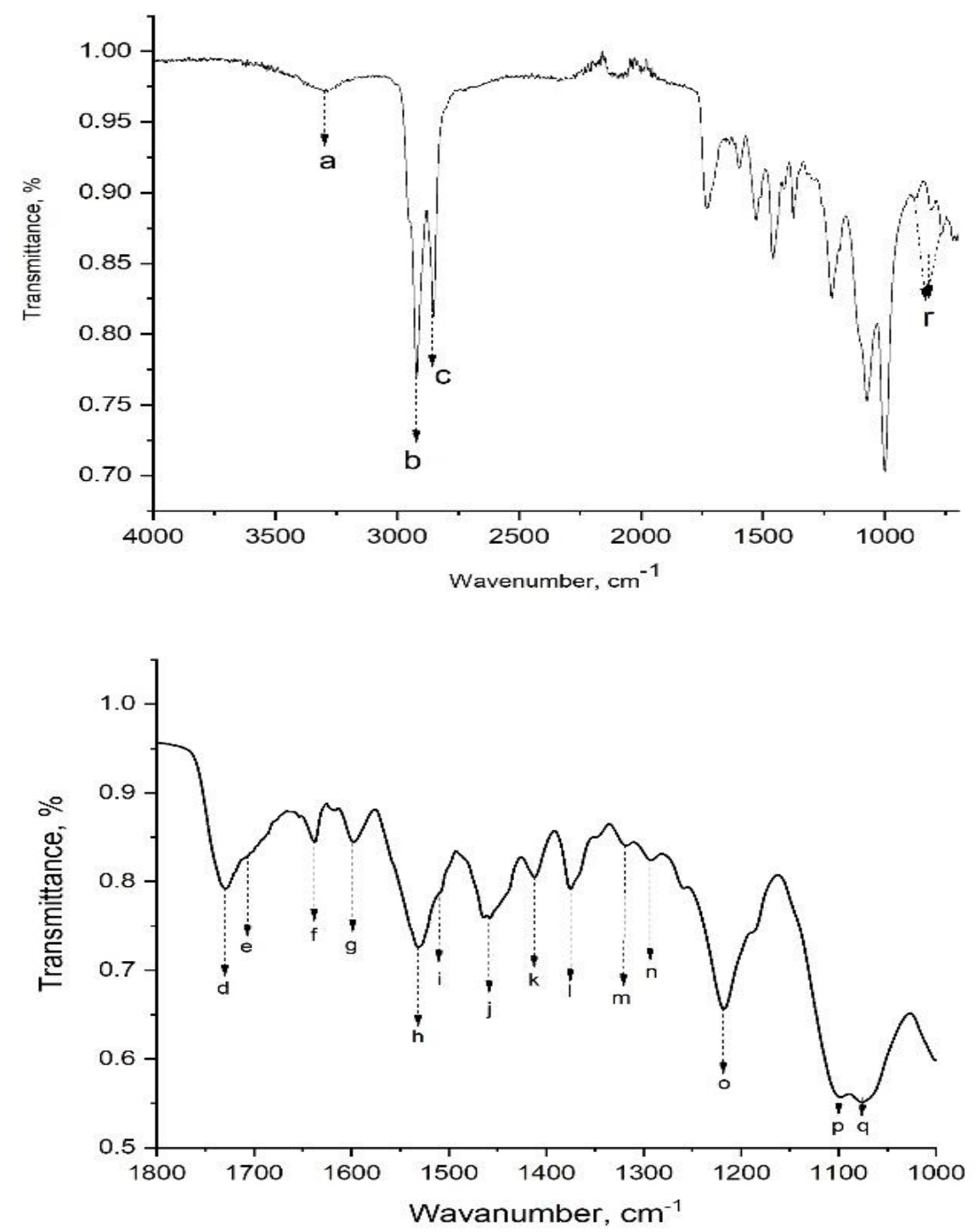

Figure 4.1. FTIR spectra of a typical CO/PO3G/TDI PUF formulation (sample 200)(top); magnified FTIR spectra of a typical CO/PO3G/TDI PUF formulation for range 1800-1000 cm-1(bottom) 
Peak assignment is summarized in the Table 4.1

Table 4.1. Peak assignment for FTIR spectra of CO/PO3G/TDI formulation (according to Li et al. (2017))

\begin{tabular}{|c|c|c|}
\hline Notation & Wavenumber $\left(\mathrm{cm}^{-1}\right)$ & Assignment \\
\hline $\mathrm{a}-\mathrm{N}-\mathrm{H}$ & $3305-3310$ & H-bonded N-H vibration band \\
\hline $\mathrm{b}-\mathrm{CH}_{2}$ & 2930 & Methylene stretching vibration mode (asymmetric) \\
\hline $\mathrm{c}-\mathrm{CH}_{2}$ & 2850 & Methylene stretching vibration mode (symmetric) \\
\hline $\mathrm{d}-\mathrm{C}=0$ & 1728 & Ester stretching vibration mode, free of H-bonds \\
\hline $\mathrm{e}-\mathrm{C}=0$ & 1705 & Hydrogen bonded urethane stretching vibration \\
\hline $\mathrm{f}-\mathrm{C}=0$ & 1643 & Urea carbonyl, strongly $\mathrm{H}$ bonded bidentate urea \\
\hline $\mathrm{g}-\mathrm{C}=\mathrm{C}$ & 1600 & Benzene ring \\
\hline h-N-H & 1531 & $\mathrm{~N}-\mathrm{H}$ vibration in secondary amine \\
\hline i -N-H & 1510 & $\mathrm{~N}-\mathrm{H}$ vibration in secondary amine \\
\hline $\mathrm{j}-\mathrm{CH}_{2}$ & 1454 & C-H bending vibration \\
\hline $\mathrm{k}-\mathrm{C}-\mathrm{N}$ & 1413 & C-N stretching vibration \\
\hline $1-\mathrm{CH}_{3}$ & 1375 & $\mathrm{CH}_{3}$ symmetric vibrations \\
\hline $\mathrm{m}-\mathrm{C}-\mathrm{N}$ & 1318 & C-N bending vibrations \\
\hline $\mathrm{n}-\mathrm{C}-\mathrm{O}$ & 1295 & C-O stretching \\
\hline $\mathrm{o}-\mathrm{C}-\mathrm{N}$ & 1223 & Asymmetric C-N vibration \\
\hline $\mathrm{p}-\mathrm{C}-\mathrm{O}-\mathrm{C}$ & 1100 & Stretching vibration mode \\
\hline $\mathrm{q}-\mathrm{C}-\mathrm{O}-\mathrm{C}$ & 1066 & Ester stretching vibration \\
\hline $\mathrm{r}-\mathrm{C}-\mathrm{H}$ & $868,817,769$ & Benzene ring hydrogen \\
\hline
\end{tabular}

The band in the $3200-3450 \mathrm{~cm}^{-1}$ region is attributed to symmetric and asymmetric stretching vibrations of the N-H of the urethane and of urea groups. The bands between 2950 and $2850 \mathrm{~cm}^{-1}$ correspond to the asymmetric and symmetric stretching vibrations of $\mathrm{CH}_{2}$, respectively. Region of the FTIR plot corresponding to $1000-1800 \mathrm{~cm}^{-1}$ is represented in Figure 4.1 (bottom). The intensive peak at $1728 \mathrm{~cm}^{-1}$ is characteristic of carbonyl group of Ricinolein and trace non-functional fatty acids that constitute CO. A 
small shoulder peak at $1705 \mathrm{~cm}^{-1}$ corresponds to hydrogen-bonded carbonyl groups, while a medium intensity peak at $1643 \mathrm{~cm}^{-1}$ confirms the presence of hydrogen bonded urea groups. The nearly overlapped bands between $1531 \mathrm{~cm}^{-1}$ and $1511 \mathrm{~cm}^{-1}$ are attributed to the stretching and bending vibrations of the C-N and N-H of the urethane moieties, respectively. The bands at $1223 \mathrm{~cm}^{-1}$ and $1100 \mathrm{~cm}^{-1}$ are associated with the ether stretching vibrations. The absence of the peak around $2260 \mathrm{~cm}^{-1}$ indicates that the $-\mathrm{NCO}$ groups have reacted with -OH group of polyols and converted into urethane linkage.

\subsection{Polymerization Reaction Conditions}

\subsubsection{Isocyanate Conversion Studies}

Traditionally, the kinetics of polyurethane formation was monitored by two direct methods that measure the concentration of reactant or reaction products: standard di(butyl)amine back titration and FTIR spectroscopy (Ruan et al. 2019). Back-titration is a well-known method for conventionally titrating free isocyanate content; however, it is both time and chemical consuming. FTIR spectroscopy is a good alternative but presents some practical limitations due to the requirements in sample preparation. Another possibility is to use the FTIR in ATR mode which can monitor the polyurethanes formation, as recently suggested by Madra et al. (2009). This technique allows the analysis of smaller samples without additional preparation. In this study the FTIR-ATR was used to determine the isocyanate conversion during polyurethane formation. According to Ajithkumar et al.(1998), kinetics of catalyzed CO/TDI reaction fits the overall expression of second order. The isocyanate absorption band is assigned at approximately 2270 $\mathrm{cm}^{-1}$ and the decay in intensity of this absorbance was used to monitor the isocyanate group conversion during the polymerization.

Figure 4.2 demonstrates the evolution of FTIR-ATR spectra during PUF sample synthesis. In order to determine isocyanates conversion during polymerization, a ratio between the transmittance of $-\mathrm{NCO}$ group and an internal standard $-\mathrm{CH}_{2}$ stretching has to be considered. Methyl group is chosen as an internal 
standard since it does not participate in PUF synthesis reaction and hence, its spectral properties remain stable during polymerization. The transmittance corresponding to the $\mathrm{CH}_{2}$ stretching region, assigned at approximately $2800-2900 \mathrm{~cm}^{-1}$, was used.

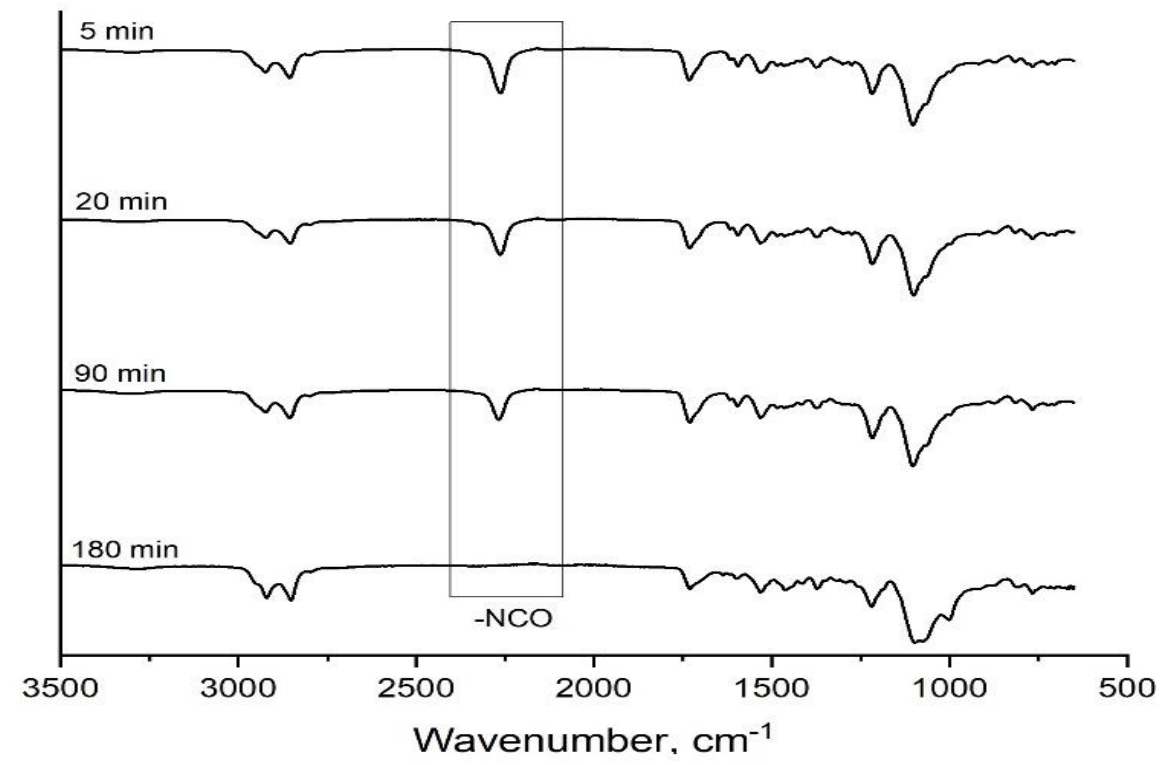

Figure 4.2. FTIR spectra change over the course of polymerization reaction in the sample of CO/PO3G/TDI foam (represents the data for $1 \mathrm{pphp}$ DBTDL, $0.1 \mathrm{pphp}$ DABCO followed by post curing)

Kinetics of CO/PO3G/TDI synthesis reaction is represented in Figures 4.3(A-D). Panels A-D correspond to different combinations of catalysts and heating regimes applied. Each panel demonstrates the dotted curve representing a relative change of $-\mathrm{NCO}$ band transmittance with respect to methylene group signal and the solid curve indicating isocyanate conversion $p$.

Dotted curve/part of the curve was constructed based on average decrease of $\mathrm{T}_{\mathrm{NCO}} / \mathrm{T}_{\mathrm{CH} 2}$ transmittance ratio during three replicates of the experiment. Trend line was obtained based on the best fit principle for either full curve or approximated as a line for initial portion of the curve. Trend line equation was applied to find the intercept part corresponding to - $\mathrm{NCO}$ group peak at initial moment of the reaction, i.e., $\left(\mathrm{T}_{\mathrm{NCO}} / \mathrm{T}_{\mathrm{CH} 2}\right)_{0}$. Black curve representing conversion $\mathrm{p}$ was plotted according to Equation 7: 


$$
p=1-\frac{T_{N C O} / T_{C H 2}}{\left(T_{N C O} / T_{C H 2}\right)_{0}}
$$
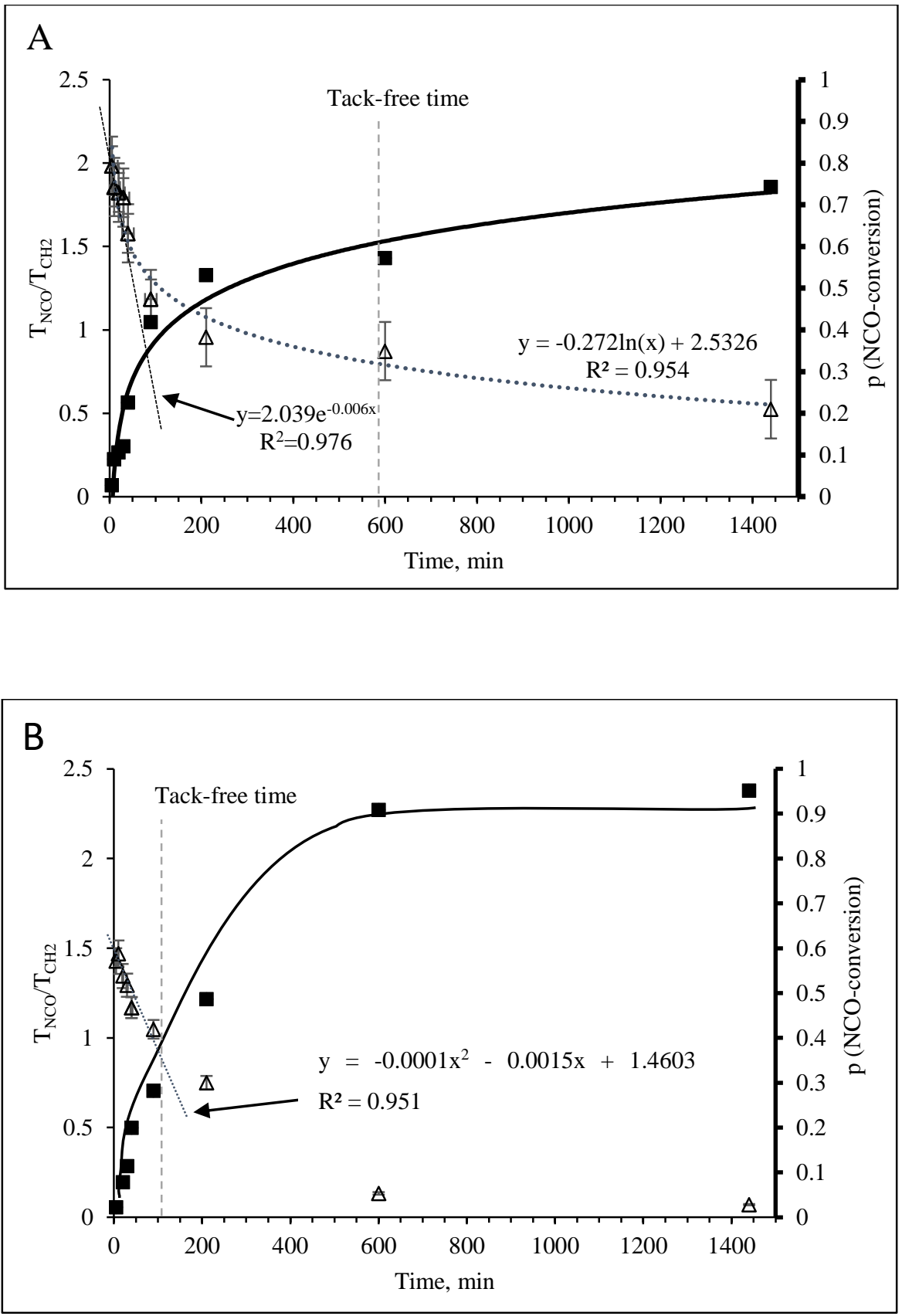

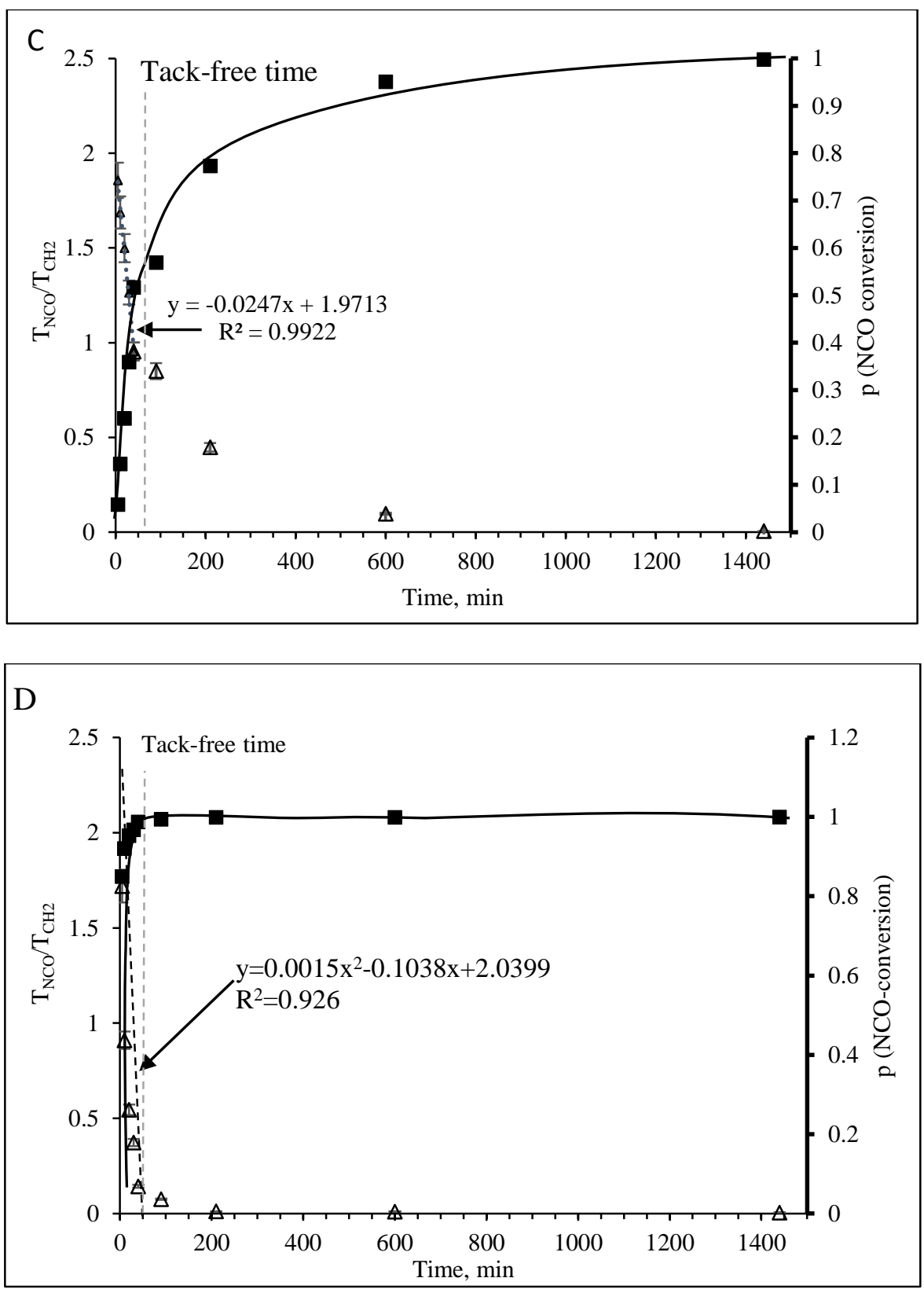

Figure 4.3. Kinetics of $\mathrm{CO} / \mathrm{PO} 3 \mathrm{G} / \mathrm{TDI}$ foam synthesis at different experimental conditions: A - 1 pphp DBTDL, no heat curing; B -1 pphp DBTDL, 0.1 pphp DABCO, no heat curing; C-1 pphp DBTDL followed by post curing at $70^{\circ} \mathrm{C} ; \mathrm{D}-1$ pphp DBTDL, 0.1 pphp DABCO followed by post curing.

As it follows from Figure 4.3 four different regimes were described by the Panels A-D. Heating regiment and combination of catalysts have significant influence on the reaction progress. For instance, conversion of isocyanate groups approaches its maximum value faster when 2 types of catalysts are applied 
(Panels $A$ and $B$ ). This significant increase in the rate of polymerization reaction can be explained by synergetic action of organo-tin and amine catalysts (Szycher 2013).

Moreover, the hydroxyl-isocyanate reaction has been well established as a second-order irreversible reaction (Broyer et al. 1978) (Equation 8) :

$$
\frac{d p}{d t}=k[O H][N C O]
$$

The conversion of isocyanate groups is directly proportional to reaction rate constant and to concentration of reactants. Since the reaction rate constant $(\mathrm{k})$ increases with temperature, polymerization reaction completes earlier at the conditions of post-curing (Panel A and C). As it follows from Panel D, the best result in terms of conversion rate was achieved by applying the combination of both catalysts and postcuring of the samples.

One of the main goals of the current study is to develop a formulation that is economical for injection moulding production. One of the ways to decrease the final product price is to keep manufacturing time as low as possible. Characteristic production time for regimes A-D are summarized in Table 4.2. It can be seen from Table 4.2 that production time for regime $\mathrm{D}$ has plummeted in comparison to regime A. In the regime $\mathrm{D}$ the sample can be demolded as short as in $18 \pm 5.2$ minutes. This parameter approaches the typical time (5-20 $\mathrm{min}$ ) required for production of custom shaped polyurethane foam via RIM technique (Hepburn 2012).

Table 4.2. Characteristic production time for regimes A-D.

\begin{tabular}{|c|c|c|c|c|}
\hline Regime & Cream time, $\mathrm{s}$ & Rise time, $\mathrm{s}$ & Gel time, min & Tack-free time, min \\
\hline A & $296 \pm 26.03$ & $618 \pm 28.9$ & $42 \pm 2.52$ & $596 \pm 8.23$ \\
\hline B & $43 \pm 6.01$ & $182 \pm 12.5$ & $6.33 \pm 0.88$ & $53.3 \pm 6.75$ \\
\hline C & $13 \pm 3.06$ & $26 \pm 2.64$ & $19.3 \pm 2.96$ & $153 \pm 14.79$ \\
\hline D & $10 \pm 2.33$ & $9 \pm 0.97$ & $1.5 \pm 0.5$ & $18 \pm 5.2$ \\
\hline
\end{tabular}




\subsubsection{Surfactant Concentration}

Silicon oil surfactant was used in this study in order to increase miscibility of the components. The amount of the surfactant was chosen based on the cells regularity and dimensional stability of the foam samples. According to Ugarte et al. (2015), cell structure regularity affects the strength of the material. Large cells weaken the foam structure and serve as tear initiators. For this reason, regularity of the foam is important to produce the insole material of sufficient tensile and tear strength. Although a typical amount of surfactant for renewable sources PUF ranged from 1.1 pphp (Ugarte et al. 2015) to 18 pphp (Gama et al. 2015), the formulations in this study were tested with 1-4 pphp of silicon surfactant.

As it follows from visual examination of the foams, the cell structure is affected by the concentration of silicon surfactant. At the low surfactant concentration (Figure 4.4, top left), there is a large variation in cell sizes, whereas at 2 and 3 pphp of surfactant the samples have more regular cells of circular shape (Figure 4.4, top right, bottom left). Finally, the foam collapses at the $4 \mathrm{pphp}$ of surfactant because the presence of surfactant interferes with the polymerisation reaction. This can also be explained by the increase

in viscosity of reaction mixture. Viscosity of reaction mixture is increasing over the course of polymerisation but the excess of a surfactant, which is viscose itself $\left(800 \mathrm{cP}\right.$ at $\left.40{ }^{\circ} \mathrm{C}\right)$, can further impact the total viscosity and misbalance the reaction.

Cell size distribution diagrams for cases B and C are presented in Figure 4.5. The composition containing 3 pphp concentration of the surfactant demonstrates bell-shaped cell-diameters distribution, hence the foam is more homogeneous and primarily contains the cells of $200 \mu \mathrm{m}$ in the diameter. The foam with 2 pphp of the surfactant is more irregular and combines larger cell sizes of 400 and $500 \mu \mathrm{m}$. Based on the results of this experiment, the concentration of $3 \mathrm{pphp}$ of silicon surfactant was chosen as optimal and used further on. 

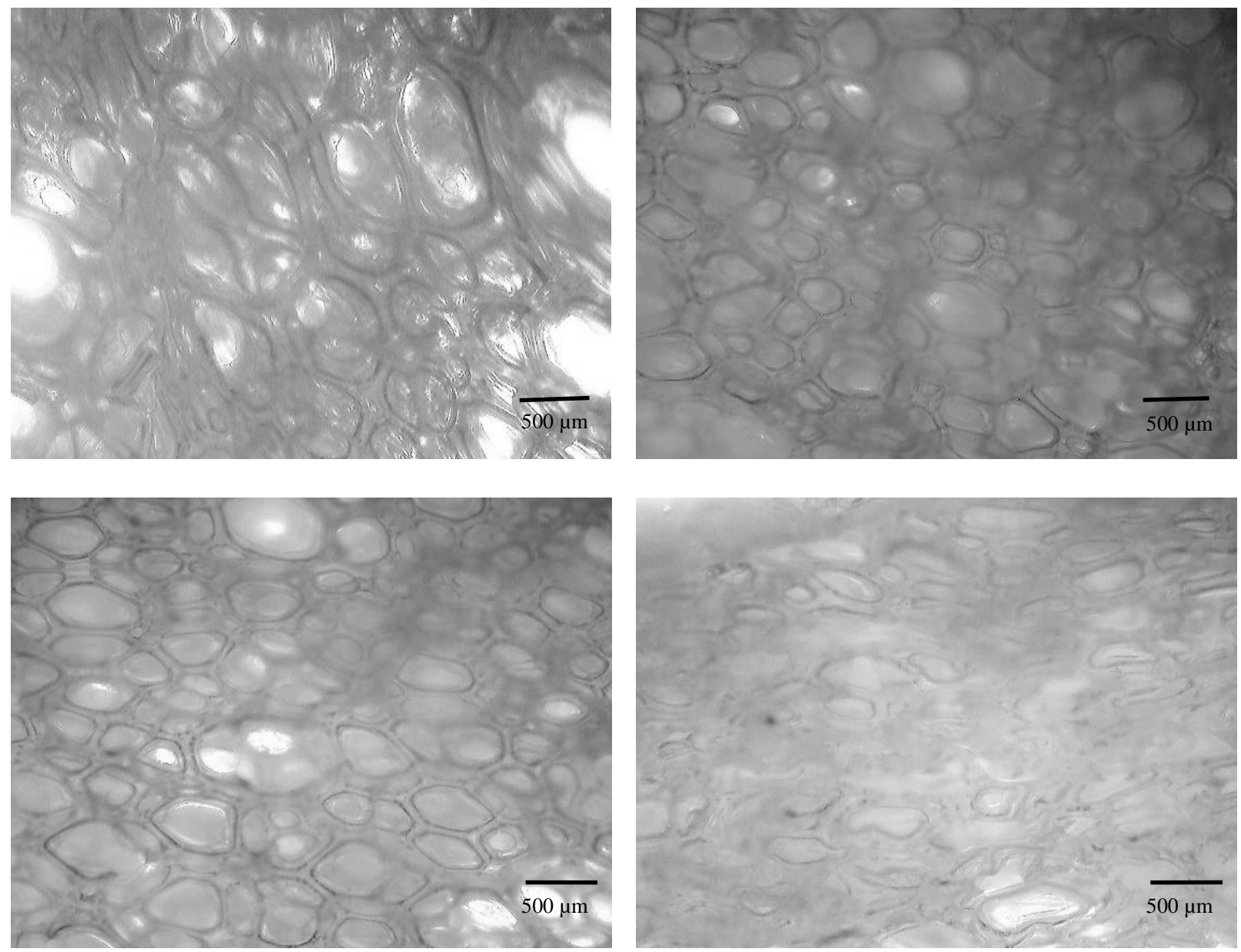

Figure 4.4. Effect of surfactant concentration on the cell structure of PUF samples. Top left-1 pphp, top right -2 pphp, bottom left-3 pphp, bottom right-4 pphp. Sample: 000 from experimental design.
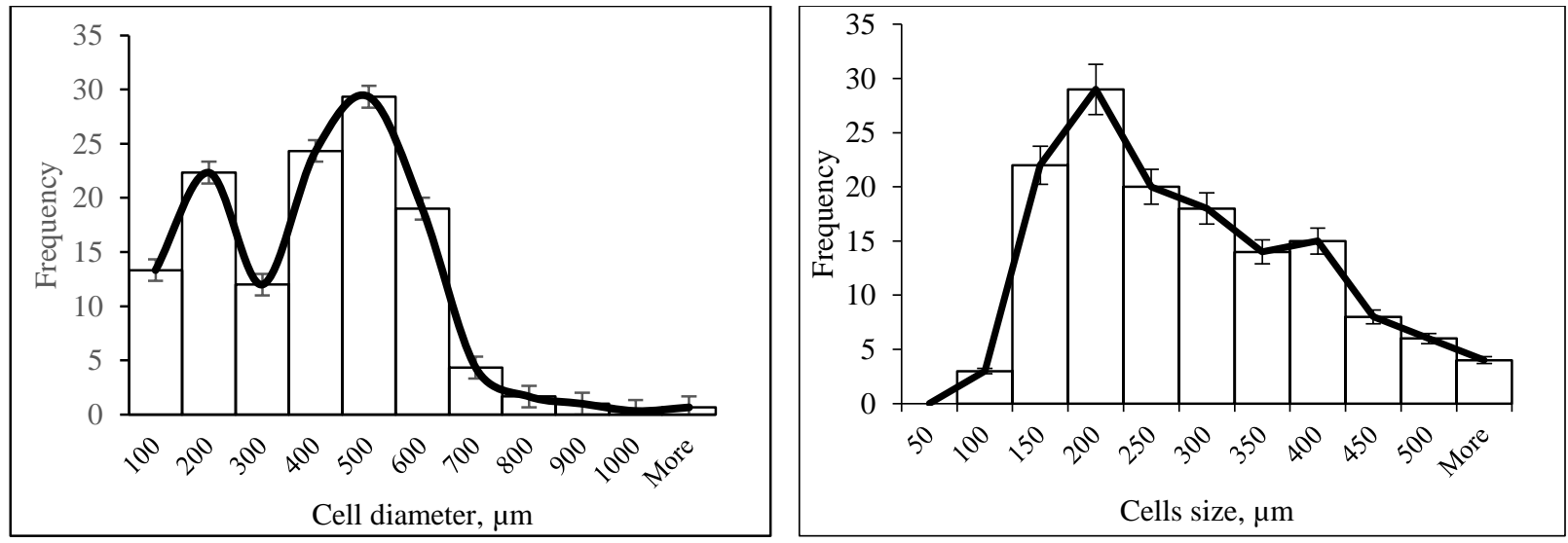

Figure 4.5. Cell diameter distribution for PUF samples with 2 pphp of surfactant (left) and 3 pphp surfactant (right) 


\subsection{Design of Experiment}

Box - Behnken experimental design for Response Surface Methodology (BB RSM) was applied for the development of empirical model, analysis of main effects, and further prediction of PUF properties.

\subsubsection{Analysis of BB RSM for Hardness of Material}

Response surface for hardness of PUF as a response variable demonstrates curvature and it is for this reason that Box - Cox transformation was employed in order to increase sensitivity of the model. The summary of the statistical analysis is presented in Tables 4.3-4.6.

Table 4.3. Summary of the method for BB RSM for hardness as a response variable

\begin{tabular}{|c|c|}
\hline \multicolumn{2}{|c|}{ Box-Cox transformation } \\
\hline Rounded $\lambda$ & -0.5 \\
\hline Estimated $\lambda$ & -0.530208 \\
\hline $95 \% \mathrm{CI}$ for $\lambda$ & $(-1.00271,0.00629)$ \\
\hline
\end{tabular}

Table 4.4. Analysis of Variance for transformed response

\begin{tabular}{|c|c|c|c|c|c|}
\hline Source & DF & Adj. SS & Adj. MS & F-Value & P-Value \\
\hline Model & 9 & 0.488857 & 0.054317 & 7.31 & 0.021 \\
\hline Linear & 3 & 0.331741 & 0.110580 & 14.89 & 0.006 \\
\hline P & 1 & 0.131139 & 0.131139 & 17.66 & 0.008 \\
\hline I & 1 & 0.200569 & 0.200569 & 27.00 & 0.003 \\
\hline W & 1 & 0.000034 & 0.000034 & 0.00 & 0.949 \\
\hline
\end{tabular}




\begin{tabular}{|c|c|c|c|c|c|}
\hline Square & 3 & 0.114418 & 0.038139 & 5.13 & 0.055 \\
\hline $\mathrm{P} * \mathrm{P}$ & 1 & 0.034681 & 0.034681 & 4.67 & 0.083 \\
\hline $\mathrm{I} * \mathrm{I}$ & 1 & 0.057868 & 0.057868 & 7.79 & 0.038 \\
\hline $\mathrm{W} * \mathrm{~W}$ & 1 & 0.039061 & 0.039061 & 5.26 & 0.070 \\
\hline 2-Way Interaction & 3 & 0.042698 & 0.014233 & 1.92 & 0.245 \\
\hline $\mathrm{P} * \mathrm{I}$ & 1 & 0.042273 & 0.042273 & 5.69 & 0.063 \\
\hline $\mathrm{P} * \mathrm{~W}$ & 1 & 0.000401 & 0.000401 & 0.05 & 0.825 \\
\hline $\mathrm{I} * \mathrm{~W}$ & 1 & 0.000024 & 0.000024 & 0.00 & 0.957 \\
\hline Error & 5 & 0.037138 & 0.007428 & & \\
\hline Lack-of-Fit & 3 & 0.029807 & 0.009936 & 2.71 & 0.281 \\
\hline Pure Error & 2 & 0.007331 & 0.003665 & & \\
\hline Total & 14 & 0.525995 & & & \\
\hline & & & & & \\
\hline & & & & & \\
\hline & & & & & \\
\hline
\end{tabular}

Table 4.5. Model Summary for transformed response.

\begin{tabular}{|c|c|c|c|}
\hline S & R-sq. & R-sq.(adj.) & R-sq.(pred.) \\
\hline 0.0861834 & $92.94 \%$ & $80.23 \%$ & $6.19 \%$ \\
\hline
\end{tabular}

Table 4.6. Coded coefficients for transformed response.

\begin{tabular}{|c|c|c|c|c|c|}
\hline Term & Coef. & SE Coef. & T-Value & P-Value & VIF \\
\hline Constant & -0.6423 & 0.0498 & -12.91 & 0.000 & \\
\hline P & 0.1280 & 0.0305 & 4.20 & 0.008 & 1.00 \\
\hline I & 0.1583 & 0.0305 & 5.20 & 0.003 & 1.00 \\
\hline W & -0.0021 & 0.0305 & -0.07 & 0.949 & 1.00 \\
\hline
\end{tabular}




\begin{tabular}{|c|c|c|c|c|c|}
\hline $\mathrm{P} * \mathrm{P}$ & 0.0969 & 0.0449 & 2.16 & 0.083 & 1.01 \\
\hline $\mathrm{I} * \mathrm{I}$ & 0.1252 & 0.0449 & 2.79 & 0.038 & 1.01 \\
\hline $\mathrm{W} * \mathrm{~W}$ & 0.1029 & 0.0449 & 2.29 & 0.070 & 1.01 \\
\hline $\mathrm{P} * \mathrm{I}$ & -0.1028 & 0.0431 & -2.39 & 0.063 & 1.00 \\
\hline $\mathrm{P} * \mathrm{~W}$ & -0.0100 & 0.0431 & -0.23 & 0.825 & 1.00 \\
\hline $\mathrm{I} * \mathrm{~W}$ & 0.0025 & 0.0431 & 0.06 & 0.957 & 1.00 \\
\hline
\end{tabular}

Regression equation in uncoded units (only statistically significant terms included):

$$
\text { Hardness }=(0.6423-0.1280 \cdot P-0.1583 \cdot I)^{-2}
$$

It follows from Table 4.5 that the proposed model has a coefficient of determination $\mathrm{R}^{2}=92.94 \%$ which is reasonably high and confirms that the model adequately responds to the change of the studied factors. Regression equation presented above demonstrates the contribution of factors to hardness property of the material. It is a complex power function that includes the terms corresponding to main effects as well as 2-way interactions.

Pareto chart (Figure 4.6, top) and Table 4.4 demonstrate significant and non-significant terms in the proposed model. As it can be seen, Factor I (i.e., isocyanate level) has the highest standardized effect, hence has the most impact on the hardness of the material. Positive value of the coefficient for Factor I (as it follows from the regression equation as well as the steepest slope on the plot of main effects (Figure 4.6, bottom)), proves the fact that isocyanate level positively contributes to the hardness of PUF. Isocyanate segments are a part of HS structure inside the PUF, hence an increase of isocyanate entails an increase in the hardness of the material.

Another significant effect is $P$, i.e. the ratio of $\mathrm{CO}: \mathrm{PO} 3 \mathrm{G}$ in the foam. Main effects plot demonstrates that mean hardness of the material is increasing when the ratio of $\mathrm{CO}: \mathrm{PO} 3 \mathrm{G}$ approaches 1:3. Also, $P$ term 
of a constitutive equation has a positive value, which proves the fact that a decrease of a ratio CO:PO3G has an opposite effect on hardness. This term causes controversies because initially it was expected that the foams with higher $\mathrm{CO}$ content have higher hardness. As is well known from the general chemistry of polyurethanes by Szycher (2013), triol-based foams are highly cross-linked materials. Despite the research expectation, elevated CO content has lowered PUF hardness. It could be the case that residual triglycerides, which do not take part in PUF formation, can act as agents softening the material.

Factor W (i.e., blowing agent level) has minimal effect on the hardness of PUF. This can be concluded from the Pareto chart (Figure 4.6) and the value of the coefficient in the constitutive equation (Table 4.6).

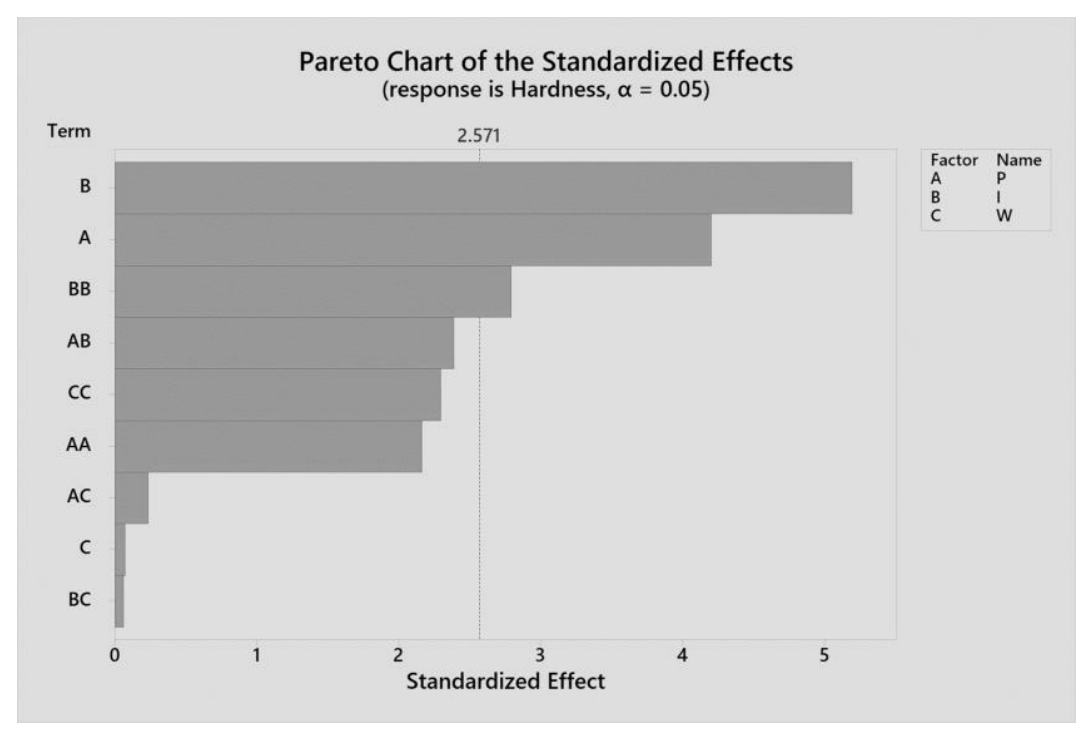

Figure 4.6 Pareto chart of the standardized effects 


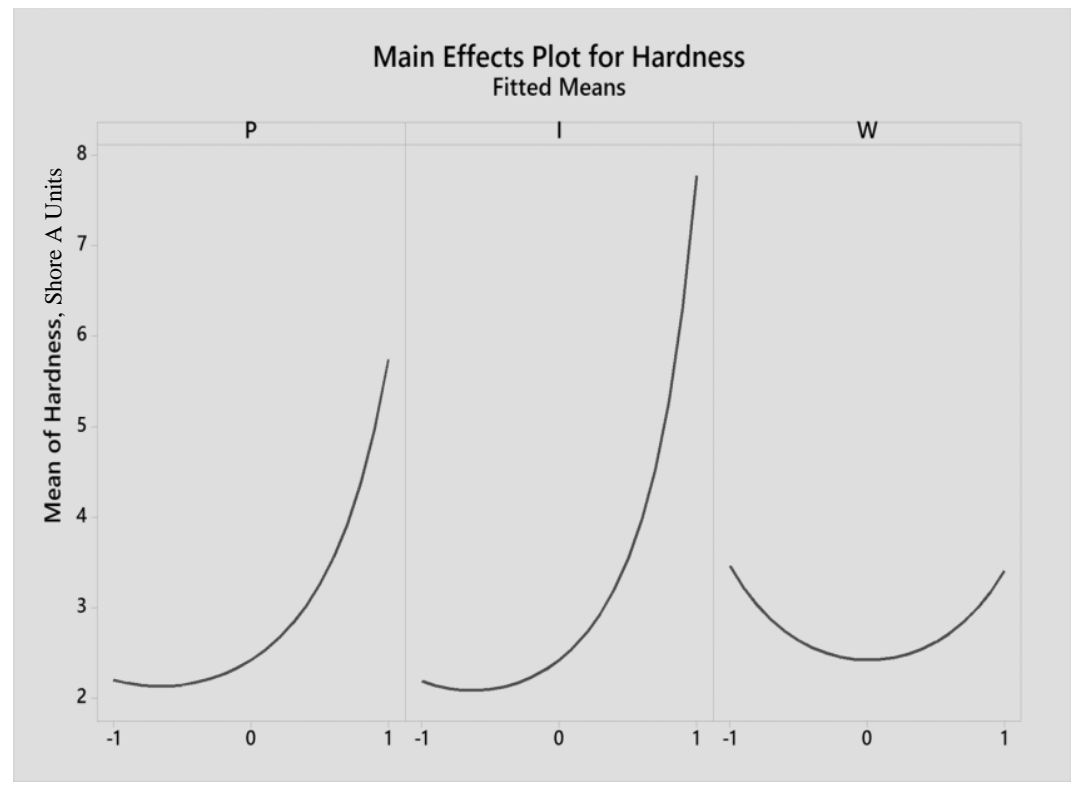

Figure 4.7. Main effects plot for hardness of PUF as a response variable.

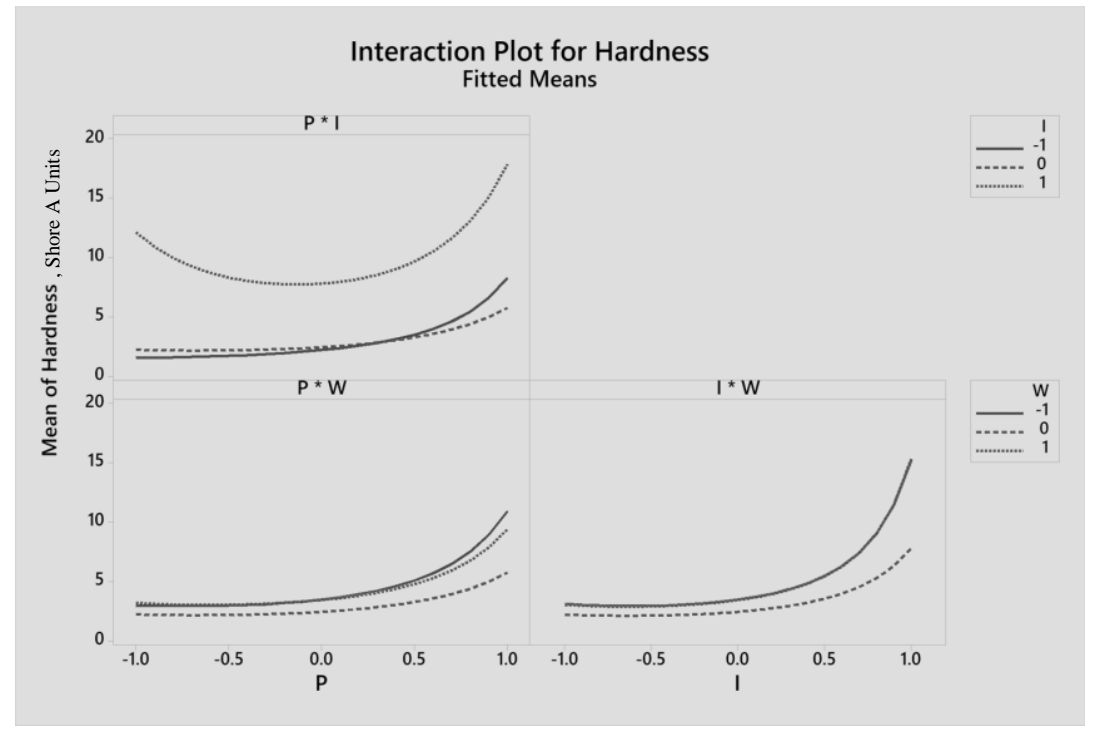

Figure 4.8. Two way interactions plot for hardness as a response variable.

The two-way interactions plot is presented in Figure 4.8. The contribution of all factors' interactions is insignificant since the slopes of interaction curves are relatively small.

Overall quality of the model can be assessed through analysis of residuals. Residual plot versus fitted values (Figure 4.9) shows random pattern implying that model responds adequately to change in factors. 
In addition, normal probability plot (Figure 4.10) demonstrates that residuals are lying close to a straight line representing normal distribution. This means that the normality requirement of the error is satisfied.

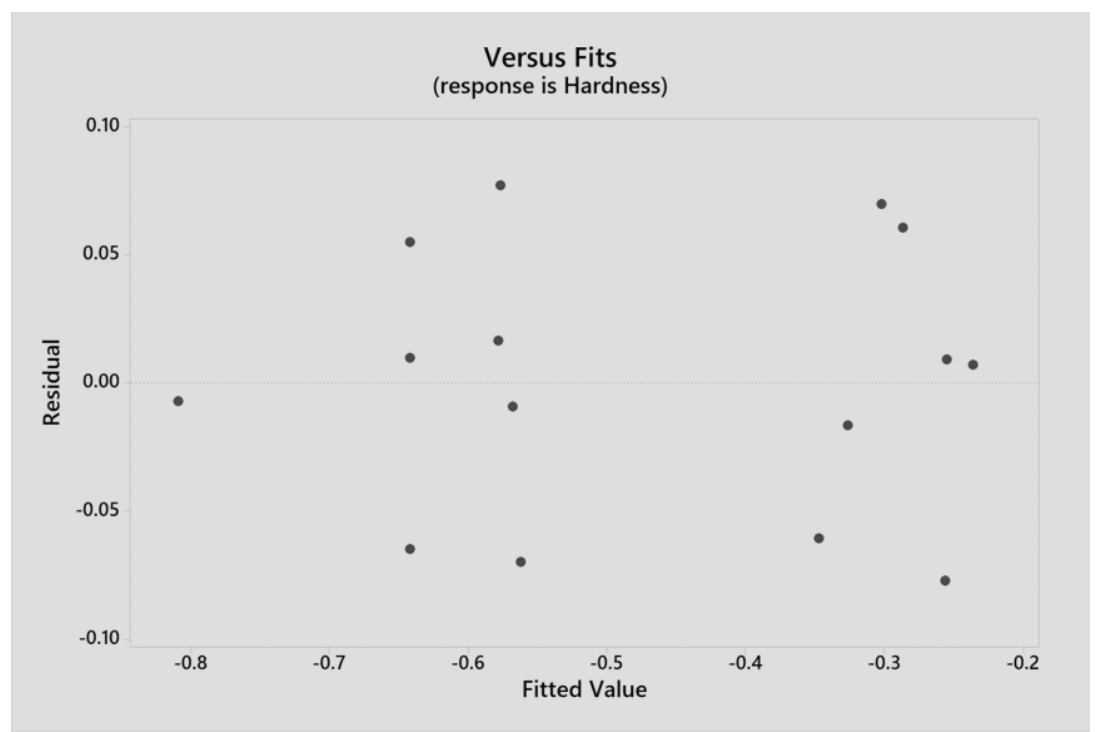

Figure 4.9. Residuals vs fitted values plot for BB RSM for hardness as a response variable.

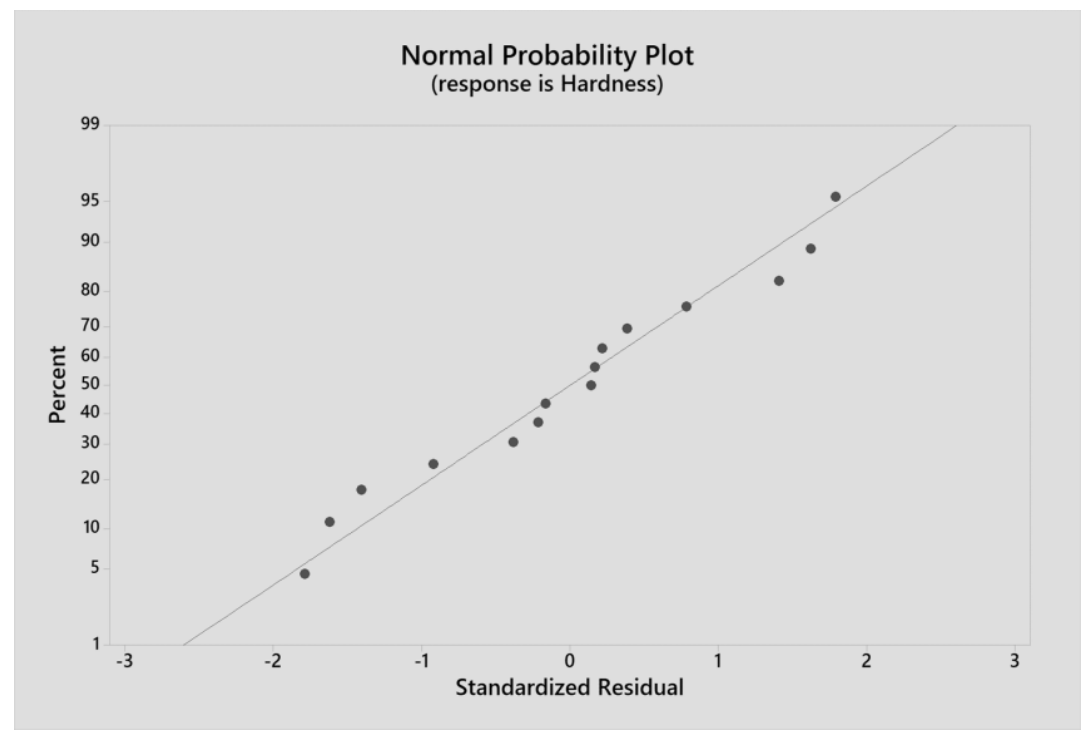

Figure 4.10. Normal probability plot for BB RSM for hardness as a response variable. 
In order to visualize the model, contour plots were constructed for hardness of PUF versus combination of factors (Figure 4.11 A-C). Contour plots served for detection of optimal parameters values in supplement to constitutive equation of the model.
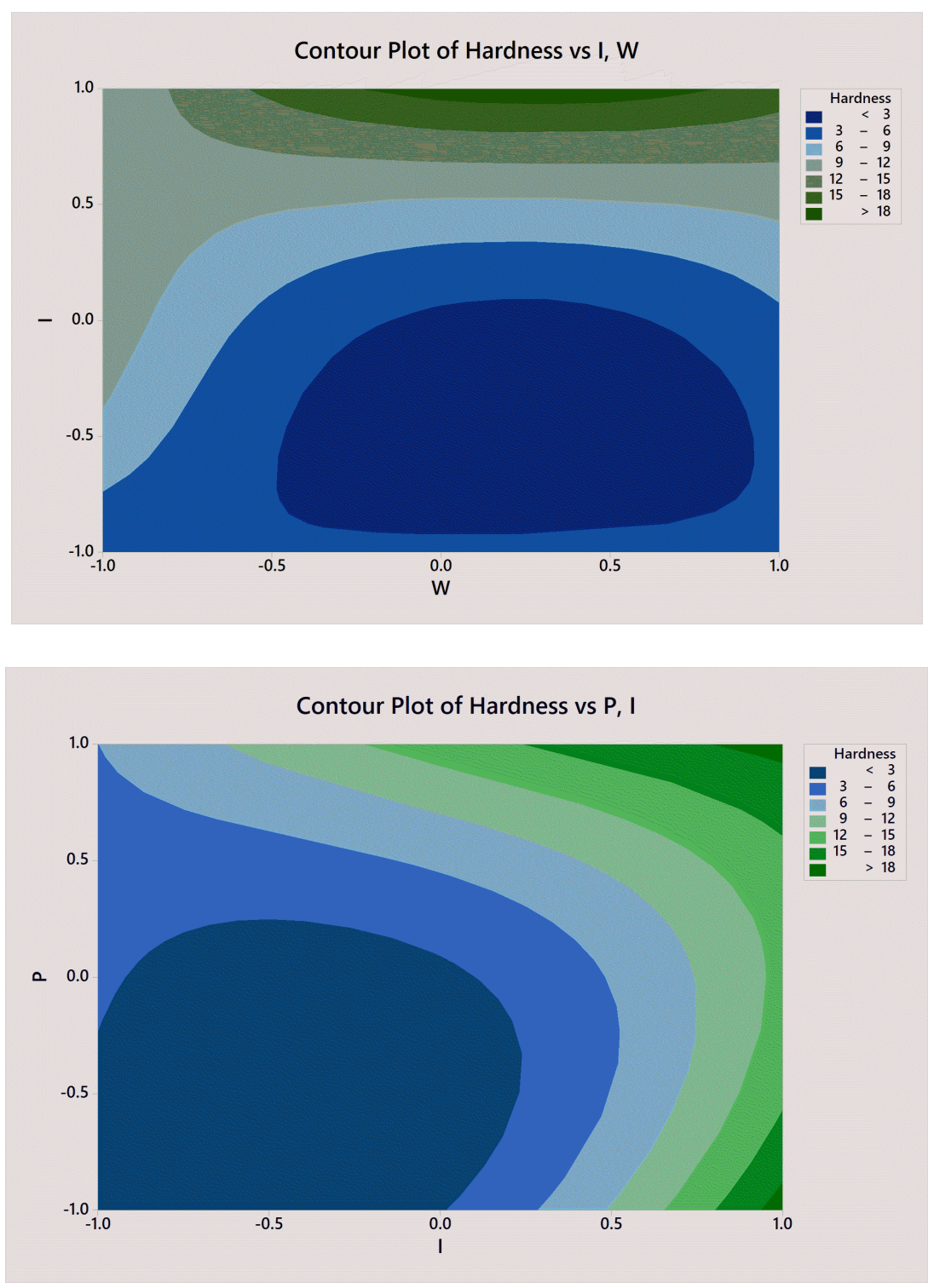


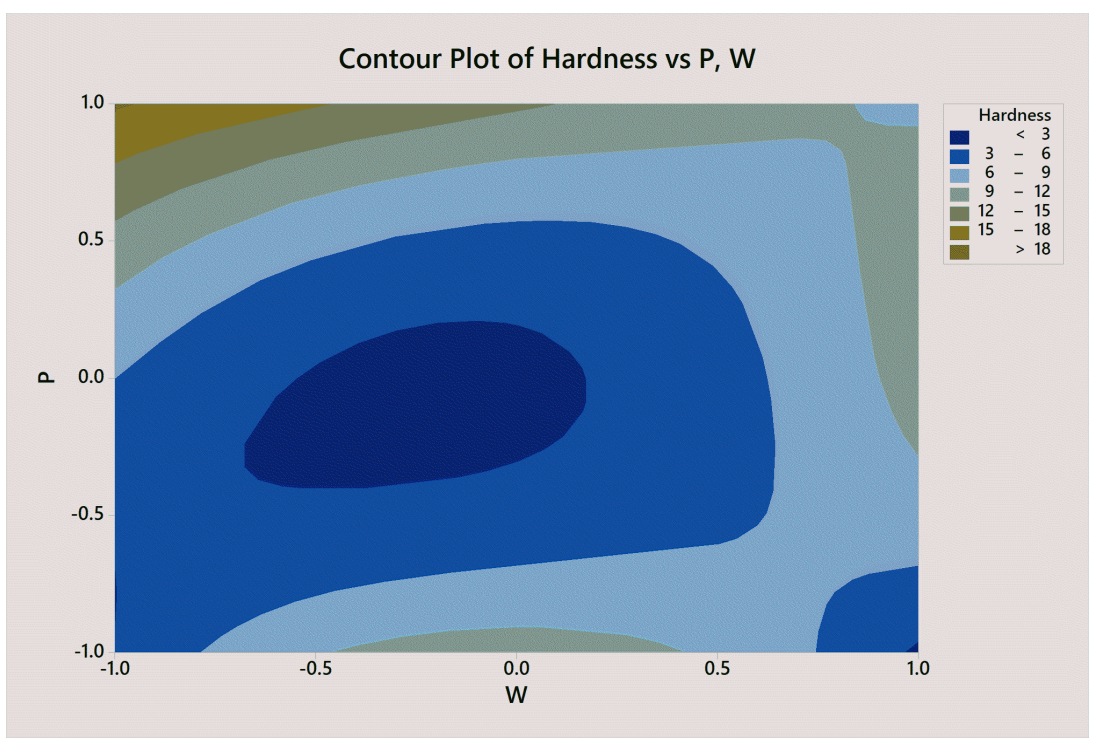

Figure 4.11. Contour plots for BB RSM for hardness as a response variable: A- hardness versus factors I, W; Bhardness versus factors $\mathrm{P}, \mathrm{I}$; C-hardness versus factors $\mathrm{P}, \mathrm{W}$

A complex pattern of the contour plot confirms a curvature of response surface. In addition, contour plot indicates that the optimal region of the parameters is located at high levels of Factors $\mathrm{P}$ and I in combination with low level of Factor W.

\subsubsection{Analysis of BB RSM for Density of Material}

BBR RSM was also applied to analyse the effect of polyols ratio, blowing agent, and isocyanate level on the density of PUF. The results of the investigation are summarized in Tables $4.7-4.10$ below.

Table 4.7. Summary of method for BB RSM for density as a response variable

\begin{tabular}{|c|c|}
\hline \multicolumn{2}{|c|}{ Box - Cox transformation } \\
\hline Rounded $\lambda$ & -1 \\
\hline Estimated $\lambda$ & -1.25029 \\
\hline $95 \%$ CI for $\lambda$ & $(-2.58979,-0.21179)$ \\
\hline
\end{tabular}


Table 4.8. Analysis of Variance for Transformed Response for density as a response variable.

\begin{tabular}{|c|c|c|c|c|c|}
\hline Source & $\mathrm{DF}$ & Adj. SS & Adj. MS & F-Value & P-Value \\
\hline Model & 9 & 27.4443 & 3.0494 & 4.74 & 0.051 \\
\hline Linear & 3 & 14.0312 & 4.6771 & 7.27 & 0.028 \\
\hline $\mathrm{P}$ & 1 & 0.6424 & 0.6424 & 1.00 & 0.364 \\
\hline I & 1 & 4.9058 & 4.9058 & 7.63 & 0.040 \\
\hline $\mathrm{W}$ & 1 & 8.4830 & 8.4830 & 13.19 & 0.015 \\
\hline Square & 3 & 4.1268 & 1.3756 & 2.14 & 0.214 \\
\hline $\mathrm{P} * \mathrm{P}$ & 1 & 0.4586 & 0.4586 & 0.71 & 0.437 \\
\hline I*I & 1 & 1.0050 & 1.0050 & 1.56 & 0.267 \\
\hline $\mathrm{W} * \mathrm{~W}$ & 1 & 2.4482 & 2.4482 & 3.81 & 0.109 \\
\hline 2-Way Interaction & 3 & 9.2863 & 3.0954 & 4.81 & 0.062 \\
\hline $\mathrm{P} * \mathrm{I}$ & 1 & 1.2950 & 1.2950 & 2.01 & 0.215 \\
\hline $\mathrm{P} * \mathrm{~W}$ & 1 & 6.8237 & 6.8237 & 10.61 & 0.023 \\
\hline $\mathrm{I} * \mathrm{~W}$ & 1 & 1.1677 & 1.1677 & 1.82 & 0.236 \\
\hline Error & 5 & 3.2163 & 0.6433 & & \\
\hline Lack-of-Fit & 3 & 1.8264 & 0.6088 & 0.88 & 0.572 \\
\hline Pure Error & 2 & 1.3899 & 0.6949 & & \\
\hline Total & 14 & 30.6607 & & & \\
\hline
\end{tabular}


Table 4.9. Model Summary for Transformed Response in case of density of PUF as a response variable

\begin{tabular}{|c|c|c|c|}
\hline S & R-sq. & R-sq.(adj) & R-sq.(pred) \\
\hline 0.802039 & $89.51 \%$ & $70.63 \%$ & $0.00 \%$ \\
\hline
\end{tabular}

Analogous to hardness of the PUF case, the response surface for density of the PUF is highly uneven. For this reason, Box - Cox transformation based on optimal lambda value was employed to achieve a nonsignificant lack-of-fit for the model. Similarly, to the hardness model, the model for density is not a linear model.

Table 4.10. Coded Coefficient for Transformed Response in case of density of PUF as a response variable.

\begin{tabular}{|c|c|c|c|c|c|}
\hline Term & Coef. & SE Coef. & T-Value & P-Value & VIF \\
\hline Constant & -4.554 & 0.463 & -9.83 & 0.000 & \\
\hline $\mathrm{P}$ & 0.283 & 0.284 & 1.00 & 0.364 & 1.00 \\
\hline $\mathrm{I}$ & -0.783 & 0.284 & -2.76 & 0.040 & 1.00 \\
\hline $\mathrm{W}$ & -1.030 & 0.284 & -3.63 & 0.015 & 1.00 \\
\hline $\mathrm{P} * \mathrm{P}$ & 0.352 & 0.417 & 0.84 & 0.437 & 1.01 \\
\hline $\mathrm{I} * \mathrm{I}$ & -0.522 & 0.417 & -1.25 & 0.267 & 1.01 \\
\hline $\mathrm{W} * \mathrm{~W}$ & 0.814 & 0.417 & 1.95 & 0.109 & 1.01 \\
\hline $\mathrm{P} * \mathrm{I}$ & 0.569 & 0.401 & 1.42 & 0.215 & 1.00 \\
\hline $\mathrm{P} * \mathrm{~W}$ & 1.306 & 0.401 & 3.26 & 0.023 & 1.00 \\
\hline $\mathrm{I} * \mathrm{~W}$ & 0.540 & 0.401 & 1.35 & 0.236 & 1.00 \\
\hline
\end{tabular}


Regression equation in uncoded units (only statistically significant coefficients included):

$$
\text { Density }=(4.554+0.783 \cdot I+1.030 \cdot W+0.522 \cdot I \cdot I-1.306 \cdot P \cdot W)^{-1}
$$

Initial evaluation of significant and non-significant terms is performed by analysis of the Pareto chart presented in Figure 4.12 and Table 4.8. As it can be seen, Factor W (i.e., blowing agent level) has the highest value of standardized effect and the steepest slope on the main effect plot (Figure 4.13), hence the main impact on the density of the PUF. This reasonable result can be explained by the fact that reaction between $\mathrm{H}_{2} \mathrm{O}$ and $-\mathrm{NCO}$ moiety is directly responsible for the formation of carbon dioxide gas, hence creation of voids. Thus, the higher the level of a blowing agent and II in the material, the lower the density of PUF.

Interestingly, the two-way interaction of $\mathrm{P}$ and $\mathrm{W}$ factors is another significant factor. Interaction plot for $\mathrm{P} * \mathrm{~W}$ (Figure 4.14) effect demonstrates that at the lowest blowing agent concentration the ratio of polyols affects density to a high extent. In addition, the coefficient for the $\mathrm{P} * \mathrm{~W}$ term in the regression equation has a negative value, which means that an increase in $\mathrm{PO}$ G content creates lower density foam. This might be caused by the presence of minor amounts of water in PO3G polymer, effect of which may be tangible at a low level of the blowing agent.

Further analysis of interactions plot (Figure 4.14) reveals that interaction of P*I line has approximately zero slope, hence a minimal effect on density. Lastly, the interaction of $\mathrm{I}^{*} \mathrm{~W}$ has impact only at the lowest level of the blowing agent. According to the plot (Figure 4.13), at a low level of the blowing agent, an increase of II leads to an extremely high density of the material. One possible explanation for this is the misbalance between blowing and polymerization reactions, which means that a part of the cells are randomly collapsed causing local increase in density. 


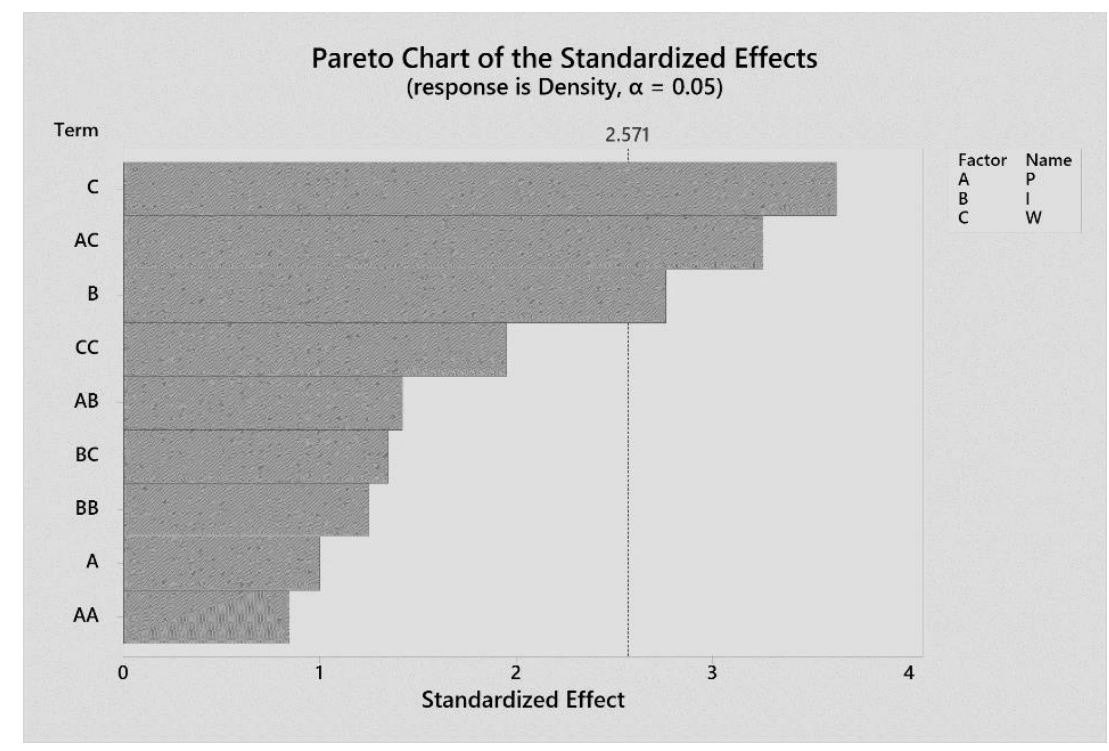

Figure 4.12. Pareto chart BB RSM modes for density as a response variable.

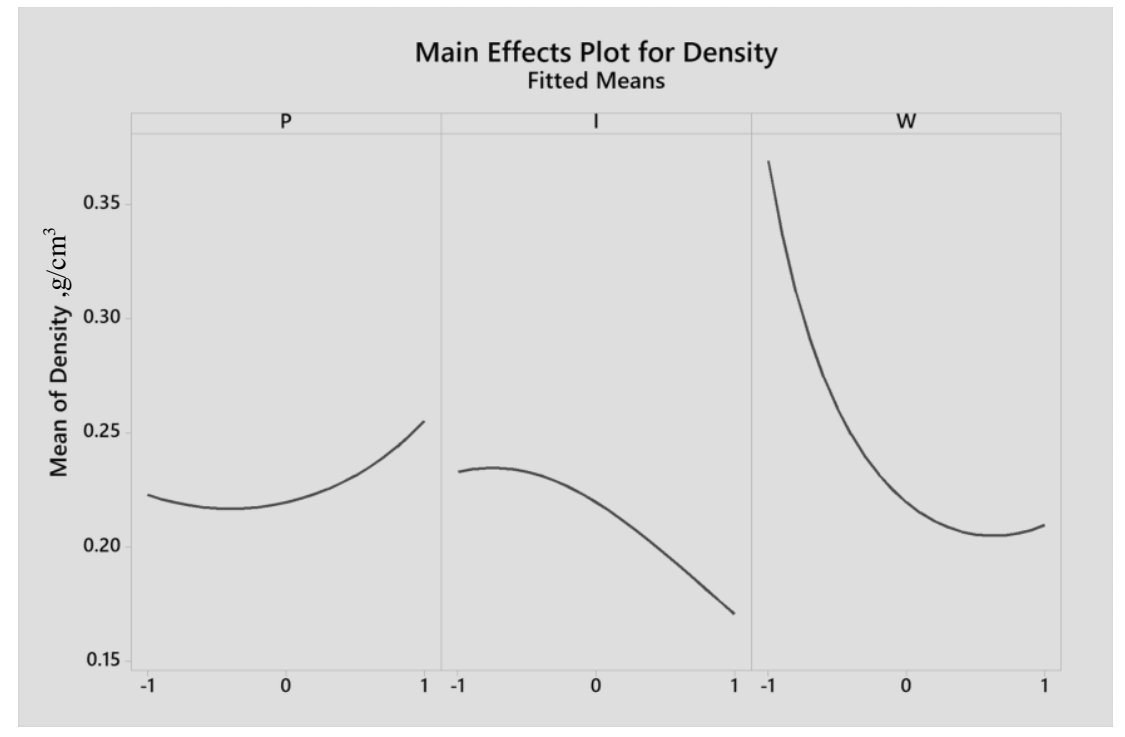

Figure 4.13. Main effects plot BB RSM for density as a response variable. 


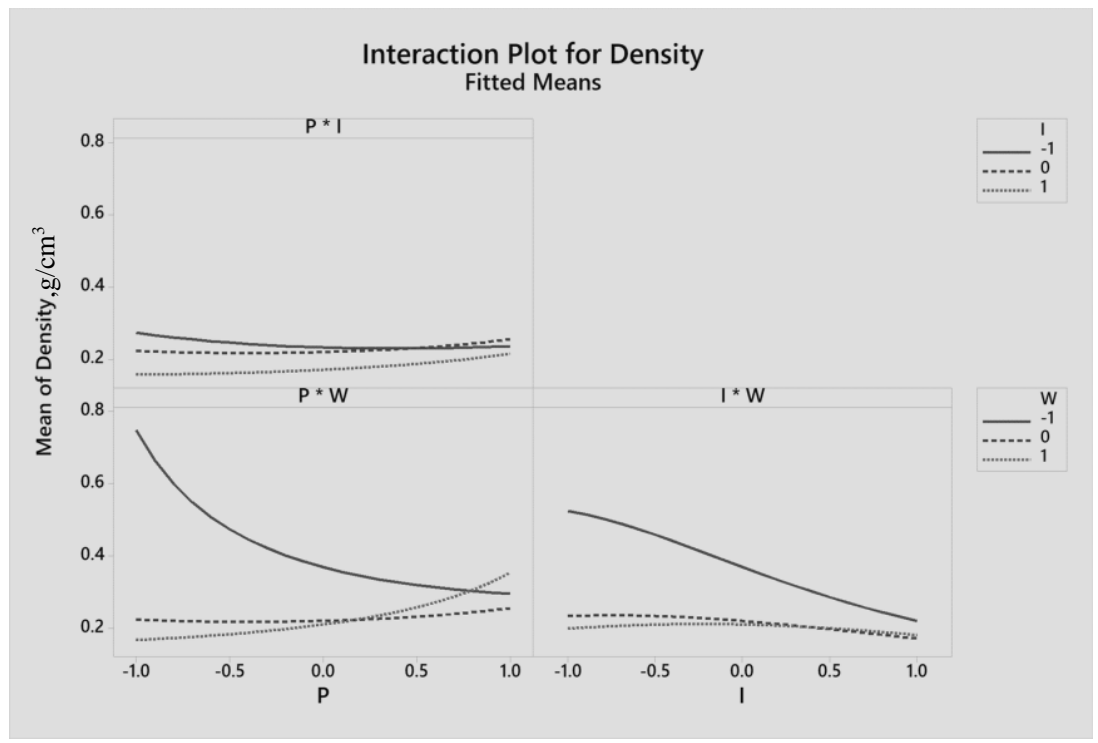

Figure 4.14. 2-way interactions plot BB RSM for density as a response variable.

Adequacy of the proposed model is assessed through analysis of residuals plots. As it can be seen from Figure 4.15, the residuals are closely aligned along the reference curve for normal probability distribution, which means the requirement of normal error distribution is satisfied. Moreover, a random pattern created on the plot of model's residuals versus fitted values (Figure 4.15) supports the fact that the model captures all explanatory information and responds well to changes in factors.

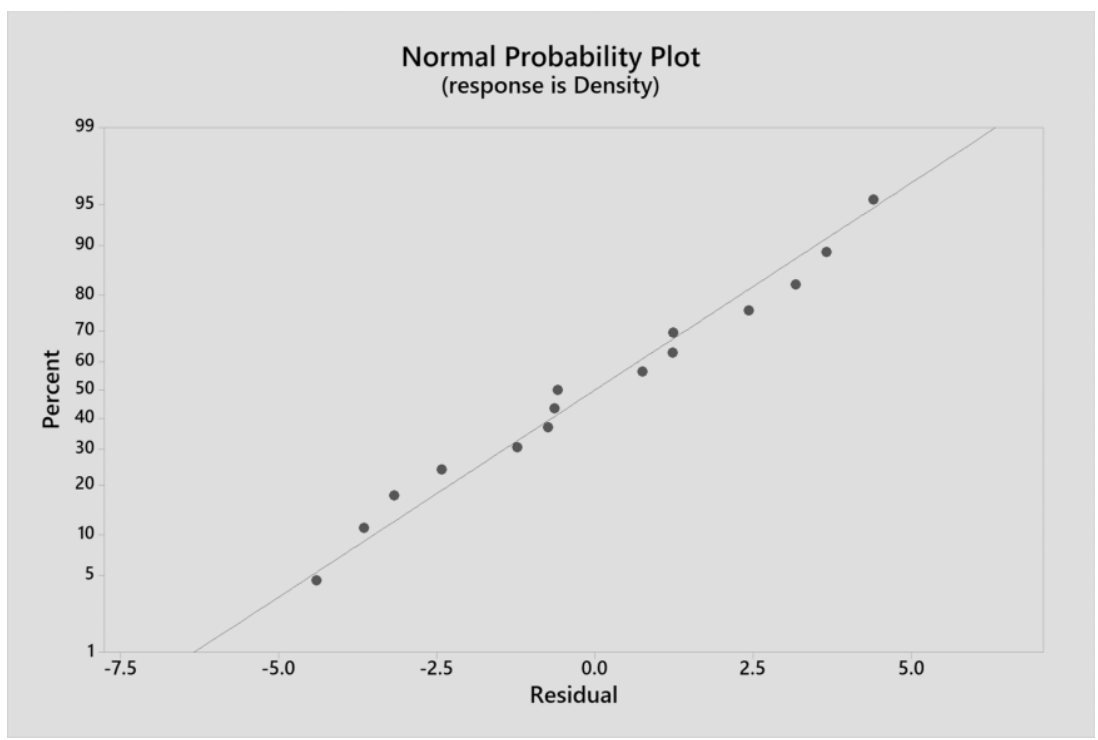

Figure 4.15 Normal Probability plot BB RSM for density of PUF as a response variable. 


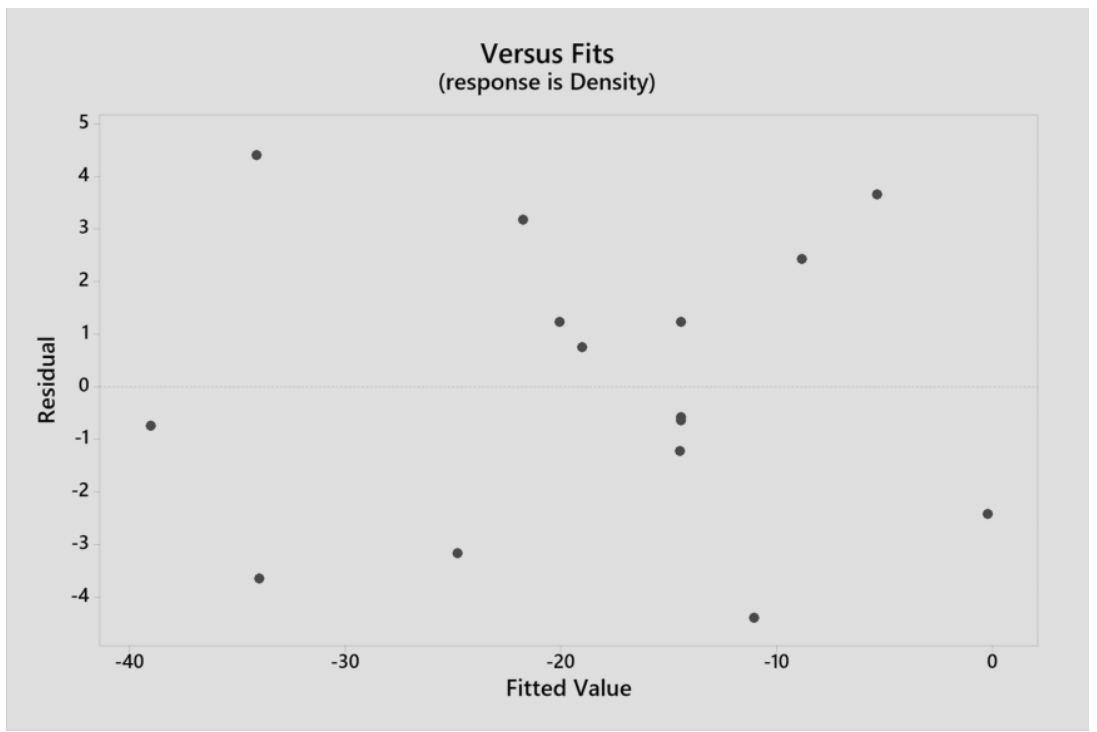

Figure 4.16. Residuals plot BB RSM for density of PUF as a response variable.

The area of optimal parameter levels can be predicted by examining contour plots in Figure $4.17 \mathrm{~A}$ C. The pattern of surfaces implies a high curvature of a response surface. Furthermore, the area corresponding to the density $0.2-0.3 \mathrm{~kg} / \mathrm{m}^{3}$ is large for all combinations of the factors, hence the design points are chosen close to optimal values. Taking into account the analysis done for hardness as a response variable, the levels of Factors P and I or either of them should be preferably kept at high level. Further expansion of the design was conducted taking into account the aforementioned inference, using constitutive equations and contour plots. 


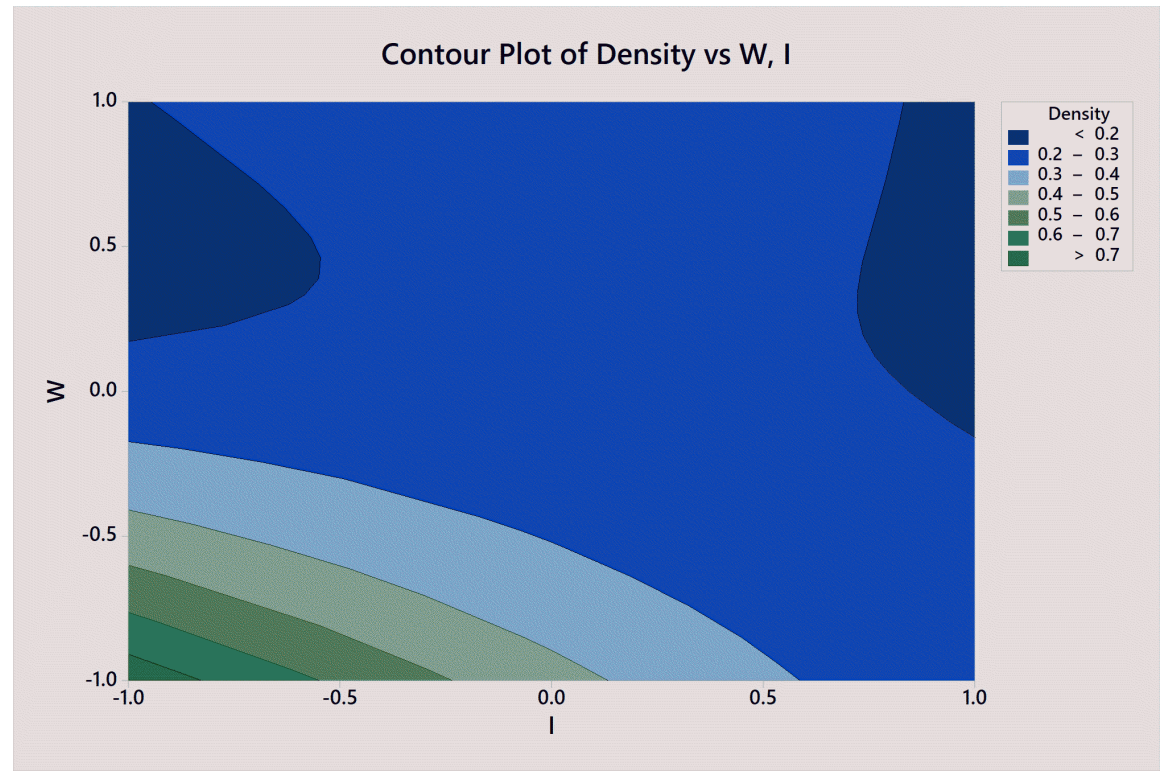

A

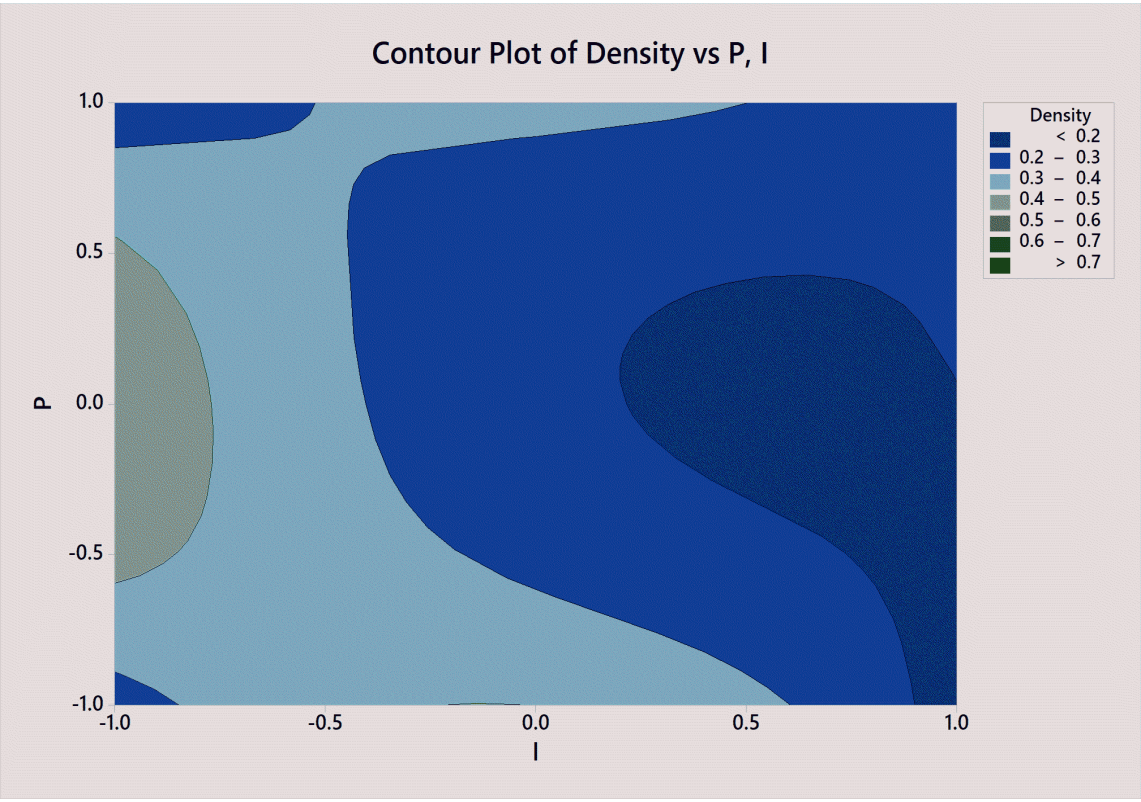




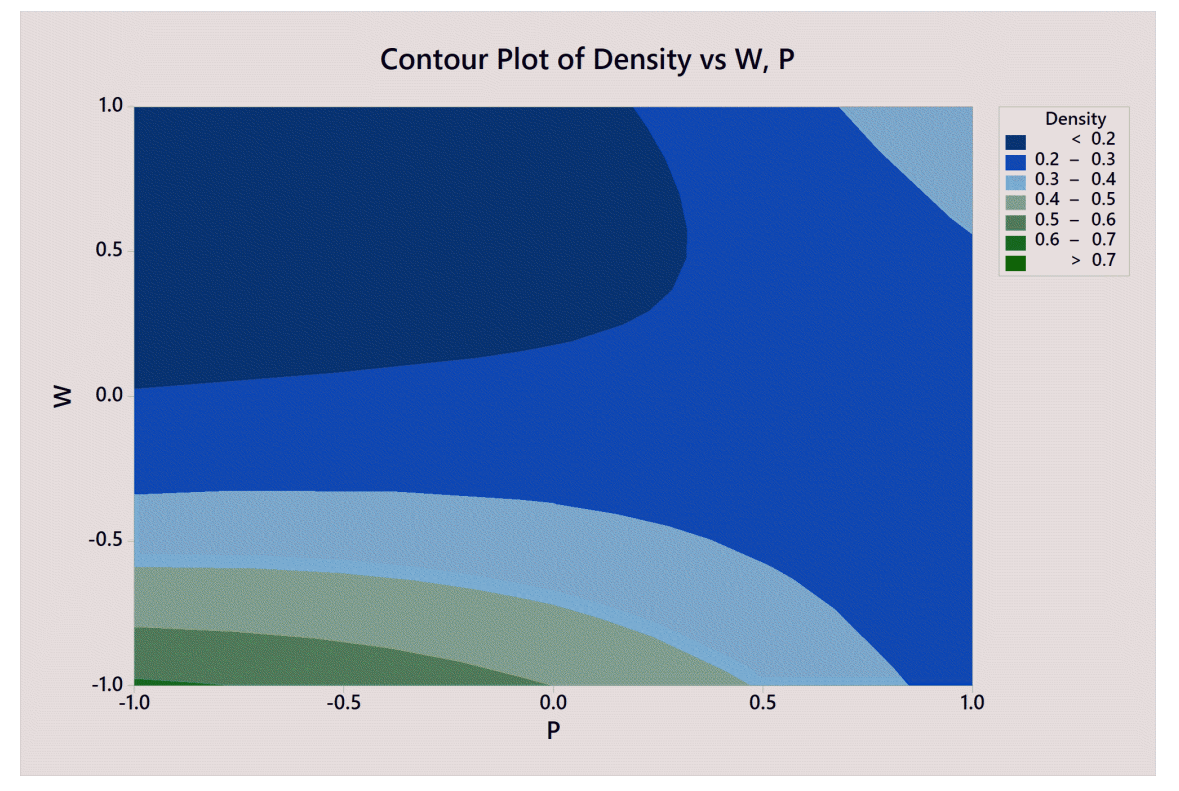

Figure 4.17. Contour plots for BB RSM for density of PUF as a response variable: A- contour plot for density vs $\mathrm{P}, \mathrm{W}$; B-contour plot for density vs W,I; C-contour plot for density vs W,P.

\subsection{Mechanical and Physical Testing}

Twenty-one samples of PUF were synthesized based on the information obtained from the analysis of BB SRM for both response variables and further tested on subject of hardness, density, tensile, compression and cushioning properties. The results obtained for PUF were compared with the characteristics of Poron Blue (PB) material that is a leader among the commercial shock absorbing materials (see also the discussion in Chapter 2). The nomenclature of samples different from DOE was introduced for convenience and brevity. It is applicable to the present Section 4.4 and further through the thesis. All samples were coded with 3-digit titles having the first digit as a level of PO3G:CO (0-ratio 25/75; 1-ratio 50/50; 2-ratio 75/25), the second digit as a II (0-II=80; $1-\mathrm{II}=100 ; 2-\mathrm{II}=120 ; 3-\mathrm{II}=140)$, and the third digit as a level of the blowing agent (0-0.5 pphp; 1-1 pphp; 2-1.5 pphp). 


\subsubsection{Hardness and Density}

The evaluation of the hardness and density of the PUFs was performed on the first stage of testing since both of these properties are primarily responsible for shock absorption capacity of the material (follows from Campbell et al.(1984)). Hardness and density diagrams that contain predicted and measured values are presented in Figure 4.18 and Figure 4.19, respectively. The area of the optimal characteristics is shaded in the diagrams.

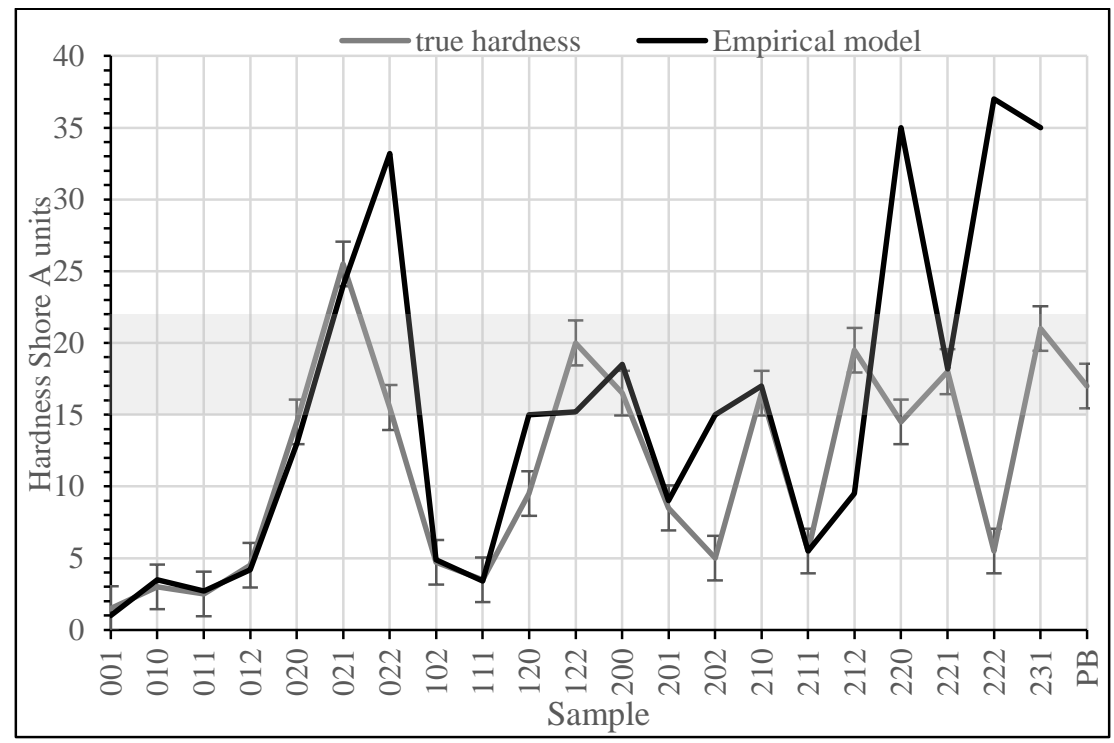

Figure 4.18.Diagram representing hardness of the materials for corresponding samples. PB- commercial reference material (Poron Blue 4080)

Figure 4.18 demonstrates deviations of the model predictions (black line) from the true values (grey line) and it follows that in some cases the error is not significant. Such a variation may be caused by the presence of factors that the developed model was not accounting for (e.g., the change in viscosity of reaction mixture depending on composition and room temperature fluctuations). Instrumental error and uneven heating could also contribute to the deviations in the results.

As it was noticed earlier in Section 4.3.1, hardness for the samples is inversely related to CO content. Some studies (Szycher 2013; Wang et al. 2015) claim that ricinolein (triglyceride of ricinoleic acid) of CO creates crosslinking due to its high functionality which, in turn, results in formation of rigid foam. However, 
the opposite trend is observed in the present study. The reason for this observation could be the presence of minor traces of other fatty acids in the composition of CO. It is well known that $\mathrm{CO}$ content varies from 90-95\% of Ricinolein as a major hydroxyl bearing component and the remaining 5-10 \% constitute fatty acids that do not have hydroxyl group and do not participate in the polymer forming reaction. At the minor $\mathrm{CO}$ ratio the effect of trace components is less pronounced. However, when the ratio of CO:PO3G is 1:1, specifically at the conditions of low II, trace fatty acids significantly alter polymer structure and affect foam's stability.

Nevertheless, hardness of eight samples $(020,022,122,200,210,212,221,231)$ falls in the required range of Shore A 15-22 hardness units. The hardness of PB reference material also satisfies this requirement.

The situation analogous to the case of hardness is observed in Figure 4.19 that represent the density of PUF samples. The deviations of model response are significant in case of samples 010, 001 and 220 due to instability of the samples. On the other hand, the model captures more closely the impact of the factors on the density for the remaining samples.

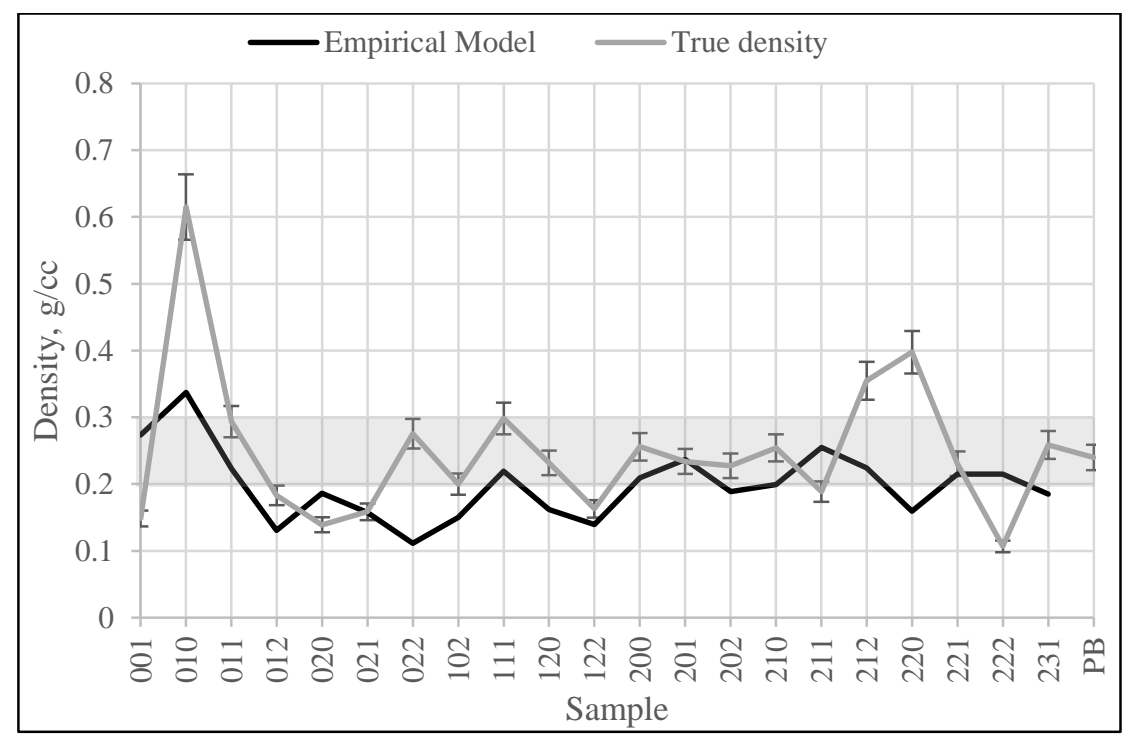

Figure 4.19. Diagram of density versus corresponding PUF sample as predicted by BB RSM (blue) and experimental values (grey). PB - reference commercial material. 
According to literature review in Chapter 2, the optimal values of PUF density are $0.2-0.3 \mathrm{~kg} / \mathrm{m}^{3}$. As can be seen from Figure 4.19, the density of 12 samples $(011,022,102,111,120,200,201,202,210,211$, $221,231)$ and reference material are falling into the required interval.

In summary, density and hardness properties of the PUFs were assessed on the initial screening stage since these two parameters are primarily responsible for quality pressure absorption and distribution capacity of the material. As a result of this investigation, 7 samples $(022,112,200,210,212,221,231)$ were sorted out as having a potential to demonstrate superior performance and continued into the further analysis.

\subsubsection{Compression Set}

Investigation of PUF performance in conditions of applied static pressure was carried out on the second step since compression set (CS) is a crucial characteristic of insole material. All samples were studied at the room temperature $\left(23^{\circ} \mathrm{C}\right)$ according to SATRA TM 64 method as described by Saraswathy et al. (2009) and at the elevated temperature $\left(40^{\circ} \mathrm{C}\right)$. The phenomena of PUF softening at the temperature close to the body temperature was described by Shariatmadari et al.(2012) and possible change in FSR sensors output (North et al. 2010) necessitate to conduct a similar test as described in SATRA TM 64, but at a higher temperature. The results of CS experiment are presented in Figure 4.20.

CS property signifies elasticity of the developed materials. The samples can recover after long-term deformation without a significant change in thickness due to high elastic effect of the material. Furthermore, the presence of elastic effect pertinent to phase separated materials confirms the presence of this property in PUFs. 


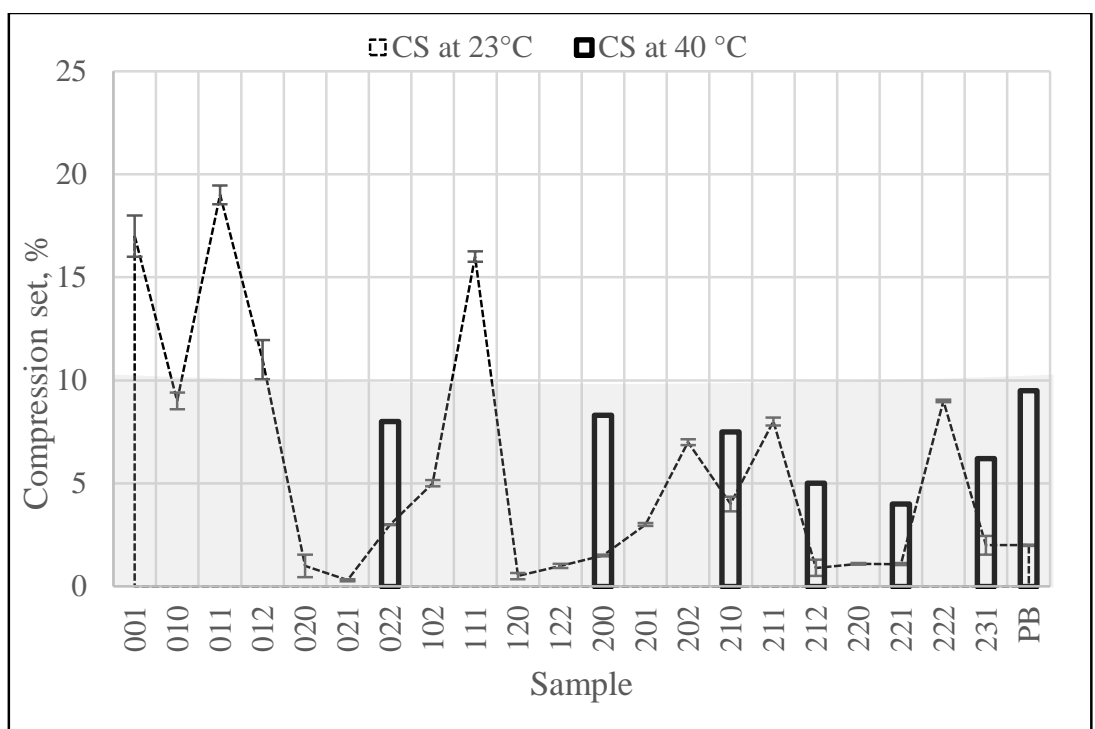

Figure 4.20. Diagram for compression set of the corresponding PUFs and reference material (PB) at standard (dotted) and elevated (bold) temperatures.

Although the link between composition and CS of the material is not clearly seen from the pattern, the trend between hardness and CS can be observed. As it can be concluded from Figure 4.21, the samples with lower hardness have higher \% of CS and the opposite trend is also true. CS value less that $5 \%$ is characteristic for samples with higher HS concentrations, i.e., II equal to 1 or 2 , because HS serve as supporting structural elements preventing PUFs deformation. Typically, all samples having Hardness Shore A 15-22, including a reference material, demonstrate CS lower than $10 \%$ at standard conditions. As it was previously described in the literature (Brodsky et al. 2012; Shariatmadari et al. 2012), the samples undergo softening at the temperature close to body temperature (however, the value of CS still remains in the acceptable range). Hence, according to the requirements outlined in Chapter 2, samples 022, 200, 210, 212, 221, 231 are applicable for insole fabrication.

To summarize, CS property of the synthesized materials as well as of the reference sample were studied. Seven samples $(022,200,210,212,231,112,221)$ have demonstrated CS within the targeted range and were used in further testing. 


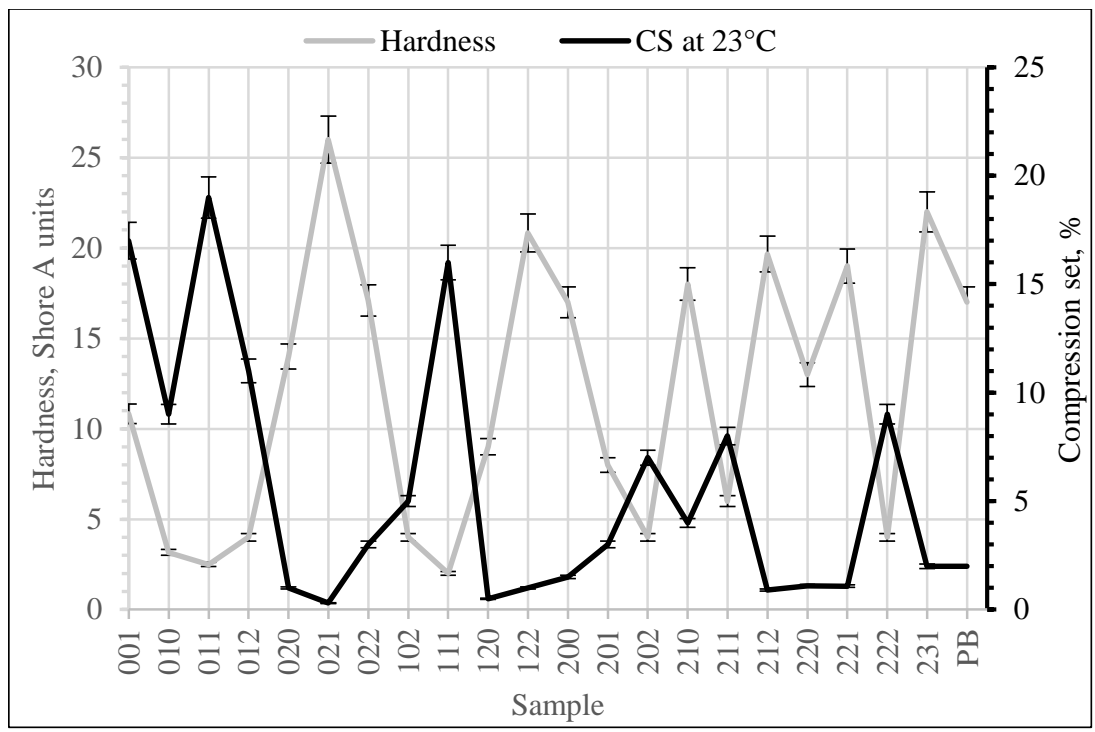

Figure 4.21. Diagram for CS of the materials (black) and hardness (grey) for corresponding PUFs and PB (reference material).

\subsubsection{Water Absorption/Desorption}

The proposed area of application for developed PUFs imposes restrictions on the water absorption/desorption abilities of the materials. According to SATRA TM6 standard, the water absorption of the insole material should be limited to $30 \%$. This value is considered optimal to provide necessary wicking property and at the same time, to prevent bacterial growth inside the foam. For this reason, all synthesized samples were tested on hydrophilicity. The results of the experiment are presented in Figure 4.22 .

As follows from the diagram in Figure 4.22, PUF samples are hydrophilic in the majority of compositions. Interaction between water and PUF can be explained by Van der Waals interactions and hydrogen bonds formation between water molecules and polar hard segments. Also, an increase in PUF density obstructs the water penetration inside the foam and for this reason the lightest foam samples 132 , 211, 222, 021 with density less than $0.2 \mathrm{~g} / \mathrm{cm}^{3}$ demonstrate exceptionally high water absorption. On the other hand, the samples with density between $0.2-0.3 \mathrm{~g} / \mathrm{cm}^{3}$ tend to have water absorption ability within the required range. 
Water desorption of all samples approaches $100 \%$ which is also a general requirement for insole materials. In conclusion, 5 samples $(022,200,210,212$, and 231) have demonstrated the required performance after discriminating the samples based on water absorption/desorption criteria.

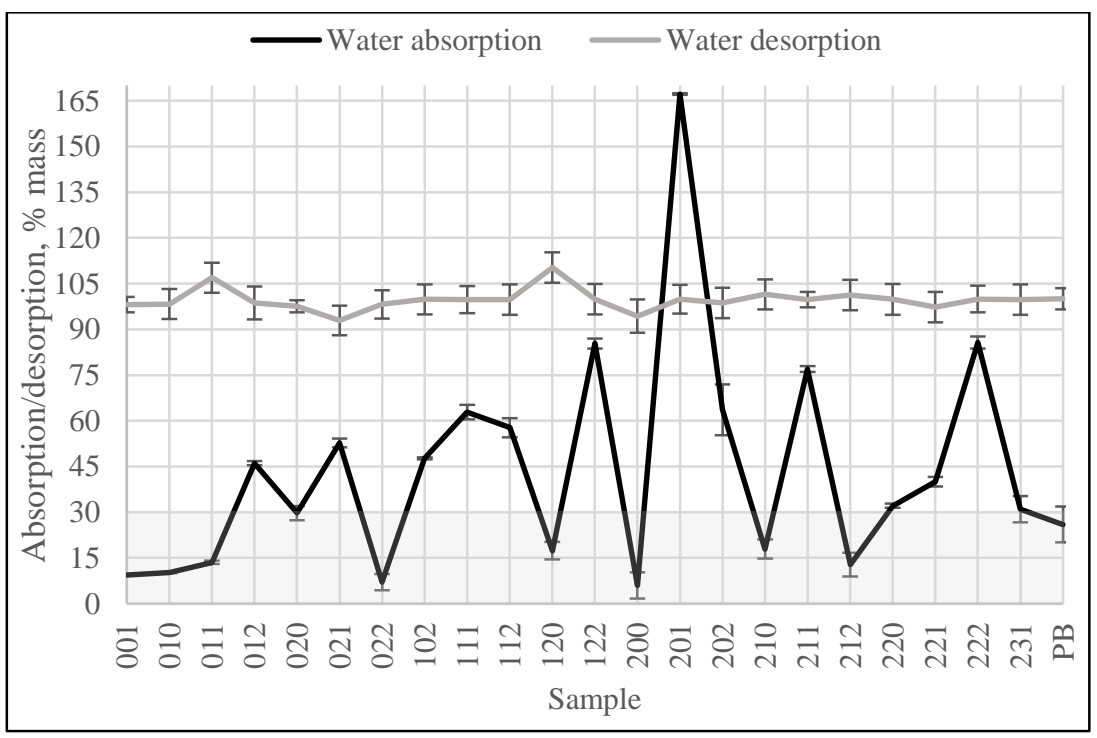

Figure 4.22. Water absorption (black) and water desorption (grey) for corresponding PUFs and reference material.

\subsubsection{Tensile Testing}

Tensile testing is a direct indication of material's strength. The value of tensile strength for Poron materials ranged from 0.9-1.2 MPa depending on thickness and design (Paton et al. 2007). Hence, this range of properties is highly desirable for newly developed PUF samples.

Moreover, tensile properties of PUF material to a large extent depend on the composition of the samples and help elucidate the internal structure of the polyurethane. As can be seen in Figure 4.23, the slopes of strain/stress curves change dramatically for different samples. For instance, the samples with higher PO3G content $(210,212)$ demonstrate higher elasticity and can be stretched up to $450 \%$. As it was described in previous research (Volynets et al. 2017), this extraordinary property stems from the presence of long polyether chains which uncoil when external force is applied. At the same time, the sample 200, which is composed of a high level of PO3G:CO has much lower present elongation (226\%) due to lower II 
and, as a consequence, lower HS concentration which play a significant role in reinforcement of the structure.

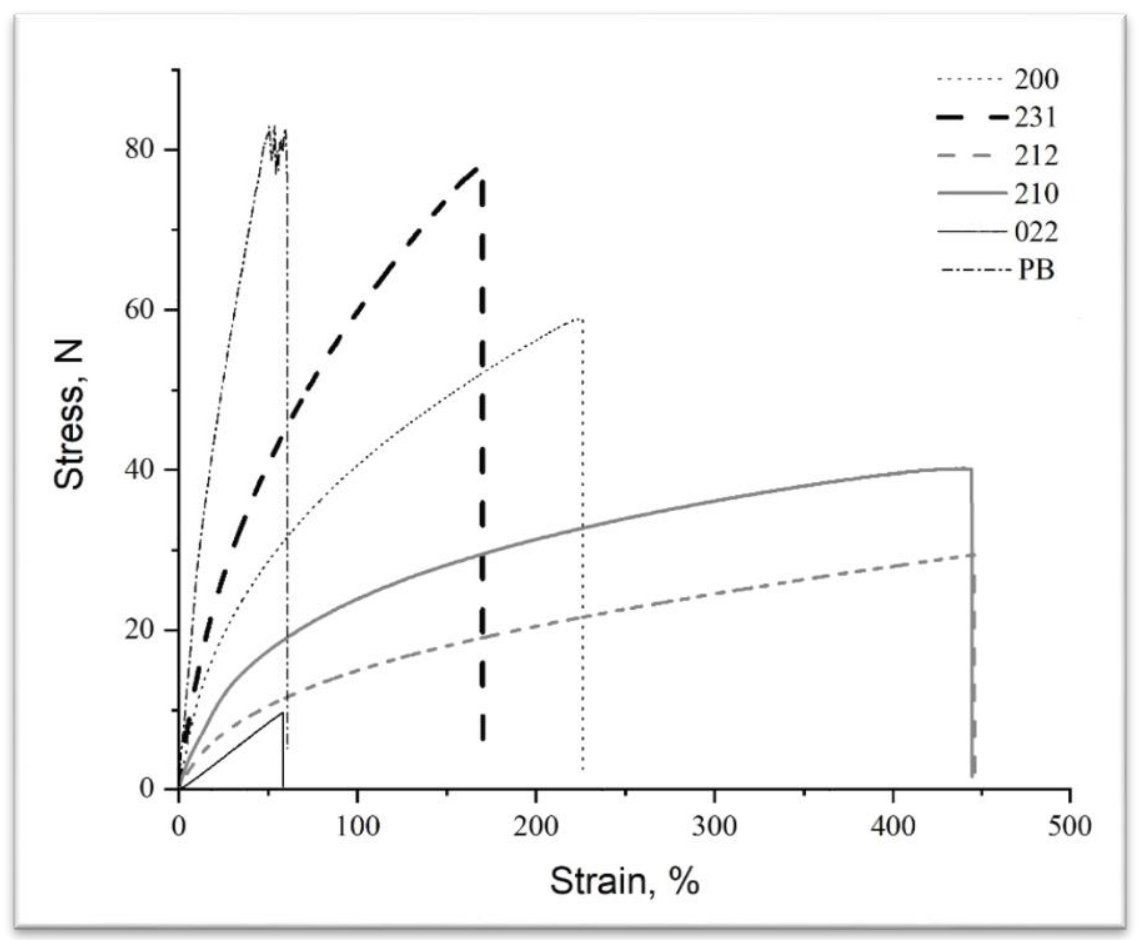

Figure 4.23.Strain/stress characteristics of developed PUFs and reference material.

Furthermore, if II exceeds 100, i.e. sample 231, where II is 140, tensile properties become affected by high crystallinity of the polymer. When polymer contains excessive concentration of HS, the movement of SS becomes restricted (Szycher 2013) and percent elongation plummets. Tensile characteristics of the samples are summarized in Table 4.11.

Table 4.11.Tensile characteristics of the PUFs and a reference material.

\begin{tabular}{|c|c|c|c|}
\hline Sample & Tensile strength, MPa & Tensile strain, \% & Modulus of elasticity, MPa \\
\hline 022 & $0.09 \pm 0.004$ & $58.5 \pm 7.05$ & $0.11 \pm 0.014$ \\
\hline 200 & $0.59 \pm 0.032$ & $226 \pm 14.53$ & $0.82 \pm 0.015$ \\
\hline 210 & $0.36 \pm 0.067$ & $430 \pm 8.97$ & $0.28 \pm 0.031$ \\
\hline 212 & $0.36 \pm 0.120$ & $444 \pm 3.50$ & $0.41 \pm 0.050$ \\
\hline 231 & $0.58 \pm 0.040$ & $161.5 \pm 5.93$ & $0.99 \pm 0.009$ \\
\hline PB & $1.83 \pm 0.560$ & $54 \pm 3.00$ & $3.7 \pm 0.580$ \\
\hline
\end{tabular}


To conclude, tensile characteristics of the developed PUFs were analyzed in the present section. Tensile strength of the samples is lower than the optimal value of $1 \mathrm{MPa}$, though is approaching the targeted value. Tensile strength can be further improved by attaching a textile support of adhesive backing on the insole, as in case of a reference PB material.

\subsubsection{Cushioning Properties}

Cushioning properties or the ability to bear and distribute weight is a key parameter of every insole material. Estimation of these characteristics is done through analysis of compression curves of PUFs. Moreover, cushioning test reflects better insole's functional performance than simple hardness or compression tests. According to Campbell et al.(1984), the synthesized samples can be categorized as moderately deformable materials with a compression curve displaying a high/moderate initial slope followed by a plateau region that gradually transforms into a steep slope in the final portion of the curve. Compression curves for the samples and the reference material are shown in Figure 4.24.

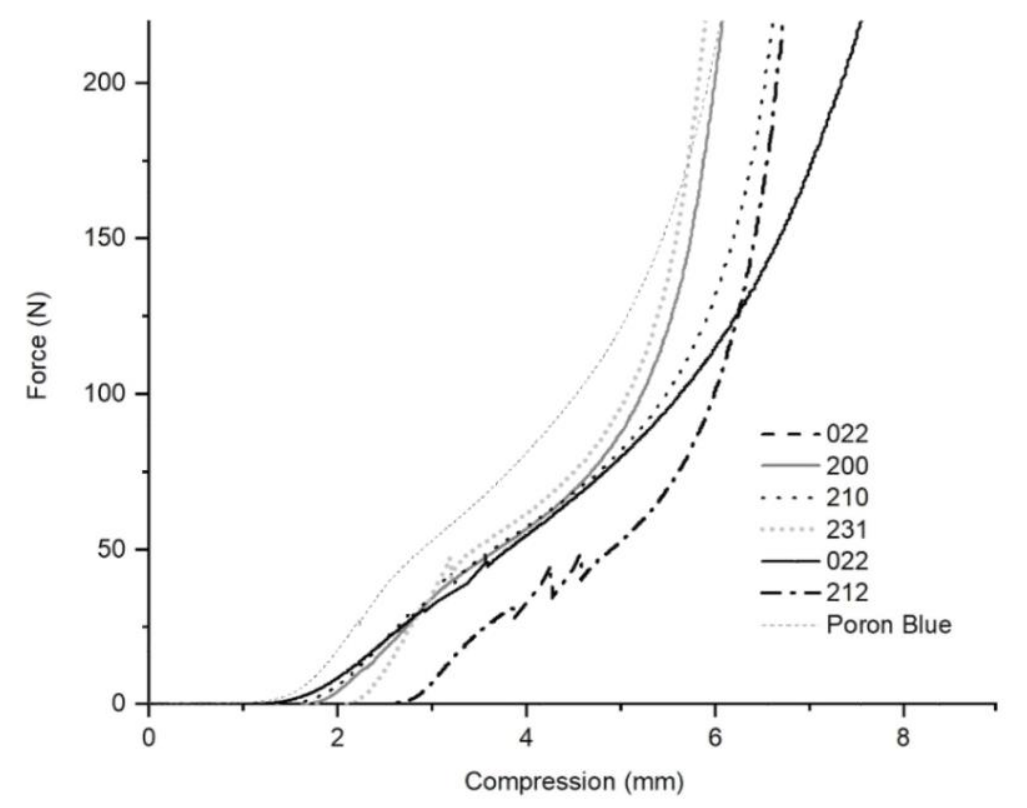

Figure 4.24. Compression curves for the developed PUFs and the reference material. 
According to SATRA 164 test, cushioning energy of the material corresponding to the area under the curve can be interpreted as a material toughness. Hence, the higher the toughness, the greater cushioning effect of the insole is likely to be in wear. Commercial material Poron Blue has the steepest curve and, as a consequence, the highest value of the cushioning energy (Table 4.12). This explains why Poron material is a widely recognized orthotics material.

Furthermore, rigid materials and very weak soft foams give low cushioning energy results since the former are incompressible and the latter "bottom out". Typical values for a wide range of commercial insoles are from 30 to $130 \mathrm{~N} \cdot \mathrm{mm}$ and the results depend on material thickness (Saraswathy et al. 2010).

Both cushioning energy and cushioning factor characterize the ability of the insole to absorb shock waves resulted from foot strike on hard surface. These two parameters can be estimated for running and walking tasks. As a result, all samples demonstrated the values of these two parameters close to the targeted values and can be recommended for use insole fabrication as effective protective insoles. It can be seen from Table 4.12 that the values of cushioning factor are slightly below the low threshold for samples 210 , 022, PB. Low cushioning factor values are associated with stiffer materials. This is also may be the case when the material has a textile cover (PB) or dense skin, as in case of PUFs.

Table 4.12. Cushioning energy and cushioning factor of the developed PUFs and a reference material.

\begin{tabular}{|c|c|c|c|c|c|}
\hline \multirow{2}{*}{$\begin{array}{c}\text { Sample } \\
\text { (thickness, mm) }\end{array}$} & \multicolumn{2}{|c|}{ Cushioning Energy, N·mm } & \multicolumn{2}{c|}{ Cushioning Factor } & \multirow{2}{*}{$\begin{array}{c}\text { Minimal insole } \\
\text { thickness (mm) }\end{array}$} \\
\cline { 2 - 5 } & Running & Walking & Running & Walking & 3.50 \\
\hline $200(7 \mathrm{~mm})$ & $277 \pm 13.89$ & $177 \pm 8.85$ & $5.4 \pm 0.27$ & $4.4 \pm 0.22$ & 2.20 \\
\hline $210(7 \mathrm{~mm})$ & $336.9 \pm 16.84$ & $210.9 \pm 10.54$ & $4.4 \pm 0.22$ & $3.7 \pm 0.23$ & 2.50 \\
\hline $022(7.5 \mathrm{~mm})$ & $466 \pm 23.33$ & $229.3 \pm 11.46$ & $3.7 \pm 0.18$ & $3.9 \pm 0.25$ & 3.50 \\
\hline $212(7 \mathrm{~mm})$ & $243.7 \pm 12.81$ & $152.8 \pm 7.64$ & $6.2 \pm 0.31$ & $5.1 \pm 0.26$ & 3.25 \\
\hline $231(6.5 \mathrm{~mm})$ & $264 \pm 13.20$ & $373.8 \pm 18.68$ & $4.9 \pm 0.24$ & $4.0 \pm 0.20$ & 2.10 \\
\hline PB $(6.5 \mathrm{~mm})$ & $373 \pm 18.69$ & $373.8 \pm 18.68$ & $3.7 \pm 0.24$ & $3.7 \pm 0.85$ & \\
\hline Targeted Value & Min. 100 & Min. 70 & $4-8$ & $4-8$ & \\
\hline
\end{tabular}


Availability of the cushioning factor for a given material makes it possible to determine the thickness of insole needed to achieve the required cushioning energy value. Therefore, the cushioning energy can be increased by increasing the thickness of the sheets. The optimum thickness required for all samples to achieve the CE of $70 \mathrm{~N} \cdot \mathrm{mm}$ was calculated and summarized in Table 4.12. Calculated thickness of the materials was used as a reference for insole prototype fabrication. The cushioning ability of the developed PUFs was evaluated in the present experiment. The new materials have cushioning properties resembling a reference material PB and have a potential to be applied as a new type of orthotic materials with increased weight bearing characteristics.

\subsection{DSC Analysis}

Differential Scanning Calorimetry (DCS) is a versatile technique that enables us to study composition of the samples and temperature transitions taking place as a response to a temperature change. The degree of phase separation of PUF can also be studied by DSC method. The thermogram of a pure PO3G polymer is presented in Figure 4.25, left. PO3G polymer is high molecular weight polyether comprising SS of the PUFs. The thermogram demonstrates typical transitions for amorphous PO3G polymer including a steplike transition at $-75.65^{\circ} \mathrm{C}$ representing the glass transition temperature $\mathrm{T}_{\mathrm{g}}$ (Figure 4.25 , right), exothermal peak at $-54{ }^{\circ} \mathrm{C}$ stands for cold temperature crystallisation $\left(\mathrm{T}_{\mathrm{c}}\right)$ and endothermal peaks at $16-34{ }^{\circ} \mathrm{C}$ are due to melting $\left(\mathrm{T}_{\mathrm{m}}\right)$ of a polydisperse polymer. These values are in good agreement with the literature (Ruan et al. 2019). 

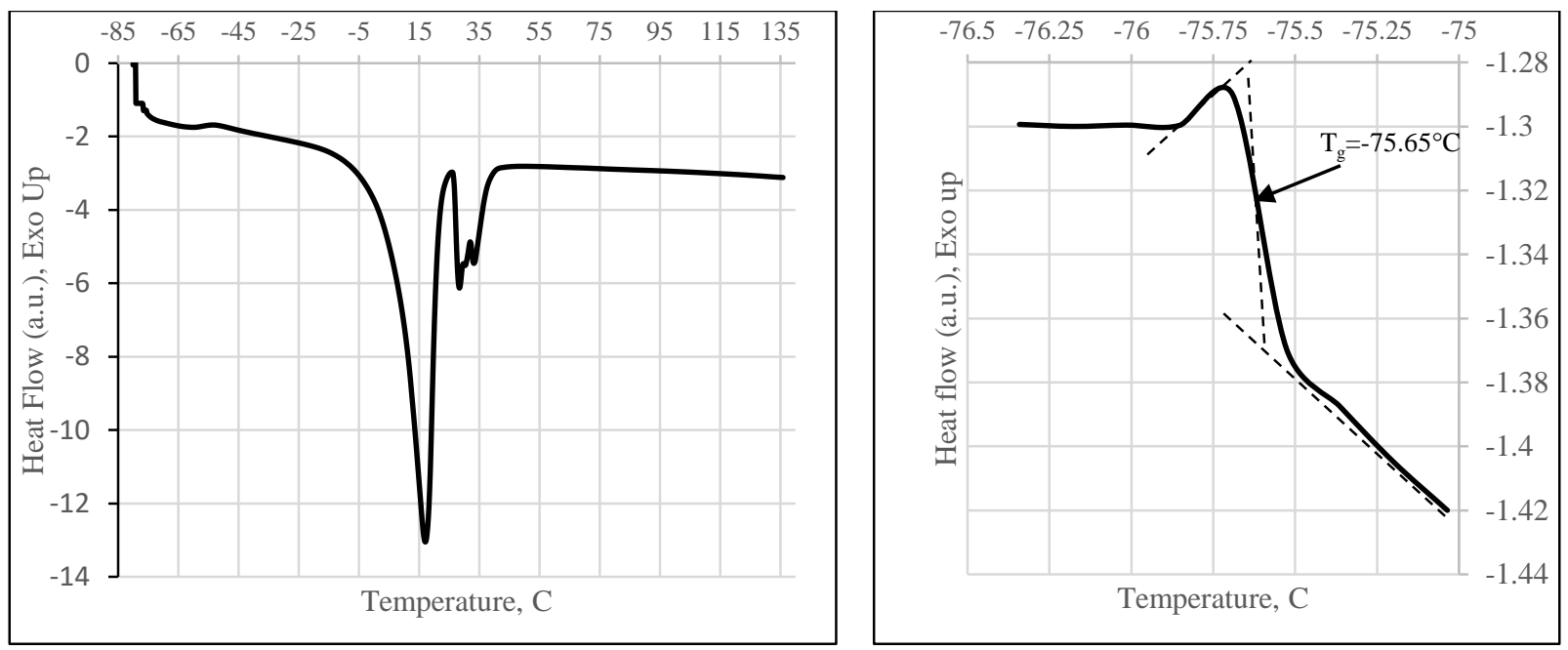

Figure 4.25. DSC thermogram of PO3G polymer (left) and enlarged section of the plot for PO3G representing glass transition (right).

Characteristic transitions for PO3G can be found in PUFs containing PO3G as part of SS. It is also possible to make conclusions about the degree of phase separation based on the shift of $\mathrm{T}_{\mathrm{g}}$ as it follows from the research done by (Saraswathy et al. 2009).

DSC thermograms for the PUFs are shown in Figure 4.26. As can be seen from the figure, all samples demonstrate the $\mathrm{T}_{\mathrm{g}}$ of SS characteristic for PO3G. In case of samples 212, 231, 022, and 210, the temperature of glass transition has shifted toward positive values implying that the movement of polyether chains is restricted, hence the domains are not well-organised in the PUFs. On the contrary, $T_{g}$ of 200 has slightly shifted towards negative range, hence demonstrating the polymer with high degree of phase separation. Moreover, samples 200 and 210 are displaying the other characteristic features of SS, i.e. cold temperature crystallisation and melting temperatures. These PUFs have lower II than the remaining samples, hence less HS that restrict the ability of SS to crystallize.

Furthermore, DSC thermogram demonstrates that samples 212,210 , and 231 are stable up to $250^{\circ} \mathrm{C}$, while 200 and 022 start to decompose at the temperatures beyond $215^{\circ} \mathrm{C}$, which can be concluded from the presence of the endothermal shift of DSC curve. 


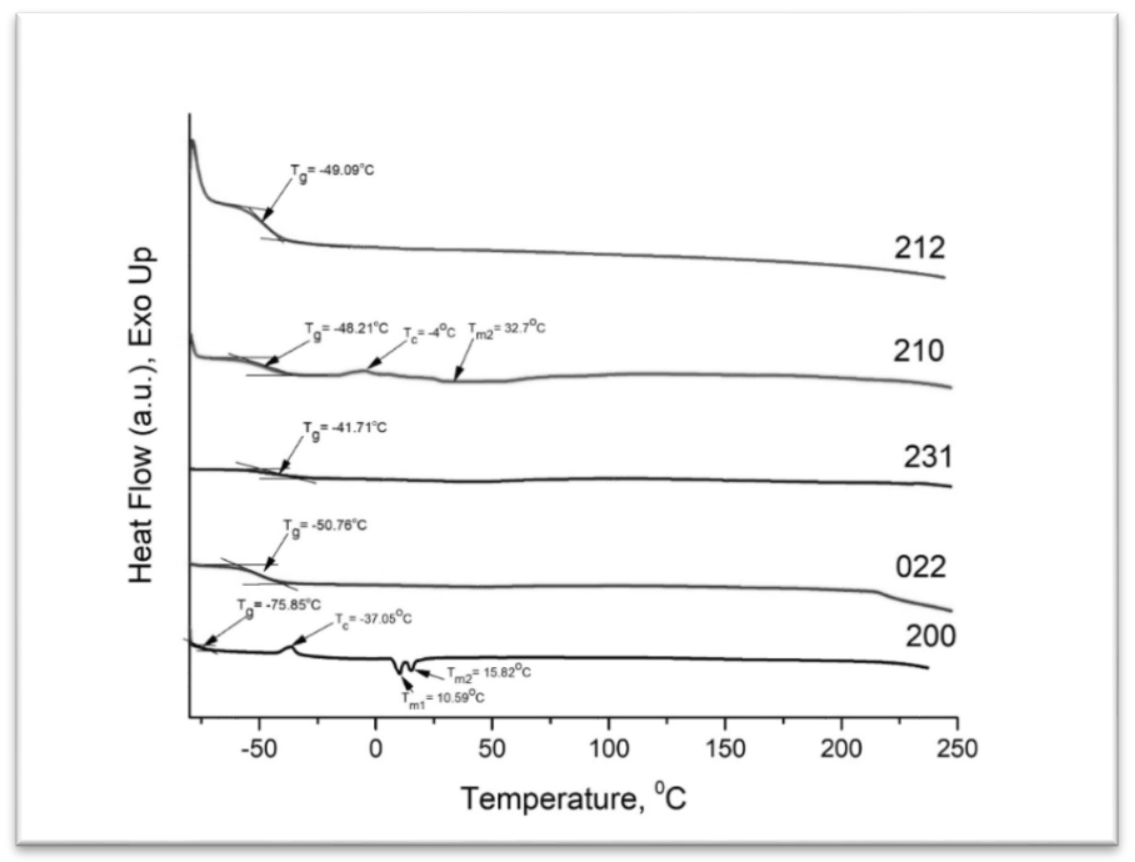

Figure 4.26. DSC thermogram for the developed PUFs.

Conclusions made based on DSC analysis are well aligned with the results of FTIR analysis of the PUFs (Figure 4.27). The samples with higher degree of phase separation have more pronounced adsorption bands corresponding to $\mathrm{H}$-bonded $\mathrm{N}-\mathrm{H}$ group at $3305-3310 \mathrm{~cm}^{-1}$, hydrogen bonded carbonyl groups of urea linkage at $1639 \mathrm{~cm}^{-1}$, and urethane linkage at $1694 \mathrm{~cm}^{-1}$.

In summary, the developed PUFs demonstrate various degree of phase separation depending on the composition. Sample 200 is most phase-separated which can also explain its unique tensile characteristics and elasticity. On the other hand, samples 231, 022, and 212 are rather phase-mixed due to presence of high amount of HS in their structure. The fact of phase separation is also confirmed by FTIR studies. 


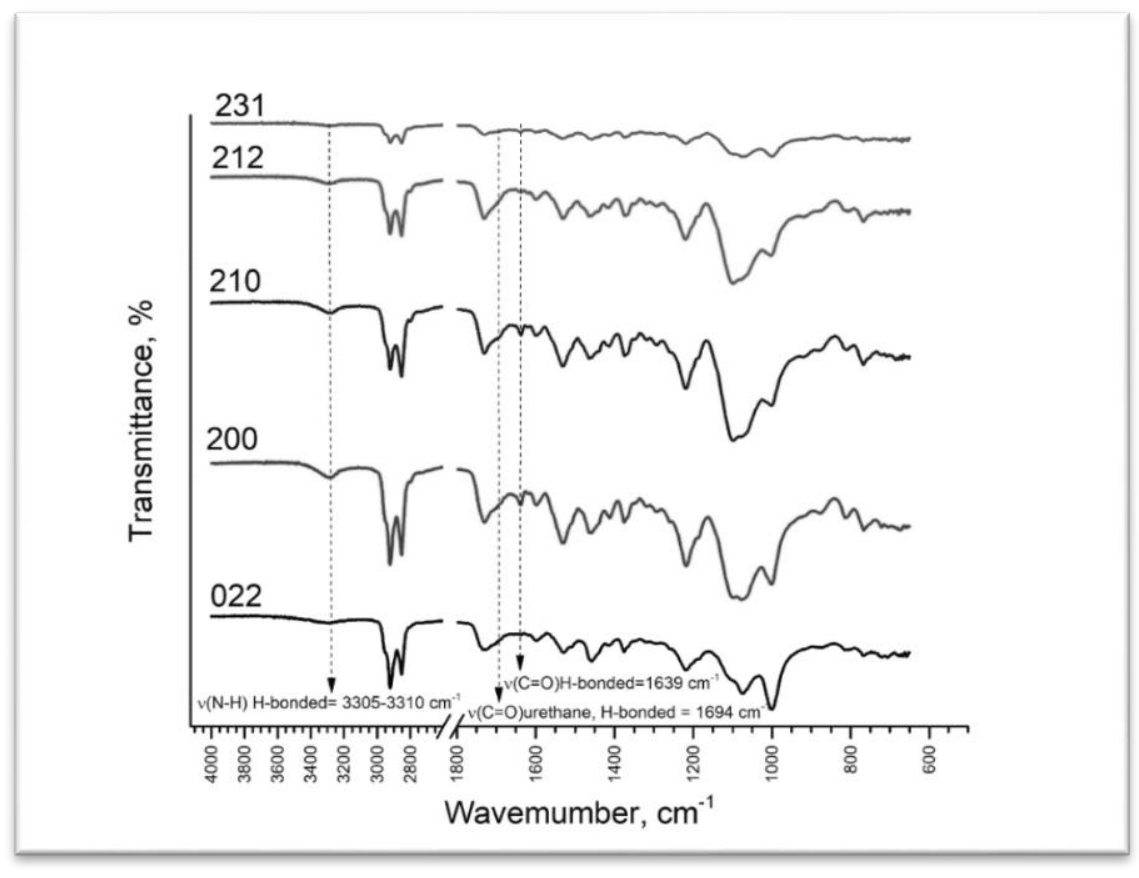

Figure 4.27. Change in transmission in the samples with various degree of phase separation

\subsection{Anaerobic Soil Biodegradation}

The aim of the present research was to study the biodegradation of the PUF derived from CO and PO3G which is a renewable, natural material and can be regarded as a practical alternative to traditional polyurethane foams. Due to molecular structure of $\mathrm{CO}$, which contains polyester segments derived from vegetable oil, the polymeric surface is susceptible to microorganism attack. Biodegradability of castor oilbased PUFs can be studied through solid media agar-agar tests (Cangemi et al. 2008) or by soil burial method as done in the research by Urgun-Demirtas et al. (2007) and Gnanasundaram et al. (2015). Agaragar tests involve bacterial strains that does not naturally occur in the environment. On the other hand, during soil burial test only bacteria naturally present in the soil decompose the samples. Hence, soil burial method is more realistic and simple than laboratory growth media tests. The anaerobic soil biodegradation is close to environmentally benign conditions. 
The majority of petroleum-based foams are not biodegradable and as a result become one of the ecological threats. Despite well-established physical recycling methods for PUF wastes, only up to $80 \%$ of initial PUF can be reused and the remaining polyurethane foam is finally landfilled (Yang et al. 2012). In this case, biodegradation ability of PUF is advantageous. The PUFs described in the present study combine two types of polyols: $\mathrm{CO}$ as a natural polyether and PO3G as a natural polyester. While biodegradation of CO-based foams is a proven fact, polyester-based PUFs are known for their stability and much better resistance to hydrolysis. At the same time, PO3G material as a corn-originated polyether is known to be biodegradable. For this reason, biodegradation of the developed PUFs has become an interesting research subject.

The structural changes in the foam were assessed with SEM and optical spectroscopy. Also, changes in FTIR spectra served as a proof of ongoing biodegradation. Destruction of polyurethane material is typically accompanied by mass loss and it is for this reason that this factor was also examined. SEM images of treated and untreated PUFs are presented in Figure 4.28. It is clearly seen that the image of the foam that underwent soil biodegradation has a surface morphology change, namely, white regions representing micro cracks and holes are observed. Optical microscopy images demonstrate more vividly the changes in cell strut morphology of PUF before and after 2 and 4 months of soil biodegradation (Figure 4.29). Despite the fact that the image for reference foam was done after 4 months from the date of foam's synthesis, the cell struts are smooth and do not have defects. However, micro cracks are visible on the struts after 2 months of biodegradation and become more pronounced after 4 months' residence in the soil media. In other words, anaerobic soil environment affects the morphology of PUF sample causing its slow deterioration. 

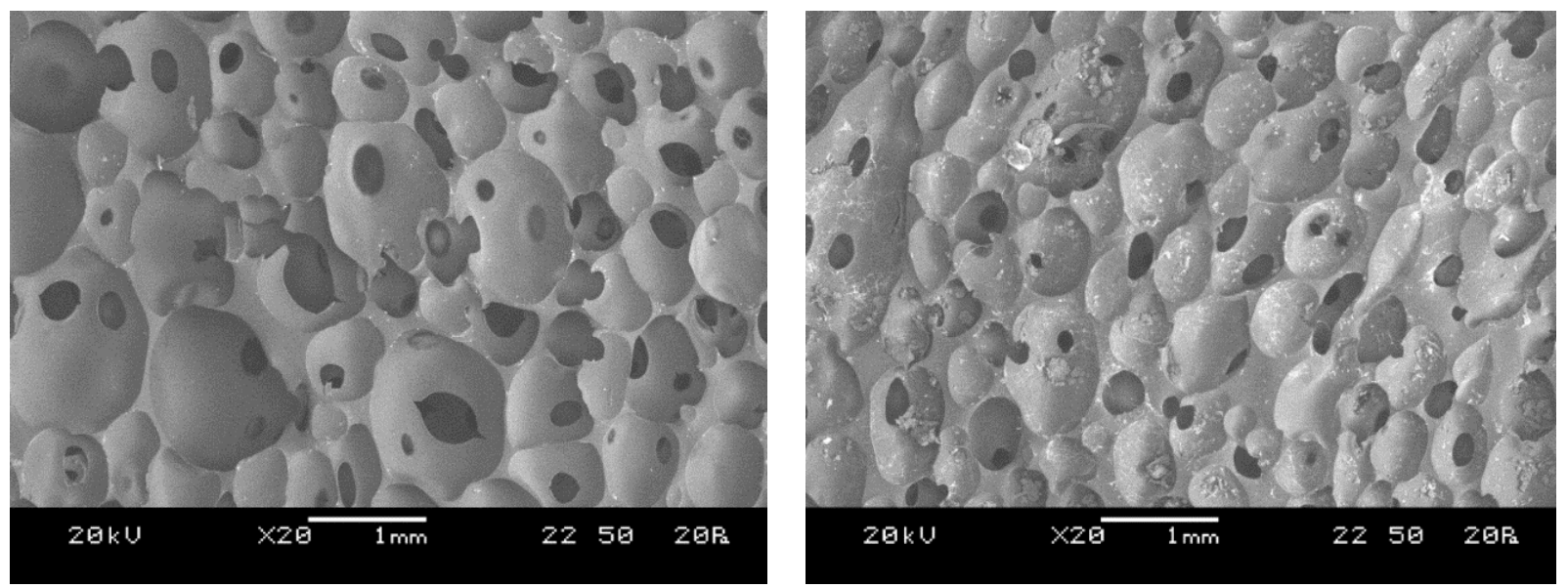

Figure 4.28. SEM images of pristine foam (left) and after 2 months of anaerobic biodegradation (right). Sample 200.
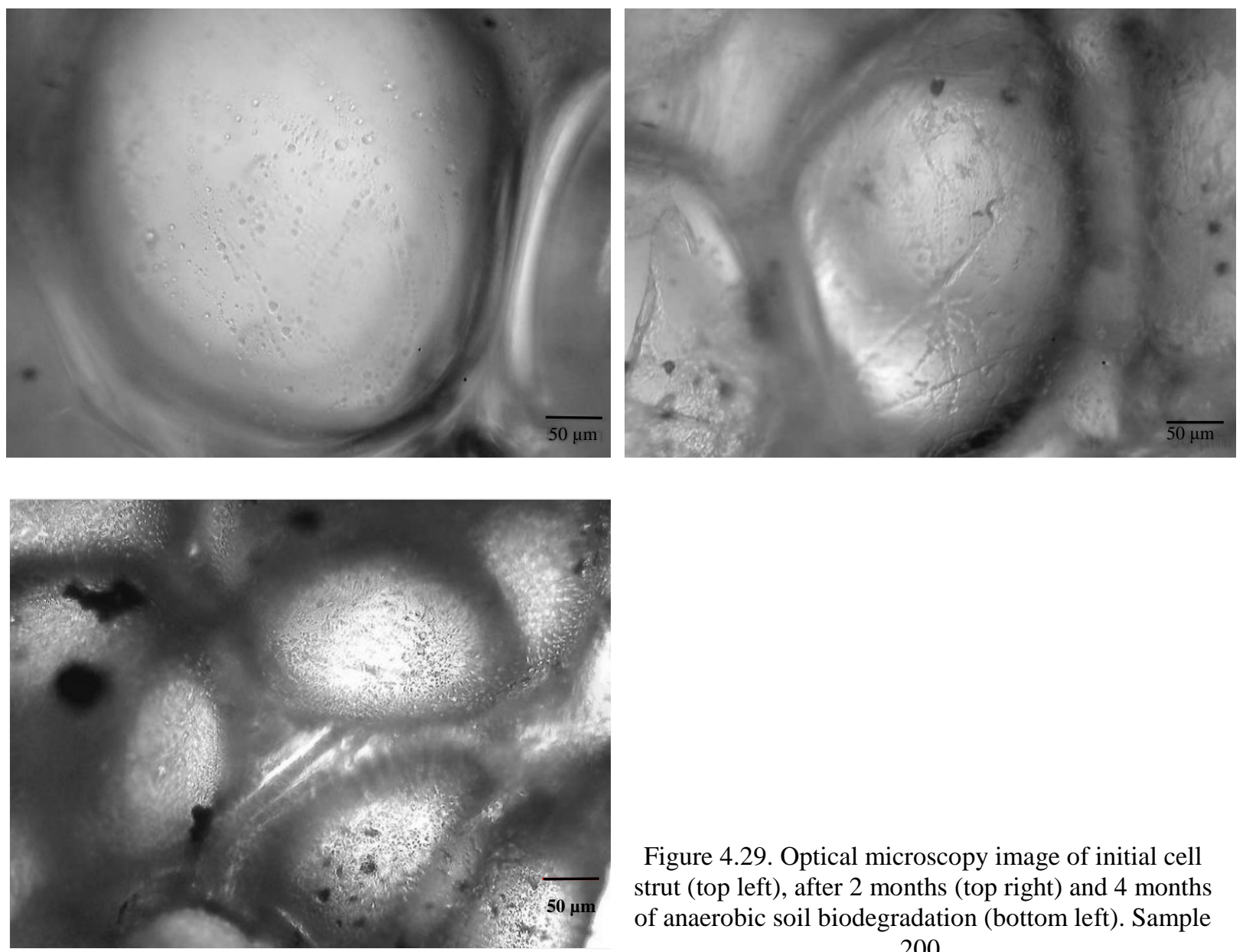

Figure 4.29. Optical microscopy image of initial cell strut (top left), after 2 months (top right) and 4 months of anaerobic soil biodegradation (bottom left). Sample 200. 
In order to substantiate the conclusions of visual PUF examination, spectral changes have been investigated. FTIR spectra of the reference foam before and after degradation are represented in Figure $4.30(A-C)$. Distinct spectral changes are observed in the N-H region of the PUF. The band at 3305-3310 $\mathrm{cm}^{-1}$ shifted to high frequency region which is explained by weakening of $\mathrm{N}-\mathrm{H}$ bonds in the polyurethane (Ferreira et al. 2017). $\mathrm{C}=\mathrm{O}$ absorption band at $1643 \mathrm{~cm}^{-1}$ (strongly $\mathrm{H}$-bonded, bidentate urea) loses intensity which corresponds to the formation of monodentate urea as it follows from the research by (Dounis et al. 1993). It is also possible to observe that the $\mathrm{C}=\mathrm{O}$ band at $1725 \mathrm{~cm}^{-1}$ shows a slight shift (to higher frequencies, $1735 \mathrm{~cm}^{-1}$ ) and broadening (Figure 4.30, B). This could corroborate the formation of carboxylic acidic species and formates due to the scission of SS chains (Wilhelm, Rivaton, and Gardette 1998). In addition, significant decrease of the band at $1537 \mathrm{~cm}^{-1}$ and $1237 \mathrm{~cm}^{-1}$ (Figure 4.30, Panel C) can be attributed to the homolysis of N-C bonds from the urea linkages in the HS.

From this approach, an insight into PUF deterioration is suggested based on prospective relationships between visual aspects and molecular fingerprints of the objects. The first visual signs of PUR foam physical deterioration (loss of transparency and formation of micro holes) may be related to the chain scission of the polyether/polyester soft segment and/or to the possible release of volatile compounds (micro holes). The development of micro cracks and ruptures on the cell bun may be a consequence of the elimination of some hydrogen-bonding interactions between HS chains in addition to the previously mentioned molecular changes. 


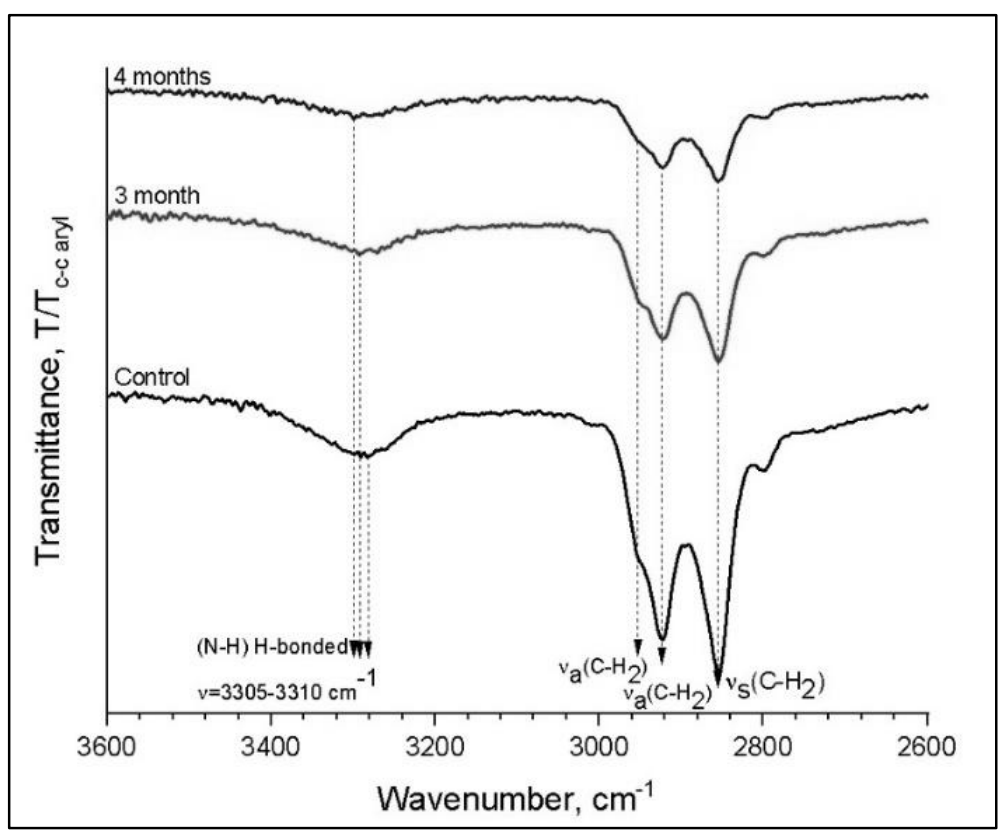

A

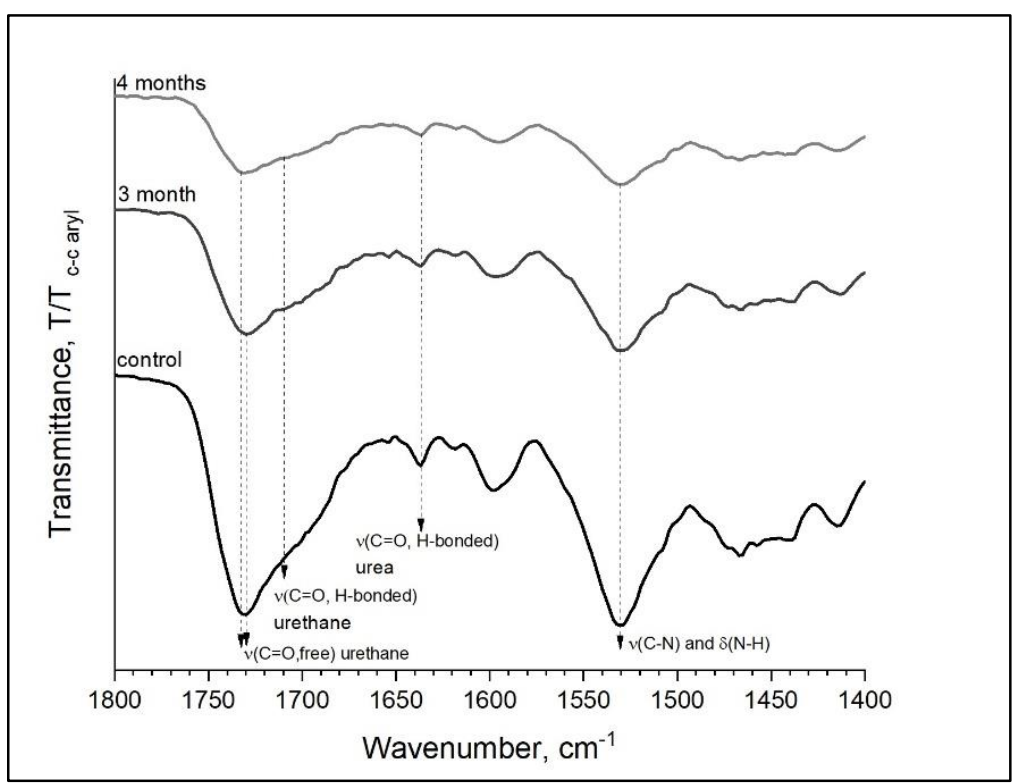




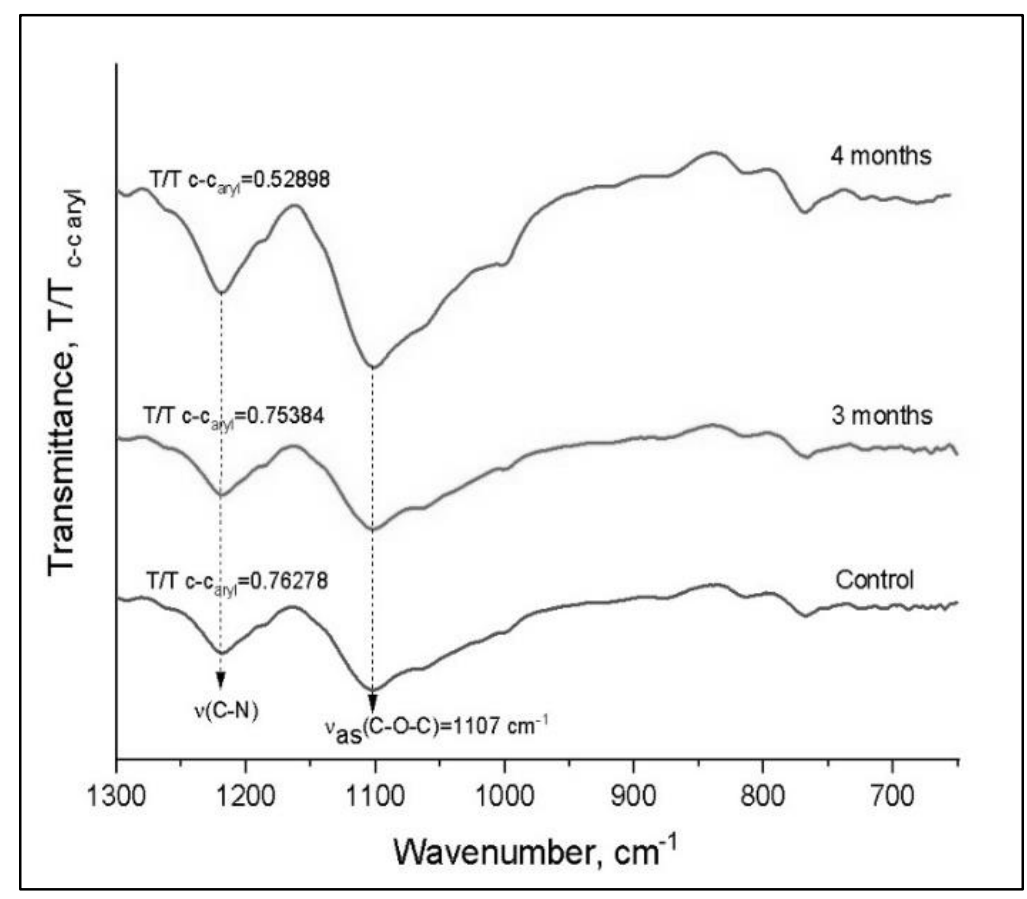

$\mathrm{C}$

Figure 4.30. Spectral changes in $\mathrm{N}-\mathrm{H}, \mathrm{C}-\mathrm{H}$ absorption region (A), $\mathrm{C}=\mathrm{O}$ absorption (B) and $\mathrm{C}-\mathrm{O}-\mathrm{C}$ (C) absorption regions of bio-degraded PU foams.

Variations in weight and mechanical properties of the PUF were also evaluated. As follows from Figure 4.31 and Table 4-13, the samples loose elasticity after being exposed to soil media. According to this figure, the material becomes denser and more brittle after 2 months and undergo further weakening after 4 months of biodegradation. Analogous changes in tensile properties for $\mathrm{CO}$ based PUFs were described by Wang et al. (2008) 


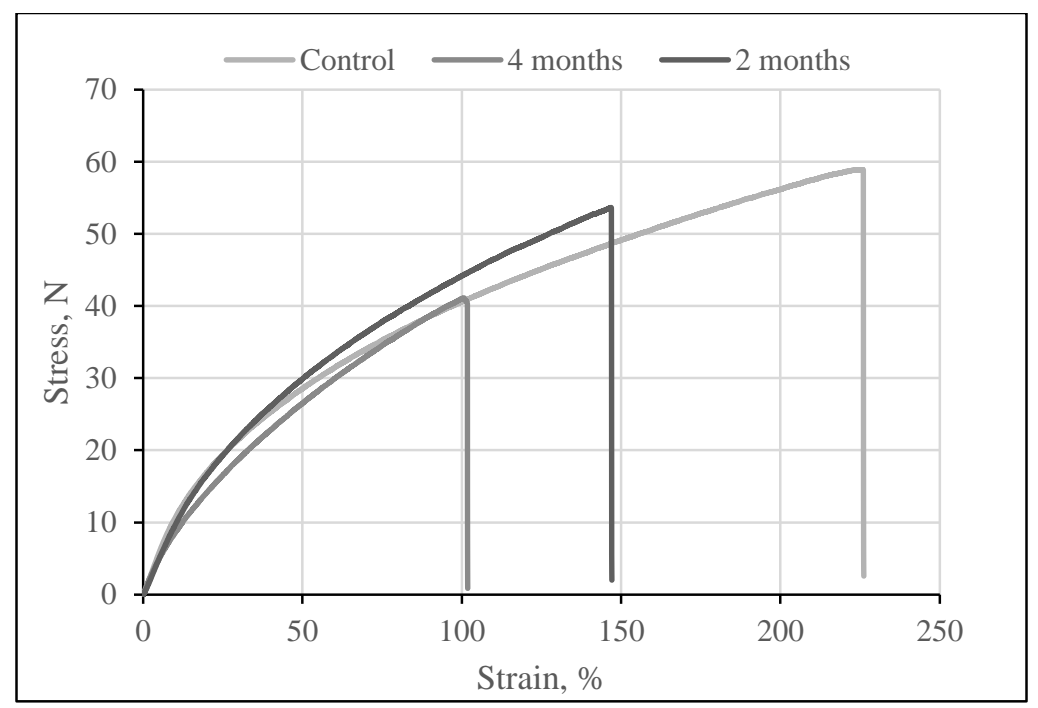

Figure 4.31. Change in mechanical properties for treated foam samples and control PUF. Sample 200.

Table 4.13. Tensile characteristics of PUF samples after 2 and 4 month of anaerobic soil biodegradation and untreated control sample.

\begin{tabular}{|c|c|c|c|}
\hline Sample & Tensile strength, MPa & Tensile strain, \% & Modulus of elasticity, MPa \\
\hline Control & $0.51 \pm 0.004$ & $210 \pm 7.05$ & $0.82 \pm 0.140$ \\
\hline 2 months & $0.41 \pm 0.032$ & $140 \pm 14.53$ & $0.69 \pm 0.015$ \\
\hline 4 months & $0.31 \pm 0.067$ & $93 \pm 8.97$ & $0.75 \pm 0.031$ \\
\hline
\end{tabular}

Finally, treated samples of PUF demonstrate a weight change in comparison to untreated specimens. The results of the analysis are summarized in Figure 4.32. According to this figure, treated and untreated samples demonstrate change in weight (however, weight loss of the samples exposed to soil environment is more pronounced for control samples). As it was described in earlier research (Hillier, Schupp, and Carney 2003), PUF may loose weight due to evaporation of residual water and emission of VOC. Analogous process can also occur in treated samples, however the results of FTIR analysis demonstrating internal changes (pattern of hydrogen bonding, weakening of hard segments) allude that the ongoing process is explained by chemical and physical perturbations in the structure of PUF. Despite the presence of the weight loss process, the reduction in sample's weight does not exceed 3.98\% (on average) after 4 months of experiment. 


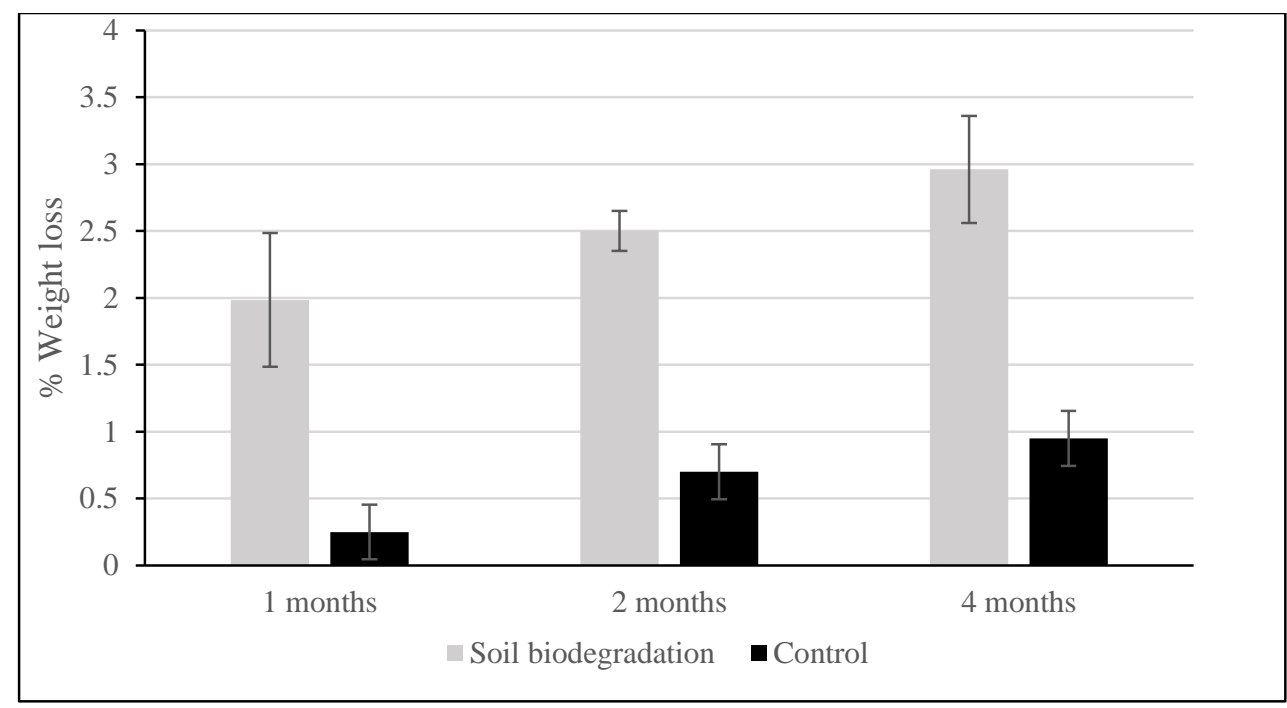

Figure 4.32.Weight loss of PUF samples after soil biodegradation versus reference samples. Sample 200

To conclude, the developed PUF formulation is susceptible to microbial biodegradation when exposed to soil media in anaerobic conditions. The samples demonstrated visual signs of biodegradation as well as characteristic spectral changes, deterioration of mechanical properties and weight loss. Mechanical properties were impacted significantly during the experiment. On the other hand, the weight loss of PUFs comprising polyether polyol goes slower than for PUFs where a sole source of -OH groups is $\mathrm{CO}$ (Wang et al. 2008). Total weight change after 4 months of experiment has reached only $2.99 \%$ on average. This important result demonstrates that the presence of renewably sourced polyether PO3G increases stability of the PUF material as it is true in case of petroleum-originated polyether. 


\section{CHAPTER 5. CONCLUSIONS AND FUTURE WORK}

\subsection{Conclusions}

Interaction of human's foot with the hard surface produces ground reaction forces which adversely affect musculoskeletal system. Hence, there is a need in protection of the foot against these forces in order to avoid injuries, ligaments tension, and soft tissue damage. A safe and simple remedy is the application of shock absorbing insoles/orthotics. Moreover, the level of shock absorption and pressure distribution is crucial for the development of WBMS device. In addition to therapeutic effect, the presence of protective cover in the WBMS device decreases plantar pressure and provides extra comfort feeling to a patient.

Literature review conducted in Chapter 2 demonstrated available testing methodologies and revealed the most favourable materials with high degree of shock attenuation. Among the presented studies, a majority of researchers agree that PU foams, PU elastomers (individually or combined) are a category of the materials with more pronounced weight-bearing properties and durability. The existing literature could only establish which class of materials (by polymeric nature) is most beneficial for a quality shock absorbing insole productions. At the same time, the available information about physical and mechanical properties of the test specimens is rather scarce. Thus, the link between mechanical characteristics and enduse performance remains obscure. For this reason, the methodology and set of parameters-to-be-designed is adopted from SATRA specifications. Standards developed by SATRA are highly respected in industry and rationality of chosen values was confirmed by comparison of its parameters with Poron ${ }^{\circledR}$, Plastazote ${ }^{\circledR}$, and Sorbothane ${ }^{\circledR}$ materials.

The analysis of research studies on PU foams demonstrated that a very limited effort has been done on the development of materials for footwear application. In particular, bio-based and biodegradable PU materials are mainly suggested for tissue engineering and biomedical purposes, however, it was found that these materials exhibit comparable strength and stability and can be applicable in large scale industrial 
processes. In light of this idea, the design of nature-originated and eco-friendly footwear components is an attractive area of research.

Besides biocompatibility and sustainability of the material, considerations made about WBMS operation requirements were taken into account. In this regard, $\mathrm{PO} 3 \mathrm{G} / \mathrm{CO}-\mathrm{based}$ polyurethane foam having moderate degree of crosslinking and demonstrating necessary viscoelastic properties was chosen as optimal for WBMS design. This material is bio-based, affordable, biodegradable, and easy to produce.

The present study demonstrated that suggested formulation of PUF can be prepared using combination of pre-polymer method and heat curing. Characteristic parameters for PUF formulation such as tack-free time and demould time are in the range of $18 \pm 5.2$ minutes which makes the proposed formulation suitable for application through RIM technique.

The effect of polyol ratio, II, and the blowing agent was studied by means of BB RSM. On the one hand, the proposed models for hardness and density as response variables appeared to be valid for general evaluation of the parameters' change. On the other hand, these models fail to determine instability of some of the formulations. Changes in PUF composition have an intricate effect on foams density and hardness. Despite theoretical expectations, the samples with highest CO content were found to be softer due to contribution of residual fatty acids comprising CO.

Mechanical testing of the samples demonstrated that in most cases PUFs with densities of 0.2-0.3 $\mathrm{g} / \mathrm{cm}^{3}$ and hardness in range of Shore A 15-22 demonstrate sufficient strength and weight-bearing characteristics. CS of the materials was as low as $0.5 \%$ which is superior to current commercial materials (e.g., Plastozote $\left.{ }^{\circledR}\right)$. Increase in temperature leads to a slight softening of the foam and results in CS of $9 \%$ on average (which is in the allowable range as compared to the commercial insole material Poron® Blue).

As demonstrated by DSC analysis, the synthesized specimens have various morphology depending on the composition. The samples with lower II and higher PO3G content (210 and 200) were found to have a well phase-separated structure, and the samples with higher II (and as a consequence with higher HS content) are rather phase-mixed. These results were previously reported in the literature (Konieczny and Loos 2019; Ruan et al. 2019). The impact of composition on the elastic properties was also studied in 
present research. As was hypothesized, the elasticity of the samples is direct proportional to high molecular polyether(PO3G) content and is inversely proportional to HS content in the PUFs.

The developed CO/PO3G/TDI formulations fall into category of "green" biodegradable materials based on results of degradability studies. Soil burial experiment indicated susceptibility of the samples to microbial attack when being exposed to the environment. Due to presence of high amount of polyether PO3G, the developed polyurethane formulations do not exhibit significant mass loss after 4 months of the experiment. On the other hand, mechanical properties of the samples were highly impacted.

In conclusion, the main contribution of the present work was finding an optimum ratio of components in a new renewably-sourced formulation $(\mathrm{CO} / \mathrm{PO} 3 \mathrm{G} / \mathrm{TDI})$ in order to achieve required properties of the end product (protective insole). As it follows from the outlined research results, several PUF samples satisfy the major requirements for quality shock absorbing materials, i.e. CE of the produced samples is higher than $70 \mathrm{~N} \cdot \mathrm{mm}$ and $\mathrm{CF}$ of the produced samples is in the range of 4-8. This, in turn, ensures superior pressure distribution and shock adsorption properties that are essential for stable functioning of FSR sensors. Taking into account hygienic properties and dimensional stability of the foams after application of steady loading at elevated temperatures, the CO/PO3G-based foams can be recommended for application in WBMS device. 


\subsection{Further recommendations}

It is recommended to further improve conditions of PUF synthesis in order to achieve higher reproducibility of the experiments. Since synthesis conditions can affect batch-to-batch variation, it is necessary to conduct a hierarchal experiment to further clarify the impact of mixing speed, mixer design, and pre-polymer viscosity on density of the specimens. Optimization of these conditions will eliminate air entrapment in the pre-polymer solution and further augment the proposed BB RSM model.

In terms of analysis, the next step includes DMA studies and TGA analysis of the samples. DMA test is necessary to estimate the change of PUF characteristics over a wide range of temperatures and further elucidate the link between the composition and cushioning properties. In addition, thermal stability of the PUFs can be measured by performing TGA of the samples. The present study is restricted only to DSC test; however, TGA will confirm stability and mass loss of the samples at broader heating ramp. Analysis of polymer structure can be performed via X-ray diffraction, that is commonly applied to elucidate the structure of polyurethane hard segments and the pattern of phase separation.

Another attractive area of research is reinforcement of the developed formulation with eco-friendly fillers as, for instance, aerogel or calcium carbonate. The foams with decreased thermal conductivity as in case of aerogel nanocomposite will significantly broaden the area of applications for this material. In particular, the resultant foam can be utilized for thermal protective footwear and insulation as described by Yang et al.(2018). Besides economical effect, the addition of calcium carbonate may augment the mechanical properties of the foam (Agarry et al. 2015) and improve a weight-bearing characteristics.

The next logical step towards a "greener" PUF is then, of course, the use of partially or potentially bio-based di-, tri-, or poly-isocyanates. While synthetic pathways to bio-based isocyanates still require phosgene as a petroleum-based reagent, there exist several commercial isocyanates with high renewable content such as isocyanates based on fatty acids or amino acids (Konieczny and Loos 2019). In a very inspiring recent research by Gustini et al. (2016), the L-lysine based ethyl ester L-lysine diisocyanate was 
compared to petrol-based hexamethylene diisocyanate, and isophorone diisocyanate in terms of reactivity and final properties of the PUF. Therefore, fully renewable PUFs can be produced. 


\section{APPENDICES}

Appendix A: Properties of commercial materials.

Table A.1. Summary of benefits and drawbacks of various types of commercial insole materials.

\begin{tabular}{|c|c|c|c|c|}
\hline Insole material & & name & Pros & Cons \\
\hline \multirow{4}{*}{ PUF } & Herbiprex® Lite & Poron $®$ & \multirow{4}{*}{$\begin{array}{l}\text { High level of shock absorption; } \\
\text { Ease of manufacturing; } \\
\text { Good air permeation; }\end{array}$} & \multirow{4}{*}{$\begin{array}{l}\text { Medium durability } \\
\text { Not biodegradable }\end{array}$} \\
\hline & Herbiprex® & Isoloss $®$ & & \\
\hline & Isoloss ${ }^{\circledR}$ & Cleron ${ }^{\circledR}$ & & \\
\hline & PPT® & Podiane ${ }^{\circledR} \mathrm{I}+$ perforado & & \\
\hline \multirow{7}{*}{ EVA } & Nora ${ }^{\circledR}$ Lunasoft SLW & Puff® & \multirow{7}{*}{$\begin{array}{l}\text { Good cushioning and support } \\
\text { properties; } \\
\text { Can be molded to the foot; }\end{array}$} & \multirow{7}{*}{$\begin{array}{l}\text { Low durability; } \\
\text { No air permeation; }\end{array}$} \\
\hline & Herbal Foam ${ }^{\circledR}$ Duro & Ethafoam ${ }^{\circledR}$ & & \\
\hline & Dr. Scholl's® insoles & Evamic $\AA$ & & \\
\hline & Nickelplast ${ }^{\circledR}$ & Nora $\circledast$ Lunalastik & & \\
\hline & Ortheva ${ }^{\circledR}$ & Dermaplast ${ }^{\circledR}$ & & \\
\hline & Orthomic $\AA$ & Step2 Evolution® & & \\
\hline & Nora ${ }^{\circledR}$ Lunairmed & Evazote $\AA$ & & \\
\hline
\end{tabular}


Table A.1 continued...

\begin{tabular}{|c|c|c|c|c|}
\hline Insole material & & name & Pros & Cons \\
\hline \multirow{4}{*}{ PE cross-linked } & Pelite® & Vitrathene ${ }^{\circledR}$ & \multirow{4}{*}{$\begin{array}{l}\text { Good initial cushioning properties; } \\
\text { Ease of manufacturing; }\end{array}$} & \multirow{4}{*}{$\begin{array}{l}\text { Medium/low durability; } \\
\text { Can be custom molded; }\end{array}$} \\
\hline & Aliplast@ & Podialene ${ }^{\circledR}$ & & \\
\hline & Gait Aid® & Plastazote ${ }^{\circledR}$ & & \\
\hline & Vitrathene ${ }^{\circledR}$ & & & \\
\hline \multirow{3}{*}{ Latex } & & & \multirow{3}{*}{$\begin{array}{l}\text { Low friction coefficient; } \\
\text { Good initial cushioning } \\
\text { performance; } \\
\text { Environmentally friendly }\end{array}$} & \multirow{3}{*}{ Low durability; } \\
\hline & suptrat A & 40100 & & \\
\hline & Verde ${ }^{\circledR}$ & Molo® & & \\
\hline \multirow{2}{*}{ PU Elastomers } & Sorbothane® & Epoflex® & \multirow{2}{*}{$\begin{array}{l}\text { High supporting factor; } \\
\text { high durability; }\end{array}$} & \\
\hline & Viscolas ${ }^{\circledR}$ & & & Not biodegradable \\
\hline \multirow[t]{2}{*}{ Neoprene foam } & Spenco® & Lynco® & \multirow{2}{*}{$\begin{array}{l}\text { Air permeability; } \\
\text { Good initial cushioning } \\
\text { performance; }\end{array}$} & \multirow{2}{*}{$\begin{array}{l}\text { Low durability; } \\
\text { Possible allergic reaction; }\end{array}$} \\
\hline & Neoprene-R® & & & \\
\hline
\end{tabular}

Table A.1 continued on the next page. 


\begin{tabular}{|c|c|c|c|}
\hline Insole material & Brand name & Pros & Cons \\
\hline PVC foam & Dynafoam ${ }^{\circledR}$ & $\begin{array}{l}\text { Medium durability; } \\
\text { Good initial cushioning; } \\
\text { Good thermal insulation properties }\end{array}$ & $\begin{array}{l}\text { No recyclable; } \\
\text { Not biodegradable; } \\
\text { No air permeation }\end{array}$ \\
\hline PMMA & Plexidur ${ }^{\circledR}$ & $\begin{array}{l}\text { Good durability; } \\
\text { Medium/good cushioning; }\end{array}$ & $\begin{array}{l}\text { No air permeation; } \\
\text { Not biodegradable; }\end{array}$ \\
\hline TPU gel/silicon rubber & MaxaCane ${ }^{\circledR}$ & $\begin{array}{l}\text { Good durability; } \\
\text { Good cushioning performance; }\end{array}$ & $\begin{array}{l}\text { No air permeation; } \\
\text { Not biodegradable; }\end{array}$ \\
\hline Felt & Ortho $\circledR_{\text {felt }}$ & $\begin{array}{l}\text { Environmentally friendly; } \\
\text { Good thermal properties; } \\
\text { Good initial supporting properties; } \\
\text { Good air permeability; }\end{array}$ & Low durability; \\
\hline Cork & Corkacell ${ }^{\circledR}$ & $\begin{array}{l}\text { Environmentally friendly; } \\
\text { Good thermal properties; } \\
\text { Good initial supporting properties; } \\
\text { Good air permeability; }\end{array}$ & Low durability; \\
\hline 3-D spacer fabric & Airsole $®$ & $\begin{array}{l}\text { Good Air permeability; } \\
\text { Good initial support; }\end{array}$ & $\begin{array}{l}\text { Low durability; } \\
\text { Expensive manufacturing; } \\
\text { Not biodegradable; }\end{array}$ \\
\hline
\end{tabular}


Appendix B: Summary of literature review on commercial materials testing.

Table B.1.Summary of studies with completed bench testing.

\begin{tabular}{|c|c|c|c|c|c|c|}
\hline Author & \multicolumn{3}{|c|}{ Materials tested } & \multirow{2}{*}{\begin{tabular}{|c|} 
Testing system \\
Analytical Hierarchal Model \\
\end{tabular}} & \multirow{2}{*}{$\begin{array}{l}\text { Parameters tested } \\
\text { Density, stiffness, } \\
\text { durability, ease of } \\
\text { fabrication }\end{array}$} & \multirow{2}{*}{$\begin{array}{c}\begin{array}{c}\text { Author's } \\
\text { recommended } \\
\text { material }\end{array} \\
\text { Poron }{ }^{\circledR}\end{array}$} \\
\hline Almomany et al. 2016(29) & Poron ${ }^{\circledR}$ & Plastazote $\AA$ & Polyurethane elastomer & & & \\
\hline \multirow[t]{10}{*}{ Campbell et al. 1982(22) } & Aliplast $₫-4 \mathrm{E}$ & Evazote $®(1.6 \mathrm{~mm})$ & Bonfoam $®$ & \multirow[t]{10}{*}{ Instron } & \multirow[t]{10}{*}{ Stress-stain curve } & \multirow{10}{*}{ 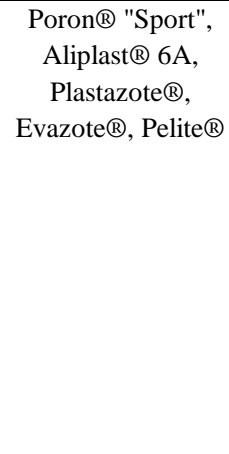 } \\
\hline & Aliplast $\circledast-10$ & Evazote $®(12.77 \mathrm{~mm})$ & Pelite $囚(1.6 \mathrm{~mm})$ & & & \\
\hline & Aliplast ${ }^{\circledR}-6 \mathrm{~A}$ & HD Neoprene & Pelite $®(12.7 \mathrm{~mm})$ & & & \\
\hline & Spenco® & "Odor Eater"® insole & Dr. Scholl $®$ cusion insole & & & \\
\hline & Neoprene $(-431$ (3.2 mm) & Ensolite $®(3.2 \mathrm{~mm})$ & Poron® Sport & & & \\
\hline & Neoprene®-431 $(6.35 \mathrm{~mm})$ & Ensolite $®(6.35 \mathrm{~mm})$ & Plastazote $® \mathrm{LD}(3.2 \mathrm{~mm})$ & & & \\
\hline & Neoprene ${ }^{\circledR} \mathrm{R} 425 \mathrm{~N}$ (3.2 mm) & Poron $®-17125$ & Plastazote LD $(6.35 \mathrm{~mm})$ & & & \\
\hline & Neoprene $® \mathrm{R} 425 \mathrm{~N}(6.35 \mathrm{~mm})$ & Poron $®-20125$ & Polyurethane foam & & & \\
\hline & Lynco® & Spenco® & Ethafoam & & & \\
\hline & $\begin{array}{l}\text { Carpet- PP (pile weight } 0.74 \\
\mathrm{~kg} / \mathrm{m} 3 \text { ) }\end{array}$ & $\begin{array}{l}\text { CarpetWool (pile weight } 1.15 \\
\mathrm{~kg} / \mathrm{m} 3 \text { ) }\end{array}$ & Celltite ${ }^{\circledR}$ & & & \\
\hline \multirow[t]{10}{*}{ Fauli et al. 2008(26) } & Evamic $®(5 \mathrm{~mm})$ & Herbimed $®(3 \mathrm{~mm})$ & Lunairmed $囚(6 \mathrm{~mm})$ & \multirow{10}{*}{$\begin{array}{c}\text { Durometer Shore C, UTM, } \\
\text { compression set testing } \\
\text { machine, compression } \\
\text { fatigue test machine, } \\
\text { permeabilimeter }\end{array}$} & \multirow{10}{*}{\begin{tabular}{|c|} 
Density, Hardness, \\
Resilience, Stress- \\
strain characteristics in \\
compression, \\
compression set \\
resistance and \\
compression fatigue \\
resistance, water \\
vapour permeability \\
and perspiration \\
resistance
\end{tabular}} & \multirow[t]{10}{*}{ Poron $\AA$ (all grades) } \\
\hline & Hebal Foam Duro (5 mm) & Herbiprex ${ }^{\circledR}$ granate $(3 \mathrm{~mm})$ & Lunalastik® (3 mm) & & & \\
\hline & Herbiform ${ }^{\circledR}$ Multicolor $(2 \mathrm{~mm})$ & Herbiprex $®$ lite $(3 \mathrm{~mm})$ & Lunasoft@ SLW (6 mm) & & & \\
\hline & Herbiform $®$ Plus perforated (1.8 & Lunairmed $®(12 \mathrm{~mm})$ & NSL® (4 mm) & & & \\
\hline & Ortheva ${ }^{\circledR}(4 \mathrm{~mm})$ & Pelite ${ }^{\circledR}(3 \mathrm{~mm})$ & Podialene ${ }^{\circledR} 160$ blanco & & & \\
\hline & Orthomic $®(3 \mathrm{~mm})$ & Plastazote ${ }^{\circledR}(3 \mathrm{~mm})$ & Podialene ${ }^{\circledR} 160$ perforated & & & \\
\hline & Orthomic $®(4 \mathrm{~mm})$ & Podialene $® 160$ azul & Podialene ${ }^{\circledR} 200(5 \mathrm{~mm})$ & & & \\
\hline & Podiane ${ }^{\circledR}$ I perforated $(1.5 \mathrm{~mm})$ & Poron ${ }^{\circledR}(5 \mathrm{~mm})$ & Poron® $(3 \mathrm{~mm})$ & & & \\
\hline & Poron $®$ medical density $(2 \mathrm{~mm})$ & Superlatex ${ }^{\circledR}(4 \mathrm{~mm})$ & Superlatex $®(5 \mathrm{~mm})$ & & & \\
\hline & Superlatex $®(5 \mathrm{~mm})$ & Verde $囚(2.6 \mathrm{~mm})$ & & & & \\
\hline
\end{tabular}


Table B.1. continued...

\begin{tabular}{|c|c|c|c|c|c|c|}
\hline \multirow[t]{6}{*}{ Lewis et al. 1991(27) } & Hygard® $(3.2 \mathrm{~mm})$ & Poron ${ }^{\circledR}$ (density $481 \mathrm{~kg} / \mathrm{m} 3$, & TL-61 Standard $(1.65 \mathrm{~mm})$ & \multirow[t]{6}{*}{ Resiliometer } & \multirow{6}{*}{$\begin{array}{l}\text { Shoch absorbtion } \\
\text { charactersitics and } \\
\text { energy return ability }\end{array}$} & \multirow[t]{6}{*}{ Poron ${ }^{\circledR}$, Hygard $\AA$} \\
\hline & Hygard $®(6.36 \mathrm{~mm})$ & 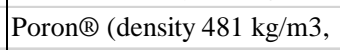 & TL-61 Standard $(1.91 \mathrm{~mm})$ & & & \\
\hline & Hygard $®(5.5 \mathrm{~mm})$ & 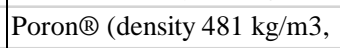 & TL-61 Standard (3.81 mm) & & & \\
\hline & Isoloss $®(1.59 \mathrm{~mm})$ & Sorbothane $®(1.52 \mathrm{~mm})$ & Viscolas $®(3.96 \mathrm{~mm})$ & & & \\
\hline & Isoloss $®(2.29 \mathrm{~mm})$ & Sorbothane ${ }^{\circledR}(2.54 \mathrm{~mm})$ & Viscolas ${ }^{\circledR}(7.92 \mathrm{~mm})$ & & & \\
\hline & Isoloss $®(3.05 \mathrm{~mm})$ & Sorbothane ${ }^{\circledR}(3.18 \mathrm{~mm})$ & Viscolas ${ }^{\circledR}(11.88 \mathrm{~mm})$ & & & \\
\hline \multirow[t]{3}{*}{ Lo et al. 2014(28) } & Nora ${ }^{\circledR}$ Lunaairmed $(6.3 \mathrm{~mm})$ & Nora $®$ Lunaarflex $(2.9 \mathrm{~mm})$ & Nora $₫$ Lunalight A $(6.3 \mathrm{~mm})$ & \multirow{3}{*}{\begin{tabular}{|c|} 
Mettler Toledo LJ16 \\
moisture analyzer, Instron \\
tensile tester, purpose built \\
impact tester, purpose built \\
equipment for friction and \\
shearing angle \\
measurement.
\end{tabular}} & \multirow{3}{*}{$\begin{array}{l}\text { Hardness, density, } \\
\text { force reduction, } \\
\text { compression stress, } \\
\text { shearing, moisture } \\
\text { regain, water vapor } \\
\text { permeability }\end{array}$} & \multirow[t]{3}{*}{ Nora ${ }^{\circledR} L u n a i r f l e x$} \\
\hline & Nora ${ }^{\circledR L u n a l a s t i k ~}(2.9 \mathrm{~mm})$ & MD EVA (3.4 mm) & Plastazote (3.2 mm) & & & \\
\hline & Pelite $(2.9 \mathrm{~mm})$ & & & & & \\
\hline \multirow[t]{2}{*}{ Pratt et al. 1986(23) } & Plastazote $($ MD $(45 \mathrm{~kg} / \mathrm{m} 3,6 \mathrm{~mm})$ & Sorbothane $₫(5-6 \mathrm{~mm})$ & Visolas $®(5-6 \mathrm{~mm})$ & \multirow{2}{*}{$\begin{array}{l}\text { Ball bearing and Kistler } \\
\text { force plate }\end{array}$} & \multirow{2}{*}{\begin{tabular}{|} 
Height of first peak \\
after contact with \\
contact of ball bearing \\
with material and \\
vertical ground force
\end{tabular}} & \multirow{2}{*}{$\begin{array}{l}\text { Poron }{ }^{\circledR} 96, \mathrm{HD} \\
\text { EVA, Lunacell® }\end{array}$} \\
\hline & Poron (PPT) 6mm & Spenco® $(5-6 \mathrm{~mm})$ & & & & \\
\hline \multirow[t]{5}{*}{ Paton et al. 2007(25) } & Cleron $®(3 \mathrm{~mm})$ & EVA HD (12 mm) & Lunace $囚 1$ Nore $(12 \mathrm{~mm})$ & \multirow{5}{*}{$\begin{array}{l}\text { Purpose build resilliometer } \\
\text { and top cyclic loader, F- } \\
\text { Scan in-shoe system. }\end{array}$} & \multirow{5}{*}{$\begin{array}{l}\text { Compression set, } \\
\text { resilience, durability, } \\
\text { static coefficient of } \\
\text { friction, density, } \\
\text { stiffness }\end{array}$} & \multirow{5}{*}{$\begin{array}{l}\text { PPT } \AA \text { (Poron), } \\
\text { Plastazote } \AA\end{array}$} \\
\hline & Cleron $®(6 \mathrm{~mm})$ & EVA MD (12 mm) & MaxaCane $®(3 \mathrm{~mm})$ & & & \\
\hline & MaxaCane $®(6 \mathrm{~mm})$ & Plastazote ${ }^{\circledR} \mathrm{LD}(6 \mathrm{~mm})$ & Poron ${ }^{\circledR} 92(6 \mathrm{~mm})$ & & & \\
\hline & Poron® $94(6 \mathrm{~mm})$ & Poron ${ }^{8} 96(6 \mathrm{~mm})$ & Poron ${ }^{\circledR} 4000(3 \mathrm{~mm})$ & & & \\
\hline & Poron® $4000(6 \mathrm{~mm})$ & PPT® (3 mm) & PPT® $(6 \mathrm{~mm})$ & & & \\
\hline \multirow[t]{2}{*}{ Rome et al. 1991(24) } & PРT® & Closed cell rubber & Plastazote $\AA$ & \multirow{2}{*}{$\begin{array}{c}\text { Durometer, micrometer, } \\
\text { hounsfield type tensiometer, } \\
\text { compression testing machine }\end{array}$} & \multirow{2}{*}{\begin{tabular}{|c|} 
Density, compression \\
strength, tensle \\
strength, hardness
\end{tabular}} & \multirow{2}{*}{$\begin{array}{l}\text { PPT }{ }^{\circledR} \text { (Poron), } \\
\text { Plastazote }{ }^{\circledR}\end{array}$} \\
\hline & Vitrathene & Plexidur® O & & & & \\
\hline \multirow{2}{*}{$\begin{array}{l}\text { Shariatmadari et al. } \\
\text { 2012(9) }\end{array}$} & Lunasoft Nora ${ }^{\circledR}$ & Poron ${ }^{\circledR}$ (grey) & Poron ${ }^{\circledR}$ (blue) & \multirow{2}{*}{$\begin{array}{l}\text { UTM with environmental } \\
\text { chamber }\end{array}$} & \multirow{2}{*}{$\begin{array}{c}\text { Compression strength, } \\
\text { tensile strength, energy } \\
\text { absorption, shear } \\
\text { strength }\end{array}$} & \multirow[t]{2}{*}{ Poron $\AA$ blue } \\
\hline & Poron® (green) & Plastazote® MD & & & & \\
\hline
\end{tabular}


Table B. 2.Summary of studies with in-shoe simulations conducted.

\begin{tabular}{|c|c|c|c|c|c|c|}
\hline \multirow{3}{*}{\begin{tabular}{|c|} 
Author \\
Brodsky et al. 2007(30)
\end{tabular}} & \multicolumn{3}{|c|}{ Materials tested } & \multirow{3}{*}{$\begin{array}{c}\text { Testing system } \\
\text { Custom-made testing jig } \\
\text { with simulated bony } \\
\text { prominence }\end{array}$} & \multirow{3}{*}{\begin{tabular}{|c|} 
Parameters tested \\
Percent compression of \\
individual materials and \\
combinations before and after \\
heating, stress-strain in \\
compression, load \\
transmisssion
\end{tabular}} & \multirow{3}{*}{\begin{tabular}{|c|}
$\begin{array}{c}\text { Author's } \\
\text { recommended }\end{array}$ \\
Poron $\AA$, Nickelplast ${ }^{\circledR}$ \\
\end{tabular}} \\
\hline & \multirow{2}{*}{$\begin{array}{l}\text { Plastazote }{ }^{\circledR} \text { (soft)/Puff(EVA) } \\
\text { Plastazote }{ }^{\circledR} \text { MD/Puff(EVA) }\end{array}$} & \multirow{2}{*}{$\begin{array}{l}\text { Plastazote }{ }^{\circledR} \\
\text { (soft)/Puff(EVA)/Poron } ® \\
\text { Plastazote } ® \\
\text { MD/Puff(EVA)/Poron }{ }^{\circledR}\end{array}$} & \multirow[t]{2}{*}{ Nickelplast ${ }^{\circledR}$} & & & \\
\hline & & & & & & \\
\hline Brodsky et al. 2012(31) & Plastazote ${ }^{\circledR} \mathrm{LD}(4.7 \mathrm{~mm})$ & Nickelplast ${ }^{\circledR}(4.9 \mathrm{~mm})$ & Poron ${ }^{\circledR}(2.8 \mathrm{~mm})$ & $\begin{array}{c}\text { Custom-made testing jig } \\
\text { with simulated bony } \\
\text { prominence }\end{array}$ & $\begin{array}{c}\text { Residual thickness of insoles } \\
\text { after cyclic compression, } \\
\text { amount of peak load } \\
\text { transmitted to bony } \\
\text { prominence. }\end{array}$ & \begin{tabular}{|c|} 
Combinations: \\
Plastazote $\AA+$ Nickelpla \\
st $\AA$, \\
Nickelplast ${ }^{\circledR}+$ Poron $®$
\end{tabular} \\
\hline \multirow[t]{10}{*}{ Campbell et al. 1984(11) } & Aliplast $\circledast-4 \mathrm{E}$ & Evazote $®(1.6 \mathrm{~mm})$ & Bonfoam ${ }^{\circledR}$ & \multirow[t]{10}{*}{$\begin{array}{c}\text { Oven and custom } \\
\text { designed equipment }\end{array}$} & \multirow[t]{10}{*}{$\begin{array}{c}\text { Log standardized strain and } \\
\text { thickness }\end{array}$} & \multirow[t]{10}{*}{$\begin{array}{l}\text { Poron }{ }^{\circledR} \text { Sport, } \\
\text { Lynco }{ }^{\circledR}\end{array}$} \\
\hline & Aliplast ${ }^{\circledR}-10$ & Evazote $®(12.77 \mathrm{~mm})$ & Pelite ${ }^{\circledR}(1.6 \mathrm{~mm})$ & & & \\
\hline & Aliplast@-6A & Neoprene $\AA$ HD & Pelite $®(12.7 \mathrm{~mm})$ & & & \\
\hline & Spenco® & "Odor Eater"® insole & Dr. Scholl $囚$ cusion insole & & & \\
\hline & Neoprene®-431 (3.2 mm) & Ensolite $®(3.2 \mathrm{~mm})$ & Poron $®$ Sport & & & \\
\hline & Neoprene $®-431(6.35 \mathrm{~mm})$ & Ensolite $®(6.35 \mathrm{~mm})$ & Plastazote® LD(3.2 mm) & & & \\
\hline & Neoprene® R 425N (3.2 mm) & Poron $®-17125$ & Plastazote $囚 \mathrm{LD}(6.35 \mathrm{~mm})$ & & & \\
\hline & Neoprene® R 425N (6.35 mm) & Poron $®-20125$ & Polyurethane foam & & & \\
\hline & Lynco® & Spenco ${ }^{\circledR}$ & Ethafoam ${ }^{\circledR}$ & & & \\
\hline & $\begin{array}{l}\text { Carpet- PP (pile weight } 0.74 \\
\mathrm{~kg} / \mathrm{m} 3 \text { ) }\end{array}$ & $\begin{array}{l}\text { CarpetWool (pile weight } 1.15 \\
\mathrm{~kg} / \mathrm{m} 3 \text { ) }\end{array}$ & Celltite ${ }^{\circledR}$ & & & \\
\hline \multirow[t]{4}{*}{ Kuncir et al. 1990(17) } & Aliplast $₫ 4 \mathrm{E}(2.54 \mathrm{~mm})$ & Evazote $₫(2.54 \mathrm{~mm})$ & Plastazote ${ }^{\circledR}$ MD (2.54 mm) & \multirow[t]{4}{*}{ Static load tester } & \multirow[t]{4}{*}{$\begin{array}{l}\text { Compression and recovery } \\
\text { rates, peak presure }\end{array}$} & \multirow{4}{*}{$\begin{array}{l}\text { Aliplast }{ }^{\circledR} 4 \mathrm{E} \text {, thicker, } \\
\text { several pair for daily } \\
\text { rotation }\end{array}$} \\
\hline & Aliplast $®$ 6A $(2.54 \mathrm{~mm})$ & Pelite ${ }^{\circledR}(2.54 \mathrm{~mm})$ & Plastazote® HD (2.54 mm) & & & \\
\hline & Pelite ${ }^{\circledR}(2.54 \mathrm{~mm})$ & Pelite ${ }^{\circledR}(2.54 \mathrm{~mm})$ & Pelite $®(2.54 \mathrm{~mm})$ & & & \\
\hline & Dermaplast $® \mathrm{MD}(2.54 \mathrm{~mm})$ & Dermaplast ${ }^{\circledR} \mathrm{HD}(2.54 \mathrm{~mm})$ & & & & \\
\hline \multirow[t]{2}{*}{ Leber et al. 1986(15) } & Plastozote $®(3.2 \mathrm{~mm})$ & Dynafoam $®(3.2 \mathrm{~mm})$ & Molo® $(3.2 \mathrm{~mm})$ & \multirow[t]{2}{*}{ Harris mat } & \multirow[t]{2}{*}{$\begin{array}{c}\text { Mean pressure reduction } \\
\text { under 1st MTPJ }\end{array}$} & \multirow[t]{2}{*}{ Poron $®$} \\
\hline & Latex foam $(3.2 \mathrm{~mm})$ & Ortho felt@ $(3.2 \mathrm{~mm})$ & Poron® (PPT) (3.2 mm) & & & \\
\hline
\end{tabular}


Table B.2.continued...

\begin{tabular}{|c|c|c|c|c|c|c|}
\hline McPoil et al. 1992(32) & PPT (3.2 mm) & Spenco ${ }^{\circledR}(3.2 \mathrm{~mm})$ & Viscolas $®(3.2 \mathrm{~mm})$ & $\begin{array}{l}\text { EMED-SF pedograph } \\
\text { force, force plate system }\end{array}$ & $\begin{array}{l}\text { Maximum vertical force, } \\
\text { vertical force-time integral } \\
\text { and maximum plantar } \\
\text { pressure }\end{array}$ & Poron ${ }^{\circledR}$, Visolas ${ }^{\circledR}$ \\
\hline \multirow[t]{3}{*}{ Pauk et al. 2015(14) } & EVA 1 ( hardness $35,10 \mathrm{~mm}$ ) & EVA 4(hardness 45, $7 \mathrm{~mm}$ ) & EVA 5( hardness 45, $4 \mathrm{~mm}$ ) & \multirow[t]{3}{*}{ Kistler platform } & \multirow[t]{3}{*}{$\begin{array}{l}\text { Ground reaction force and } \\
\text { friction force }\end{array}$} & \multirow[t]{3}{*}{ EVA1, EVA 2, EVA 3} \\
\hline & EVA 3( hardness 65, 6 mm) & EVA 2( hardness $65,7 \mathrm{~mm}$ ) & EVA 6 ( hardness $45,8 \mathrm{~mm}$ ) & & & \\
\hline & Chrome leather(1,5 mm) & Tanned leather (4 mm) & Cowhide leather (3mm) & & & \\
\hline \multirow[t]{2}{*}{ Sanfilippo et al. 1992(33) } & Poron $₫(3.2 \mathrm{~mm})$ & Pelite ${ }^{\circledR}(3.2 \mathrm{~mm})$ & Plastazote ${ }^{\circledR}(3.2 \mathrm{~mm})$ & \multirow[t]{2}{*}{$\begin{array}{l}\text { EMED-SF pedograph } \\
\text { force, force plate system }\end{array}$} & \multirow{2}{*}{$\begin{array}{l}\text { Vertical force, force time } \\
\text { integral, peak plantar } \\
\text { pressure, pressure time } \\
\text { itegral and contact area }\end{array}$} & \multirow[t]{2}{*}{$\begin{array}{l}\text { Poron }{ }^{\circledR} \text { and } \\
\text { Plastazote }{ }^{\circledR}\end{array}$} \\
\hline & Nickelplast $®(3.2 \mathrm{~mm})$ & Spenco® $(3.2 \mathrm{~mm})$ & & & & \\
\hline
\end{tabular}

Table B. 3.Summary of studies with biomechanical testing conducted.

\begin{tabular}{|c|c|c|c|c|c|c|}
\hline \multirow{2}{*}{\begin{tabular}{|c} 
Author \\
Birke et al. 1999 (36)
\end{tabular}} & \multicolumn{3}{|c|}{ Materials tested } & \multirow{4}{*}{$\begin{array}{c}\text { Testing method } \\
\text { Pedar } \circledast \text { in-shoe system }\end{array}$} & \multirow{4}{*}{$\begin{array}{c}\text { Parameters tested } \\
\text { Mean peak plantar pressure }\end{array}$} & \multirow{4}{*}{$\begin{array}{c}\begin{array}{c}\text { Author's recommended } \\
\text { material }\end{array} \\
\text { Poron® (Shore O 22-32) }\end{array}$} \\
\hline & Poron $®($ Shore O 14), $6 \mathrm{~mm}$ & Poron®(Shore O 27),6 mm & Poron®(Shore O 40),6 mm & & & \\
\hline & Poron $₫($ Shore O 17),6 mm & Poron $®($ Shore O 32),6 mm & Poron $\AA($ Shore O 55),6 mm & & & \\
\hline & Poron $₫($ Shore O 22), $6 \mathrm{~mm}$ & & & & & \\
\hline \multirow[t]{3}{*}{ Burns et al. 2008(40) } & $\begin{array}{l}\text { Laminate: Microcell } \\
\text { Puff/Poron®/Microcell Puff }\end{array}$ & $\begin{array}{l}\text { Step } 2 \text { Evolution }{ }^{\circledR} \text { insole } \\
\text { (countured, multidensity) }\end{array}$ & Spenco $\circledast(3 \mathrm{~mm})$ & \multirow[t]{3}{*}{$\begin{array}{c}\text { Pedar® X in-shoe system, Foot } \\
\text { health status questionary }\end{array}$} & \multirow[t]{3}{*}{$\begin{array}{l}\text { Peak plantar pressure, force time } \\
\text { integral, foot comfort }\end{array}$} & \multirow{3}{*}{\begin{tabular}{|c} 
Laminate: Poron ${ }^{\circledR}$ \\
Performance(top)/Poron ${ }^{\circledR}$ \\
Medical(bottom) $(6 \mathrm{~mm})$, \\
Step 2 Evolution®
\end{tabular}} \\
\hline & Microcell Puff (6mm) & Poron® Performance (6mm) & $\begin{array}{l}\text { Laminate: Spenco }{ }^{\circledR} \text { (top, } \\
3 \mathrm{~mm} \text { )/Poron }{ }^{\circledR} \text { (bottom, }\end{array}$ & & & \\
\hline & Poron ${ }^{\circledR}$ (soft, 6mm) & $\begin{array}{l}\text { Laminate: Poron }{ }^{\circledR} \\
\text { Performance(top)/Poron }{ }^{\circledR} \\
\text { Medical(bottom) }(6 \mathrm{~mm})\end{array}$ & Poron ${ }^{\circledR}$ (extra soft, 6 mm) & & & \\
\hline \multirow[t]{2}{*}{ Healy et al. 2012(37) } & LD polyurethane (Shore A 20- & LD EVA (Shore A 25, $3 \mathrm{~mm}$ ) & MD EVA (Shore A 50, 3 & \multirow[t]{2}{*}{ F-scan $\circledast$ in-shoe system } & \multirow{2}{*}{$\begin{array}{l}\text { Stance duration, peak pressure, } \\
\text { peak force, pressure time }\end{array}$} & \multirow{2}{*}{$\begin{array}{c}\text { MD polyurethane (Shore A } \\
55,3 \mathrm{~mm})\end{array}$} \\
\hline & MD polyurethane (Shore A 55, & & & & & \\
\hline \multirow[t]{3}{*}{ Johnson et al.1988 (35) } & Nonshock ${ }^{\circledR}$ & Sorbothane ${ }^{\circledR}$ (walking insole) & Sorbothane $®$ (red) & \multirow[t]{3}{*}{ Accelerometer } & \multirow[t]{3}{*}{ Shock factor } & \multirow[t]{3}{*}{ Sorbothane $®$ (lightweight) } \\
\hline & Sorbothane $\circledast$ (heel insert) & Sorbothane ${ }^{\circledR}$ (lightweight) & Sorbothane $囚$ (soft blue) & & & \\
\hline & Sorbolite ${ }^{\circledR}$ & Sorbothane ${ }^{\circledR}$ (hard blue) & Viscolas ${ }^{\circledR}$ & & & \\
\hline Mohamed et al. 2004 & Plastozote $®$ Medium density & $\begin{array}{l}\text { Lamianate: Plastozote } ®+ \\
\text { Aliplast } ₫\end{array}$ & & Pedar® in-shoe system & $\begin{array}{l}\text { Peak plantar pressure, maximum } \\
\text { mean pressure, pressure time } \\
\text { integral, mean force and contact }\end{array}$ & $\begin{array}{c}\text { Lamianate: Plastozote }{ }^{\circledR}+ \\
\text { Aliplast } \circledast\end{array}$ \\
\hline
\end{tabular}


Table B.3. continued...

\begin{tabular}{|c|c|c|c|c|c|c|}
\hline \multirow[t]{2}{*}{ Pratt et al. 1986(23) } & Plastazote $\circledast(45 \mathrm{~kg} / \mathrm{m} 3), 6 \mathrm{~mm}$ & Poron $\circledast(\mathrm{PPT}), 6 \mathrm{~mm}$ & Spenco $®, 5-6 \mathrm{~mm}$ & \multirow[t]{2}{*}{$\begin{array}{c}\text { Accelerometer held between the } \\
\text { teeth of a person, force plate }\end{array}$} & \multirow[t]{2}{*}{$\begin{array}{l}\text { Acceleration and vertical } \\
\text { reaction ground force }\end{array}$} & \multirow[t]{2}{*}{ Viscolas ${ }^{\circledR}$ and Poron ${ }^{\circledR}$} \\
\hline & Sorbothane $₫, 5-6 \mathrm{~mm}$ & Visoclas ${ }^{\circledR}, 5-6 \mathrm{~mm}$ & & & & \\
\hline \multirow[t]{2}{*}{ Pratt et al. 1990(34) } & Gait Aid® (proprietary insole) & PPT Poron $(3.5 \mathrm{~mm})$ & Viscolas ${ }^{\circledR}$ & \multirow[t]{2}{*}{ JP Biomechanics Shock meter } & \multirow[t]{2}{*}{ Shock factor } & \multirow[t]{2}{*}{ Viscolas ${ }^{\circledR}$ and Poron ${ }^{\circledR}$} \\
\hline & Plastazote ${ }^{\circledR}(45 \mathrm{~kg} / \mathrm{m} 3), 3 \mathrm{~mm}$ & & & & & \\
\hline Rogers et al. 2006(39) & Poron $(6 \mathrm{~mm})$ & $\begin{array}{l}\text { Laminate: Plastozote(top, } 3.2 \\
\mathrm{~mm} \text { ) + Poron (bottom, } 3.2 \mathrm{~mm} \text { ) }\end{array}$ & & F-scan $\circledast$ in-shoe system & Peak plantar pressure & $\begin{array}{l}\text { Combined: Plastozote + } \\
\text { Poron }\end{array}$ \\
\hline Tang et al. 2014(42) & EVA (shore A 35, mm) & EVA (shore A 55, mm) & Globotech $\circledast$ Comfort & F-scan $®$ in-shoe system & $\begin{array}{c}\text { Mean peak pressure, maximum } \\
\text { peak pressure, pressure time } \\
\text { integral }\end{array}$ & EVA ( Shore A 55) \\
\hline \multirow[t]{2}{*}{ Tong et al. 2010(38) } & $\begin{array}{l}\text { Slow Recovery Poron }{ }^{\circledR} \text { (extra } \\
\text { soft } 4708 \text {-blue), } 6.2 \mathrm{~mm}\end{array}$ & $\begin{array}{l}\text { Laminate: Plastozote }{ }^{\circledR} \\
\text { (top,Shore A 30) + Poron } ® \\
\text { (bottom, soft 4708-blue), } 6.2 \\
\text { mm }\end{array}$ & \begin{tabular}{|l|} 
Laminate: Plastozote ${ }^{\circledR}$ \\
(top,Shore A 15) + Poron ${ }^{\circledR}$ \\
(bottom, soft 4708-blue), 6.2 \\
$\mathrm{~mm}$
\end{tabular} & \multirow[t]{2}{*}{ F-scan $®$ in-shoe system } & $\begin{array}{c}\text { Minimum, maximum and mean } \\
\text { peak pressure }\end{array}$ & \multirow[t]{2}{*}{$\begin{array}{c}\text { Laminate: Plastozote } \AA \text { HD } \\
\text { + Poron } ® 4708\end{array}$} \\
\hline & Poron® (soft), $6.2 \mathrm{~mm}$ & & & & & \\
\hline
\end{tabular}


Appendix C: Properties of raw materials.

Table C.1. Raw materials properties. a - number average molecular weight; b- melting temperature; c- functionality

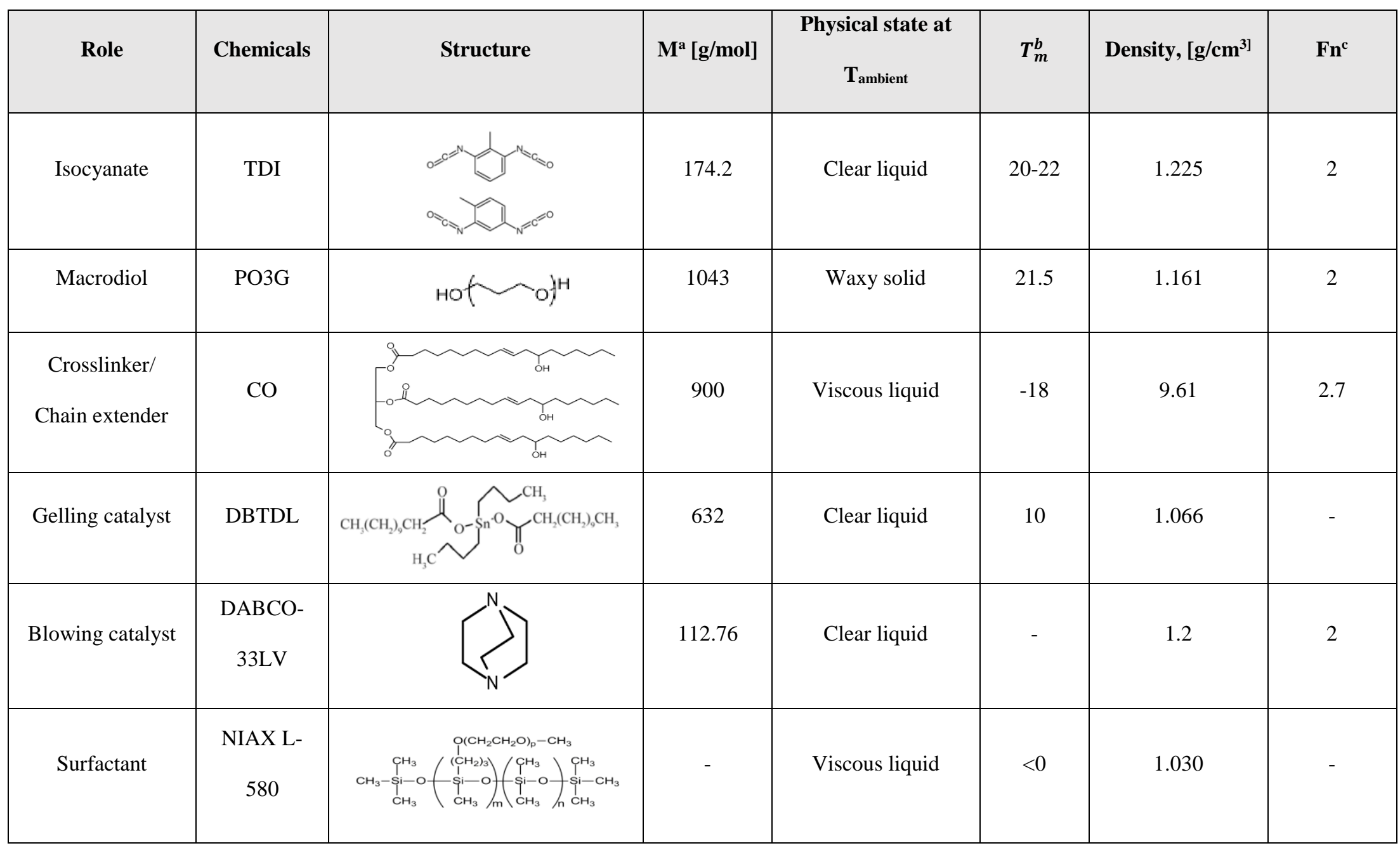


Appendix D: Raw data for selected experiments.

Table D.1. Raw data for density measurements experiment.

\begin{tabular}{|c|c|c|c|c|}
\hline \multirow{2}{*}{ Sample } & \multicolumn{3}{|c|}{ Density } & \multirow{2}{*}{$\mathrm{x} \pm(\mathrm{SE})$} \\
\cline { 2 - 4 } & $\mathrm{T} 1$ & $\mathrm{~T} 2$ & $\mathrm{~T} 3$ & \\
\hline 231 & 0.258 & 0.27 & 0.22 & $0.25 \pm 0.0184$ \\
\hline 212 & 0.31 & 0.28 & 0.32 & $0.30 \pm 0.0147$ \\
\hline 210 & 0.215 & 0.309 & 0.27 & $0.26 \pm 0.033$ \\
\hline 200 & 0.28 & 0.29 & 0.2 & $0.26 \pm 0.034$ \\
\hline 022 & 0.21 & 0.31 & 0.26 & $0.26 \pm 0.035$ \\
\hline
\end{tabular}

D.3. Raw data for compression set experiment.

\begin{tabular}{|c|c|c|c|c|}
\hline \multirow{2}{*}{ Sample } & \multicolumn{3}{|c|}{ Compression set, \% } & \multirow{2}{*}{ x $\pm(\mathrm{SE})$} \\
\cline { 2 - 4 } & $\mathrm{T} 1$ & $\mathrm{~T} 2$ & $\mathrm{~T} 3$ & \\
\hline 231 & 2 & 1.9 & 2.5 & $2.1 \pm 0.23$ \\
\hline 212 & 1.8 & 1.5 & 1.6 & $1.6 \pm 0.11$ \\
\hline 210 & 4.8 & 4.6 & 4.5 & $4.6 \pm 0.11$ \\
\hline 200 & 2 & 2.05 & 2.1 & $2.05 \pm 0.04$ \\
\hline 022 & 2.51 & 2.7 & 2.3 & $2.5 \pm 0.14$ \\
\hline
\end{tabular}

Table D.2. Raw data for hardness testing experiment.

\begin{tabular}{|c|c|c|c|c|}
\hline \multirow{2}{*}{ Sample } & \multicolumn{3}{|c|}{ Hardness, Shore A units } & \multirow{2}{*}{ X $\pm(\mathrm{SE})$} \\
\cline { 2 - 4 } & $\mathrm{T} 1$ & $\mathrm{~T} 2$ & $\mathrm{~T} 3$ & \\
\hline 231 & 22 & 24.5 & 18.2 & $21.57 \pm 2.243$ \\
\hline 212 & 17 & 15.5 & 16 & $16.17 \pm 0.540$ \\
\hline 210 & 18 & 14 & 17.5 & $16.50 \pm 1.541$ \\
\hline 200 & 13.5 & 16 & 17 & $15.50 \pm 1.275$ \\
\hline 022 & 15.5 & 18 & 15 & $16.17 \pm 1.137$ \\
\hline
\end{tabular}

D.4. Raw data for water adsorption experiment.

\begin{tabular}{|c|c|c|c|c|}
\hline \multirow{2}{*}{ Sample } & \multicolumn{3}{|c|}{ Water adsorption, $\%$} & \multirow{2}{*}{$x^{-} \pm(S E)$} \\
\hline & $\mathrm{T} 1$ & $\mathrm{~T} 2$ & T3 & \\
\hline 231 & 31 & 33.5 & 28 & $30.8 \pm 1.94$ \\
\hline 212 & 15.5 & 15.7 & 15.2 & $15.6 \pm 1.02$ \\
\hline 210 & 15 & 16 & 16.9 & $15.97 \pm 0.67$ \\
\hline 200 & 5 & 8 & 6.74 & $6.54 \pm 1.07$ \\
\hline 022 & 9 & 5.3 & 4.98 & $6.42 \pm 1.57$ \\
\hline
\end{tabular}

D.5. Raw data for tensile test experiment.

\begin{tabular}{|c|c|c|c|c|c|c|c|c|c|c|c|c|}
\hline \multirow{2}{*}{ Sample } & \multicolumn{3}{|c|}{ Tensile strength, $\mathrm{MPa}$} & \multirow{2}{*}{$\bar{x} \pm(\mathrm{SE})$} & \multicolumn{3}{|c|}{ Tensile strain, $\%$} & \multirow{2}{*}{$x \overline{ \pm}(\mathrm{SE})$} & \multicolumn{3}{|c|}{ Modulus of elasticity, MPa } & \multirow{2}{*}{$x \overline{ \pm}(\mathrm{SE})$} \\
\hline & $\mathrm{T} 1$ & $\mathrm{~T} 2$ & T3 & & $\mathrm{T} 1$ & $\mathrm{~T} 2$ & T3 & & $\mathrm{T} 1$ & $\mathrm{~T} 2$ & T3 & \\
\hline 231 & 0.49 & 0.78 & 0.49 & $0.58 \pm 0.040$ & 158 & 153 & 172 & $161.5 \pm 5.93$ & 1.05 & 0.91 & 0.88 & $0.99 \pm 0.009$ \\
\hline 212 & 0.21 & 0.46 & 0.41 & $0.36 \pm 0.120$ & 450 & 439 & 444 & $444 \pm 3.50$ & 0.38 & 0.37 & 0.51 & $0.41 \pm 0.050$ \\
\hline 210 & 0.28 & 0.43 & 0.37 & $0.36 \pm 0.067$ & 430 & 446 & 416 & $430 \pm 8.97$ & 0.21 & 0.4 & 0.27 & $0.28 \pm 0.031$ \\
\hline 200 & 0.78 & 0.49 & 0.52 & $0.59 \pm 0.032$ & 245 & 226 & 210 & $226 \pm 14.53$ & 0.91 & 0.78 & 0.80 & $0.82 \pm 0.015$ \\
\hline 022 & 0.08 & 0.1 & 0.09 & $0.09 \pm 0.004$ & 247 & 63 & 67 & $58.5 \pm 7.05$ & 0.11 & 0.08 & 0.13 & $0.11 \pm 0.014$ \\
\hline
\end{tabular}




\section{REFERENCES}

Agarry, Samuel E., Ganiyu K. Latinwo, Tinuade J. Afolabi, and Semiu A. Kareem. 2015. "Model Predictive Performance of Filled Flexible Polyurethane Foam.” American Journal of Polymer Science 5(1):1-9.

Ajithkumar, S., S. S. Kansara, and N. K. Patel. 1998. "Kinetics of Castor Oil Based Polyol-Toluene Diisocyanate Reactions.” European Polymer Journal 34(9):1273-76.

Almomani, A. and Dina W. Al-Qudah. 2016. "Material Selection for Footwear Insole Using Analytical Hierarchal Process." International Journal of Materials and Metallurgical Engineering 10(4):44549.

Anon. 2015. "Work-Related Injuries Satistics in Canada 2016." 1-152. Retrieved (https://www.worksafebc.com/en).

Anon. 2017. Canadian Joint Replacement Registry: Hip and Knee Replacements in Canada. Ottawa, ON: CIHI.

Basal, Guldemet and Sevcan Ilgaz. 2009. “A Functional Fabric for Pressure Ulcer Prevention.” Textile Research Journal 79(16):1415-26.

Birke, James and James Foto. 1999. "Effect_of_Orthosis_Material_Hardness_on_Walking.” Journal of Prosthetics and Orthotics 11(2):43-46.

Brent, Lynne. 2007. “Key Properties of Insole Materials.” SATRA Bulletin (March):16-19.

Bril, A. Tkachenko, V. David, M. Scherer, H. Jagos, P. Kafka, and A. Sabo. 2016. "Development of a Wearable Live-Feedback System to Support Partial Weight-Bearing While Recovering from Lower Extremity Injuries.” Procedia Engineering 147:157-62.

Brodsky, James W., Jonathan Brajtbord, Scott C. Coleman, Sourendra Raut, and Fabian E. Polo. 2012. "Effect of Heating on the Mechanical Properties of Insole Materials." Foot \& Ankle International 33(9):772-78. 
Brodsky, James W., Fabian E. Pollo, Domingo Cheleuitte, and Brian S. Baum. 2007. "Physical Properties, Durability, and Energy-Dissipation Function of Dual-Density Orthotic Materials Used in Insoles for Diabetic Patients." Foot \& Ankle International 28(8):880-89.

Broyer, Ephraim, Christopher W. Macosko, Frank E. Critchfield, and Lee F. Lawler. 1978. "Curing and Heat Transfer in Polyurethane Reaction Molding." Polymer Engineering \& Science 18(5):382-87.

Burns, Joshua, Lindy Begg, and Mauro Vicaretti. 2008. "Comparison of Orthotic Materials on Foot Pain, Comfort, and Plantar Pressure in the Neuroischemic Diabetic Foot." Journal of the American Podiatric Medical Association 98(2):143-48.

Campbell, G. J., M. McLure, and E. N. Newell. 1984. "Compressive Behavior after Simulated Service Conditions of Some Foamed Materials Intended as Orthotic Shoe Insoles." J Rehabil Res Dev 21(2):57-65.

Campbell, G., E. Newell, and M. Mclure. 1982. “Compression Testing of Foamed Plastics and Rubbers for Use as Orthotic Shoe Insoles.” Prosthetics and Orthotics International 6(1):48-52.

Cangemi, José M., Antonia M. dos Santos, Salvador C. Neto, and Gilberto O. Chierice. 2008. “Biodegradation of Polyurethane Derived from Castor Oil.” Polímeros 18(3):201-6.

Chen, Chih-tun, Nancy Burton-Wurster, and Tekoppele Johan. 1999. "Compositional and Metabolic Changes Damaged Cartilage Are Peak-Stress, Stress-Rate, and Loading-Duration Dependent." Journal of Orthopedic Research 17(6):870-79.

Dounis, Dimitrios V, J. Cal Moreland, Garth L. Wilkes, Dave A. Dillard, and Robert B. Turner. 1993. “The Mechano-Sorptive Behavior of Flexible Water-Blown Polyurethane Foams.” Journal of Applied Polymer Science 50(2):293-301.

Edwards, Julie and Keith Rome. 1992. "A Study of the Shock Attenuating Properties of Materials Used in Chiropody." The Foot 2(2):99-105.

Ewers, B. J., D. Dvoracek-Driksna, M. W. Orth, and R. C. Haut. 2001. "The Extent of Matrix Damage and Chondrocyte Death in Mechanically Traumatized Articular Cartilage Explants Depends on Rate of 
Loading." Journal of Orthopaedic Research 19(5):779-84.

Faulí, Angel Camp, Cristina Llobell Andrés, Norberto Porta Rosas, Maria José Fernández, Enrique Montiel Parreño, and César Orgilés Barceló. 2008. "Physical Evaluation of Insole Materials Used to Treat the Diabetic Foot." Journal of the American Podiatric Medical Association 98(3):229-38.

Ferreira, Joana Lia, Ana M. Ramos, Joana Lia, Isabel Pombo, and Rita Macedo. 2017. "Shedding New Light on Polyurethane Degradation: Assessing Foams Condition in Design Objects." Polymer Degradation and Stability 144(July 2018):354-65.

Gama, Nuno V., Belinda Soares, Carmen S. R. Freire, Rui Silva, Carlos P. Neto, Ana Barros-Timmons, and Artur Ferreira. 2015. "Bio-Based Polyurethane Foams toward Applications beyond Thermal Insulation." Materials and Design 76:77-85.

Gao, Zhenzhong, Jun Peng, Tuhua Zhong, Jin Sun, Xiaobo Wang, and Chao Yue. 2012. "Biocompatible Elastomer of Waterborne Polyurethane Based on Castor Oil and Polyethylene Glycol with Cellulose Nanocrystals." Carbohydrate Polymers 87(3):2068-75.

Gnanasundaram, Saraswathy, Srinivasan Kannan, Mohan Ranganathan, Bhabendra Nath Das, and Asit Baran Mandal. 2015. "Preparation and Characterization of Footwear Soling Materials Based on Biodegradable Polyurethane.” Polymer - Plastics Technology and Engineering 54(15):1585-95.

Gustini, Liliana, Cristina Lavilla, Lasse Finzel, Bart A. J. Noordover, Marco M. R. M. Hendrix, and Cor E. Koning. 2016. "Sustainable Coatings from Bio-Based, Enzymatically Synthesized Polyesters with Enhanced Functionalities.” Polymer Chemistry 7(43):6586-97.

Hawkey, S. and S. Ghaffar. 2015. "Neoprene Orthopaedic Supports: An Underrecognised Cause of Allergic Contact Dermatitis." Case Reports in Orthopedics 2015(Figure 3):1-3.

Healy, Aoife, Dave N. Dunning, and Nachiappan Chockalingam. 2012. "Effect of Insole Material on Lower Limb Kinematics and Plantar Pressures during Treadmill Walking." Prosthetics and Orthotics International 36(1):53-62.

Healy, Aoife, David N. Dunning, and Nachiappan Chockalingam. 2010. "Materials Used for Footwear 
Orthoses: A Review.” Footwear Science 2(2):93-110.

Hellstrand Tang, Ulla, Roland Zügner, Vera Lisovskaja, Jon Karlsson, Kerstin Hagberg, and Roy Tranberg. 2014. "Comparison of Plantar Pressure in Three Types of Insole given to Patients with Diabetes at Risk of Developing Foot Ulcers - A Two-Year, Randomized Trial.” Journal of Clinical and Translational Endocrinology 1(4):121-32.

Hepburn, Claude. 2012. Polyurethane Elastomers. Second Edi. edited by S. Edition. London: Elsivier Applied Science.

Hillier, K., Thomas Schupp, and I. Carney. 2003. “An Investigation into VOC Emissions from Polyurethane Flexible Foam Mattresses." Cellular Polymers 22:237-59.

Hong, J. L., C. P. Lillya, and J. C. W. Chien. 1992. "Degree of Phase-Separation in Polyether Polyurethane Copolymers with Different Chemical Structures of Hard Segments.” Polymer 33(20):4347-51.

Hurkmans, H. L. P., J. B. J. Bussmann, E. Benda, J. A. N. Verhaar, and H. J. Stam. 2006. “Accuracy and Repeatability of the Pedar Mobile System in Long-Term Vertical Force Measurements." Gait and Posture 23(1):118-25.

Ionescu, Mihail. 2005. "Synthesis of High Molecular Weight Polyether Polyols with Double Metal Cyanide Catalysts (DMC Catalysts).” Chemistry and Technology of Polyols for Polyurethanes 167-84.

Ionescu, Milhail. 2007. Chemistry and Technology of Polyols for Polyurethanes. . Vol. 2. Second edi. Shawbury: Smithers Rapra.

Johnson, G. R. 1988. “The Effectiveness of Shock-Absorbing Insoles during Normal Walking.” Prosthetics and Orthotics International 12(2):91-95.

Konieczny, Jakob and Katja Loos. 2019. “Green Polyurethanes from Renewable Isocyanates and Biobased White Dextrins." Polymers 11(2).

Kuncir, Eric J., Roy W. Wirta, and Frank L. Golbranson. 1990. "Load-Bearing Characteristics of Polyethylene Foam: An Examination of Structural and Compression Properties." The Journal of Rehabilitation Research and Development 27(3):229. 
Leber, C. and P. M. Evanski. 1986. "A Comparison of Shoe Insole Materials in Plantar Pressure Relief." Prosthetics and Orthotics International 10(3):135-38.

Lee, You Jung, Chang Kyu Park, and Seong Hun Kim. 2018. "Fabrication of Castor-Oil/Polycaprolactone Based Bio-Polyurethane Foam Reinforced with Nanocellulose.” Polymer Composites 39(6):2004-11.

Lewis, G., T. Tan, and Y. S. Shiue. 1991. "Characterization of the Performance of Shoe Insert Materials.” Journal of the American Podiatric Medical Association 81(8):418-24.

Li, Hongwei, Nubla Mahmood, Zhen Ma, Mingqiang Zhu, Junqi Wang, Jilu Zheng, Zhongshun Yuan, Qin Wei, and Charles (Chunbao) Xu. 2017. "Preparation and Characterization of Bio-Polyol and BioBased Flexible Polyurethane Foams from Fast Pyrolysis of Wheat Straw." Industrial Crops and Products 103:64-72.

Liu, Yanping, Wai Man au, and Hong hu. 2014. "Protective Properties of Warp-Knitted Spacer Fabrics under Impact in Hemispherical Form. Part I: Impact Behavior Analysis of a Typical Spacer Fabric.” Textile Research Journal 84(4):422-34.

Liu, Yanping, Hong hu, Hairu Long, and li Zhao. 2012. "Impact Compressive Behavior of Warp-Knitted Spacer Fabrics for Protective Applications.” Textile Research Journal 82(8):773-88.

LLC., Sensitronics. 2017. "FSR 101 Force Sensing Resistor Theory and Applications.” 1-15.

Lo, Wai Ting, Kit Lun Yick, Sun Pui Ng, and Joanne Yip. 2014. "New Methods for Evaluating Physical and Thermal Comfort Properties of Orthotic Materials Used in Insoles for Patients with Diabetes." Journal of Rehabilitation Research and Development 51(2):311-24.

Luo, Z. P., L. J. Berglund, and K. N. An. 1998. "Validation of F-Scan Pressure Sensor System: A Technical Note." Journal of Rehabilitation Research and Development 35(2):186-91.

Macalino, AD, VA Salen, and LQ Reyes. 2017. "Castor Oil Based Polyurethanes: Synthesis and Characterization.” IOP Conference Series: Materials Science and Engineering 229:012016.

Madra, Hande, S. Birgul Tantekin-Ersolmaz, and F. Seniha Guner. 2009. "Monitoring of Oil-Based Polyurethane Synthesis by FTIR-ATR.” Polymer Testing 28(7):773-79. 
McPoil, T. G. and M. W. Cornwall. 1992. "Effect of Insole Material on Force and Plantar Pressures during Walking." Journal of the American Podiatric Medical Association 82(8):412-16.

Mohamed, O., K. Cerny, L. Rojek, K. Herbert, R. Turner, and S. Waistell. 2004. "The Effects of Plastazote(R) and Aliplast(R)/Plastazote(R) Orthoses on Plantar Pressures in Elderly Persons With Diabetic Neuropathy." Journal of Prosthetics and Orthotics 16(2):55-63.

Nguyen Dang, Luong, Sinh Le Hoang, Minna Malin, Jürgen Weisser, Torsten Walter, Matthias Schnabelrauch, and Jukka Seppälä. 2016. "Synthesis and Characterization of Castor Oil-Segmented Thermoplastic Polyurethane with Controlled Mechanical Properties.” European Polymer Journal $81: 129-37$.

North, Kylee, Sean D. Maass, and Robert W. Hitchcock. 2010. “An Insole Sensor for Recording Weight Bearing Behavior during Tibial Fracture Rehabilitation." 2010 Annual International Conference of the IEEE Engineering in Medicine and Biology Society, EMBC'10 1856-59.

Ogunfeyitimi, O., A. Okewale, and P. Igbokwe. 2012. "The Use of Castor Oil as a Reactive Monomer in Synthesis of Flexible Polyurethane Foam." International Journal of Multidisciplinary Sciences and Engineering 3(10):10-14.

Paton, Joanne, Ray B. Jones, Elizabeth Stenhouse, and Graham Bruce. 2007. "The Physical Characteristics of Materials Used in the Manufacture of Orthoses for Patients with Diabetes." Foot \& Ankle International 28(10):1057-63.

Pauk, J., J. Tolstoj-Sienkiewicz, M. Ihnatouski, T. Kuzmierowski, and E. Chojnowski. 2015. "Influence of Insole Materials on Friction and Ground Reaction Force during Gait." Journal of Friction and Wear 36(4):319-23.

Pratt, D. J. 1990. “Long Term Comparison of Some Shock Attenuating Insoles.” Prosthetics and Orthotics International 14:59-62.

Pratt, D. J., P. H. Rees, and C. Rodgers. 1986. “Technical Note: Assessment of Some Shock Absorbing Insoles." Prosthetics and Orthotics International 10(1):43-45. 
Prociak, Aleksander, Elżbieta Malewska, Maria Kurańska, Szymon Bąk, and Paulina Budny. 2018. "Flexible Polyurethane Foams Synthesized with Palm Oil-Based Bio-Polyols Obtained with the Use of Different Oxirane Ring Opener.” Industrial Crops and Products 115(May 2017):69-77.

Radin, E. L., K. H. Yang, C. Riegger, V. L. Kish, and J. J. O’Connor. 1991. "Relationship between Lower Limb Dynamics and Knee Joint Pain [Published Erratum Appears in J Orthop Res 1991 Sep;9(5):776].” J Orthop Res 9(3):398-405.

Rogers, K., S. Otter, and I. Birch. 2006. "The Effect of PORON and Plastozote Insoles on Forefront Plantar Pressure.” British Journal of Podiatry 9(4):111-14.

Rome, K. 1991. "A Study of the Properties of Materials Used in Podiatry." Journal of the American Podiatric Medical Association 81(2):73-83.

Ruan, Mengmeng, Huacheng Luan, Guiyou Wang, and Michael Shen. 2019. "Bio-Polyols Synthesized from Bio-Based 1,3-Propanediol and Applications on Polyurethane Reactive Hot Melt Adhesives.” Industrial Crops and Products 128(November 2018):436-44.

Sanfilippo, P. B., R. M. Stess, and K. M. Moss. 1992. "Dynamic Plantar Pressure Analysis. Comparing Common Insole Materials." Journal of the American Podiatric Medical Association 82(10):507-13.

Saraswathy, G., G. Gopalakrishna, and BN Das. 2010. Development of Novel Porous Viscoelastic Polyurethane Insoles and Study of Their Efficiency in Reducing Plantar Pressure PRESSURE.

Saraswathy, G., Gautham Gopalakrishna, B. N. Das, R. Mohan, Ganga Radhakrishnan, and S. Pal. 2009. "Development of Polyurethane-Based Sheets by Coagulation Method and Study of Mechanical and Cushion Properties for Therapeutic Footwear Applications.” Polymer - Plastics Technology and Engineering 48(3):239-50.

Shariatmadari, Mohammad Reza, Russell English, and Glynn Rothwell. 2012. "Effects of Temperature on the Material Characteristics of Midsole and Insole Footwear Foams Subject to Quasi-Static Compressive and Shear Force Loading.” Materials and Design 37:543-59.

Szycher, M. 2013. Szycher's Handbook of Polyurethanes. Second edi. Roca Raton: Taylor and Francis 
Group.

Tong, Jasper W. K. and Eddie Y. K. Ng. 2010. "Preliminary Investigation on the Reduction of Plantar Loading Pressure with Different Insole Materials (SRP - Slow Recovery Poron®, P - Poron®, PPF Poron ${ }^{\circledR}+$ Plastazote, Firm and PPS - Poron ${ }^{\circledR}+$ Plastazote, Soft).” Foot 20(1):1-6.

Ugarte, L., A. Saralegi, R. Fernández, L. Martín, M. A. Corcuera, and A. Eceiza. 2015. "Flexible Polyurethane Foams Based on 100\% Renewably Sourced Polyols." Industrial Crops and Products $62: 545-51$.

Urgun-Demirtas, Meltem, Dileep Singh, and Krishna Pagilla. 2007. "Laboratory Investigation of Biodegradability of a Polyurethane Foam under Anaerobic Conditions." Polymer Degradation and Stability 92(8):1599-1610.

Volynets, Bohdan, Hamza Nakhoda, Mustafa Abu Ghalia, and Yaser Dahman. 2017. "Preparation and Characterization of Poly(2-Hydroxyethyl Methacrylate) Grafted Bacterial Cellulose Using Atom Transfer Radical Polymerization.” Fibers and Polymers 18(5):859-67.

Wang, Cai, Yudong Zheng, Yajie Xie, Kun Qiao, Yi Sun, and Lina Yue. 2015. "Synthesis of Bio-Castor Oil Polyurethane Flexible Foams and the Influence of Biotic Component on Their Performance."

Wang, Hong Juan, Min Zhi Rong, Ming Qiu Zhang, Jing Hu, Hui Wen Chen, and Tibor Czigány. 2008. “Biodegradable Foam Plastics Based on Castor Oil.” Biomacromolecules 9(2):615-23.

Wilhelm, Catherine, Agnès Rivaton, and Jean-Luc Gardette. 1998. "Infrared Analysis of the Photochemical Behaviour of Segmented Polyurethanes: 3. Aromatic Diisocyanate Based Polymers." Polymer 39(5):1223-32.

Wilson, M. 1991. "Measuring the Comfort Contribution of Cushion Insocks." SATRA Bulletin October:262-63.

Wu, Jhy-Wen, Wen-Fa Sung, and Hsin-Sen Chu. 1999. "Thermal Conductivity of Polyurethane Foams.” International Journal of Heat and Mass Transfer 42(12):2211-17.

Yang, Guang, Xueyang Liu, and Vitali Lipik. 2018. "Evaluation of Silica Aerogel-Reinforced Polyurethane 
Foams for Footwear Applications.” Journal of Materials Science 53(13):9463-72.

Yang, Wenqing, Qingyin Dong, Shili Liu, Henghua Xie, Lili Liu, and Jinhui Li. 2012. "Recycling and Disposal Methods for Polyurethane Foam Wastes.” Procedia Environmental Sciences 16:167-75.

Yeganeh, Hamid and Mohammad Reza Mehdizadeh. 2004. "Synthesis and Properties of Isocyanate Curable Millable Polyurethane Elastomers Based on Castor Oil as a Renewable Resource Polyol.” European Polymer Journal 40(6):1233-38.

Yick, K. L. and C. Y. Tse. 2013. Handbook of Footwear Design and Manufacture. First edit. edited by A. Luximon. Cambridge: Woodhead Publishing Series. 